\title{
COMPOSTOS QUIMIOTERÁPICOS DE OURO: UMA VISÃO GERAL DOS COMPLEXOS ANTICÂNCER DE Au(I/III) EM RELAÇÃO À ESTRUTURA DO LIGANTE
}

\author{
Giset Y. Sánchez Delgado ${ }^{a, *,(i), ~ C a m i l a ~ A . ~ S . ~ R . ~ C o n d e ́ a, ~ H e ́ l i o ~ F . ~ D o s ~ S a n t o s ~}{ }^{\mathrm{a}}$ e Maribel Navarro ${ }^{\mathrm{a}, \#}$ \\ aDepartamento de Química, Universidade Federal de Juiz de Fora, Campus Universitário, 36036-900 Juiz de Fora - MG, Brasil
}

Recebido em 21/02/2020; aceito em 23/04/2020; publicado na web em 10/06/2020

\begin{abstract}
GOLD CHEMOTHERAPEUTIC COMPOUNDS: AN OVERVIEW OF ANTICANCER Au(I/III)-COMPLEXES IN RELATION TO THE STRUCTURE OF THE LIGAND. Gold compounds engage an important place in the field of medicinal chemistry due to their therapeutic properties. Since the last four decades, $\mathrm{Au}(\mathrm{I})$ and $\mathrm{Au}(\mathrm{III})$ complexes have attracted the attention of researchers due to their anti-tumor proprieties and the different mechanisms of action they display in comparison to conventional anticancer platinum compounds. Au(I/III) complexes can inhibit the activity of enzymes containing thiols including thioredoxin reductase; nevertheless, the affinity for several therapeutic targets has been confirmed in recent years. The properties conferred by auxiliary ligands such as phosphines $\left(\mathrm{PR}_{3}\right)$ and $\mathrm{N}$-heterocyclic carbenes (NHCs) to gold complexes have been key to the development of more promising anticancer compounds. In the same way, it has happened with the inclusion of some multidentate ligands in $\mathrm{Au}(\mathrm{III}) \mathrm{complexes,}$ increasing their stability and selectivity for tumor cells. In this review, we discuss the anticancer effects of $\mathrm{Au}(\mathrm{I})$ complexes containing $\mathrm{PR}_{3}$ and NHCs ligands as well as $\mathrm{Au}(\mathrm{III})$ complexes containing multidentate ligands especially those that have high cytotoxicity and information on the mechanism of action, as well as attempts to target identification and validation.
\end{abstract}

Keywords: $\mathrm{Au}(\mathrm{I})$ complexes; $\mathrm{Au}(\mathrm{III})$ complexes; anticancer activity; phosphines; N-heterocyclic carbenes.

\section{INTRODUÇÃO}

Desde tempos imemoriáveis, o ouro vem sendo usado no tratamento de diversas doenças, as quais lhe concederam virtudes e muitas propriedades curativas. Porém, sua primeira aplicação como terapêutico foi registrada cerca de 2500 a.C., quando ouro era utilizado pelas medicinas chinesa e árabe. ${ }^{1} \mathrm{O}$ interesse moderno na aplicação do ouro nesta área origina-se em 1890, quando Robert Koch observou a inibição do bacilo da tuberculose pelo sal cianeto de $\mathrm{Au}(\mathrm{I})$, embora tenha sido demonstrado que esse tinha poucos benefícios para o tratamento da doença. A partir daí, aumentou-se o interesse pela busca de compostos de $\mathrm{Au}(\mathrm{I})$ com potencial antituberculose e de baixa toxicidade. ${ }^{1,2}$

Durante a década de 1925-1935, sais de tiolato de $\mathrm{Au}(\mathrm{I})$ foram utilizados para o tratamento da tuberculose, apesar da falta de evidências experimentais de que esses curassem a doença. Já em 1929, o cientista francês Jacques Foriester investigou o uso de compostos de ouro para o tratamento de artrite reumatoide (AR); entretanto, somente em 1960 que ensaios clínicos controlados provaram a eficácia da terapia com ouro. ${ }^{2-4}$

Atualmente, alguns tiolatos injetáveis de $\mathrm{Au}(\mathrm{I})$, representados na Figura 1, são pouco usados clinicamente, porém, mantêm-se na classe de drogas antirreumáticas que retardam a progressão da doença. Em 1985, o composto de fosfina de Au(I), conhecido como Auranofina (AF) (Figura 1) foi aprovado para o tratamento da artrite reumatoide. A AF substituiu o tratamento clínico com tiolatos injetáveis de Au(I) sendo usada amplamente por muitos anos, mostrando alguns efeitos secundários. Posteriormente, AF mostrou-se menos eficaz do que outras drogas antirreumáticas, tais como o metotrexato, o que levou a uma diminuição do seu uso clínico. Em meados dos anos 80, a AF mostrou-se um potente inibidor do crescimento de células tumorais in vitro, com atividade antitumoral in vivo limitada em modelos tumorais de camundongos. ${ }^{3,5}$

*e-mail: gysdelgado@ice.ufjf.br

\#e-mail alternativo: maribel.navarro@ufjf.edu.br
Desde então, a busca por compostos promissores de ouro anticâncer tem sido continuamente ativa e um grande número de complexos de $\mathrm{Au}(\mathrm{I})$ e $\mathrm{Au}(\mathrm{III})$ têm sido sintetizados nas últimas décadas. Tais compostos de ouro vem sendo testados como agentes anticâncer e têm mostrado resultados bastante promissores. Alguns desses compostos também têm sido testados como possíveis agentes antiparasitários, antimicrobiais, anti-VIH, entre outros. ${ }^{6-12}$
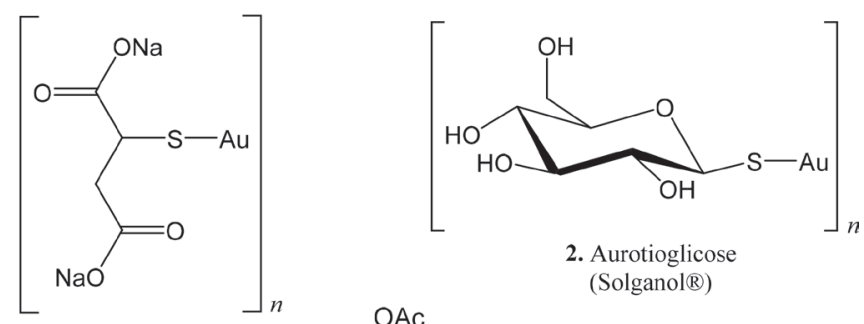

1. Aurotiomalato de sódio (Miocrisina $\left.{ }^{\circledR}\right)$

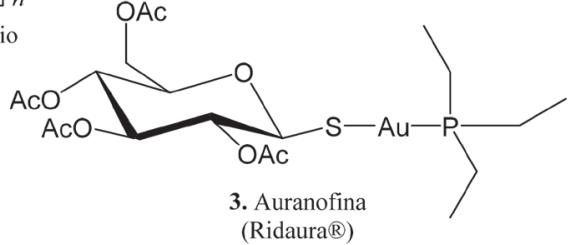

Figura 1. Compostos de ouro utilizados no tratamento da artrite reumatoide. 1 e 2 são polímeros solúveis em água

A AF, utilizada como antiartrítico, exibiu potenciais efeitos anticancerígenos in vitro em diferentes linhagens celulares de câncer humano e mostrou efeitos in vivo no modelo de camundongos com leucemia P388. ${ }^{5}$ Mediante tais resultados, uma grande variedade de análogos de AF foram testados como agentes anticâncer, apresentando os complexos de $\mathrm{Au}(\mathrm{I})$ como potenciais inibidores do crescimento de células tumorais in vitro. Estudos de relação estrutura-atividade sobre AF indicaram que o ligante fosfina é muito mais importante para a atividade biológica do que a fração de tioglucose. ${ }^{3}$ De fato, extensivos estudos mecanísticos mostraram que tanto a $\mathrm{AF}$ como o $\left[\mathrm{Au}\left(\mathrm{PEt}_{3}\right) \mathrm{Cl}\right]$ afetam a função mitocondrial, levando a indução de vias apoptóticas. ${ }^{3,13}$ 
Nos últimos anos, tem sido relatada a atividade antitumoral de complexos lineares de $\mathrm{Au}(\mathrm{I})$ contendo carbenos N-heterocíclicos (NHC). Tais compostos NHC são considerados ligantes alternativos às fosfinas e atuam como fortes ligantes doadores de elétrons para uma ampla gama de metais de transição. Além disso, o fato de os NHCs serem altamente estáveis, facilmente sintetizados e quimicamente modificados, aumenta-se o interesse na obtenção de novas drogas onde esses ligantes coordenam-se aos metais de transição. ${ }^{14}$ Vários complexos $\mathrm{Au}(\mathrm{I})-\mathrm{NHC}$ foram sintetizados realizando variações sistemáticas de diferentes grupos alquila no átomo de nitrogênio secundário para facilitar a captação celular. Tal interesse se dá pelo fato de que este tipo de alterações estruturais permitiu aos pesquisadores obterem informações importantes sobre lipofilicidade, carga, reatividade, citotoxicidade e interação com proteínas/enzimas, como a tiorredoxina redutase (TrxR). Assim, foram preparados um grande número de compostos de ouro estruturalmente diversificados, estabilizados por ligantes de fosfinas $\mathrm{PR}_{3}$ e NHCs, e verificou-se que estes induzem efeitos anticancerígenos importantes, tanto in vitro como in vivo. ${ }^{4,15} \mathrm{Na}$ Figura 2, é apresentado o número das publicações nos últimos 20 anos sobre complexos de $\mathrm{Au}(\mathrm{I})$ e $\mathrm{Au}(\mathrm{III})$ como agentes anticâncer. É interessante notar que na última década esse tema tem atraído atenção dos cientistas. Os complexos de $\mathrm{Au}(\mathrm{I})$ tiveram aproximadamente o dobro do número publicações comparado aos complexos de Au(III), o que é atribuído ao grande número de compostos derivados da $\mathrm{AF}$ que foram testados como agentes quimioterapêuticos nesta última década.

Complexos de ouro exibem uma elevada propensão às enzimas, especialmente aquelas que contêm grupos tióis. Essa característica é atribuída à forte afinidade de ligação dos íons de ouro com tióis. ${ }^{3-5,13}$ A maioria das enzimas que contém tióis, tais como a TrxR, glutationa redutase (GR) e cisteína protease, encontram-se altamente expostas em células cancerosas proporcionando, assim, potenciais alvos para a terapia com complexos de ouro. ${ }^{4}$ Várias estruturas de adutos de $\mathrm{Au}^{1+}$-proteína têm sido estudadas usando cristalografia de raios X. A maioria dessas estruturas apresentam interações entre as ligações Cys-S-Au-S-Cys e/ou Cys-S-Au-ligante no sítio ativo da enzima, motivo pelo qual acredita-se que a ligação Au-S seja responsável pela forte inibição observada da atividade enzimática. ${ }^{4}$ GR e TrxR são dissulfeto-redutases que contêm grupos tióis no sítio ativo e a TrxR também contém um resíduo selenocisteína ( $\mathrm{Sec}$ ) que é exclusivo da TrxR dos mamíferos. Ambas as enzimas (GR e TrxR) desempenham um papel fundamental na regulação redox de importantes processos celulares, como síntese de $\mathrm{ADN}$, transcrição, crescimento celular e resistência a fármacos. No caso da TrxR, acredita-se que sua inibição pode causar um estresse oxidativo celular devido à acumulação de espécies reativas de oxigênio o que, posteriormente, leva à liberação de sinalizadores de apoptose causando a morte celular. ${ }^{13} \mathrm{~A}$ inibição da atividade da TrxR foi estudada por

Complexos de $\mathrm{Au}(\mathrm{I})$

120

(a)

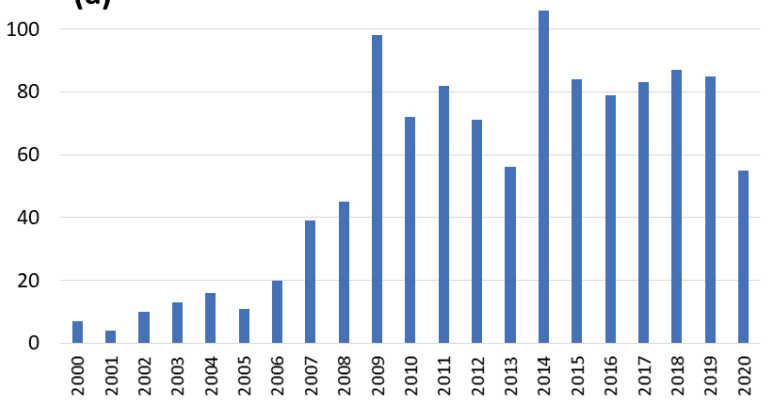

Smith et al., ${ }^{16}$ em camundongos utilizando aurotioglicose (ATG) como inibidor. Doses baixas de $0,025 \mathrm{mg}^{\mathrm{de}} \mathrm{ATG} \mathrm{g} \mathrm{g}^{-1}$ por peso corporal de ratos causaram uma inibição significativa e prolongada da atividade da TrxR no fígado, coração, rim e pâncreas. ${ }^{16}$ Um estudo detalhado sobre as interações $\mathrm{Au}(\mathrm{I})$-TrxR por espectrometria de massas indicou que até quatro fragmentos de $\mathrm{Au}-\mathrm{PEt}_{3}$ podem ser ligados à proteína. Estudos in vitro mostraram formas similares de interação em adutos de $\mathrm{Au}(\mathrm{I})$ com tiorredoxina-glutationa redutase (TGR), uma enzima parasitária similar à TrxR, após reação com a $\mathrm{AF}^{4,17}$ Com base nessas observações, têm-se proposto caminhos de reação, como o representado na Figura 3, para a inibição da TrxR por complexos de $\mathrm{Au}(\mathrm{I}) .{ }^{18} \mathrm{~A}$ interação da enzima na sua forma reduzida com complexos de $\mathrm{Au}(\mathrm{I})$ também pode levar à formação do complexo proteína-selenolato de ouro (TrxR-Se-Au-X) pela reação com o resíduo Sec498 e, posteriormente, o produto final conteria o íon $\mathrm{Au}(\mathrm{I})$ preso pelas ligações Se-Au-S. Embora interações Au-Se não tenham sido elucidadas neste tipo de adutos, algumas reações entre compostos de ouro e selenol têm apresentado informações relevantes. ${ }^{19,20}$ Semelhante à substituição de ligantes de fosfina por tióis, tal reação de deslocamento do ligante ocorre na presença de selenol. A reação entre o composto $\left[\mathrm{Au}\left(\mathrm{PEt}_{3}\right) \mathrm{Cl}\right]$ com o selenol leva à formação do complexo contendo ligações Se-Au-PEt ${ }_{3}$. Logo, o ataque nucleofílico do selenol no centro de ouro leva à eliminação de $\mathrm{PEt}_{3}$ e o íon $\mathrm{Au}^{1+}$ é preso pelas ligações $\mathrm{Se}-\mathrm{Au}-\mathrm{Se}$ e, após liberação, a fosfina sofre uma oxidação espontânea para produzir $\mathrm{O}=\mathrm{PEt}_{3} \cdot{ }^{20}$ Embora a Sec e Cys sejam amplamente consideradas como principais alvos de ligação dos íons $\mathrm{Au}$, a coordenação entre íons $\mathrm{Au}(\mathrm{I})$ e histidina (His) também tem sido observada. Zou et al. ${ }^{21}$ relataram a estrutura cristalina de um aduto de $\left[\mathrm{Au}\left(\mathrm{PEt}_{3}\right) \mathrm{Cl}\right]$ com a enzima ciclofilina 3 (Cyp-3). Essa enzima contém quatro resíduos de cisteína, dos quais os resíduos Cys163 e Cys168 são acessíveis para ligação Au-S. No entanto, a estrutura cristalina do aduto $\mathrm{Au}^{1+}{ }_{-}$ Cyp-3 não apresentou a esperada coordenação $S_{\text {Cys }}-A u(I)$, em vez disso, evidenciou-se a ligação $\mathrm{N}_{\mathrm{His}}-\mathrm{Au}(\mathrm{I})-\mathrm{PEt}_{3}$. $\mathrm{O}$ ensaio acoplado com a enzima quimotripsina revelou que a ligação de His133-Au(I) de Cyp-3 pode inibir significativamente a atividade da peptidilprolil isomerase (PPIase) (também conhecida como CypA) com o composto $\left[\mathrm{Au}\left(\mathrm{PEt}_{3}\right) \mathrm{Cl}\right]$ em uma concentração inibitória média $\left(\mathrm{IC}_{50}\right) \mathrm{de}$ $14 \mathrm{nmol} \mathrm{L}^{-1} .^{21}$ De fato, estudos teóricos sugerem que a reação com selenatos é mais rápida e espontânea do que com tióis. Porém, a energia de ativação para a reação de $\mathrm{Au}(\mathrm{I})$ com histidina se mostra bastante próxima à da cisteína. ${ }^{22,23}$

Complexos de $\mathrm{Au}(\mathrm{III})$ por terem geometria quadrática plana e serem isoeletrônicos dos complexos de Pt(II) (configuração eletrônica de valência $\mathrm{d}^{8}$ ), têm sido considerados desde os anos 80 como outra classe de compostos promissores para o tratamento do câncer, SIDA e outras doenças. Em contraste com os complexos de Pt(II), complexos

\section{Complexos de $\mathrm{Au}(\mathrm{III})$}

60

(b)

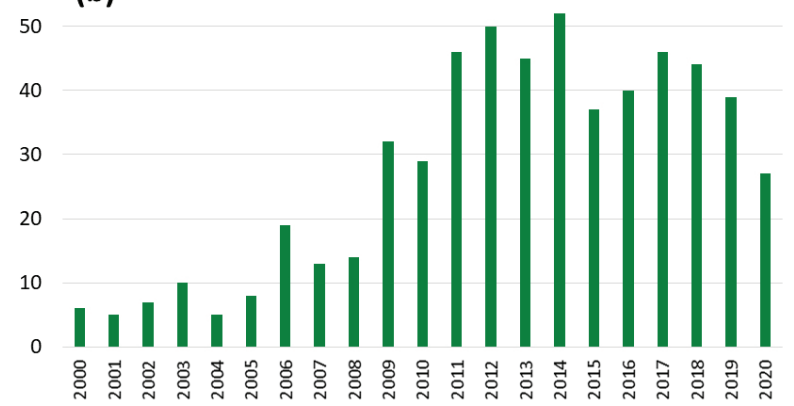

Figura 2. Número de artigos publicados sobre complexos Au(I) e Au(III) como agentes anticâncer nos últimos 20 anos. Dados obtidos do Scifinder usando as palavras: “complexes, Gold(I), anticancer” para $(a)$ e “complexes, Gold(III), anticancer” para (b) 


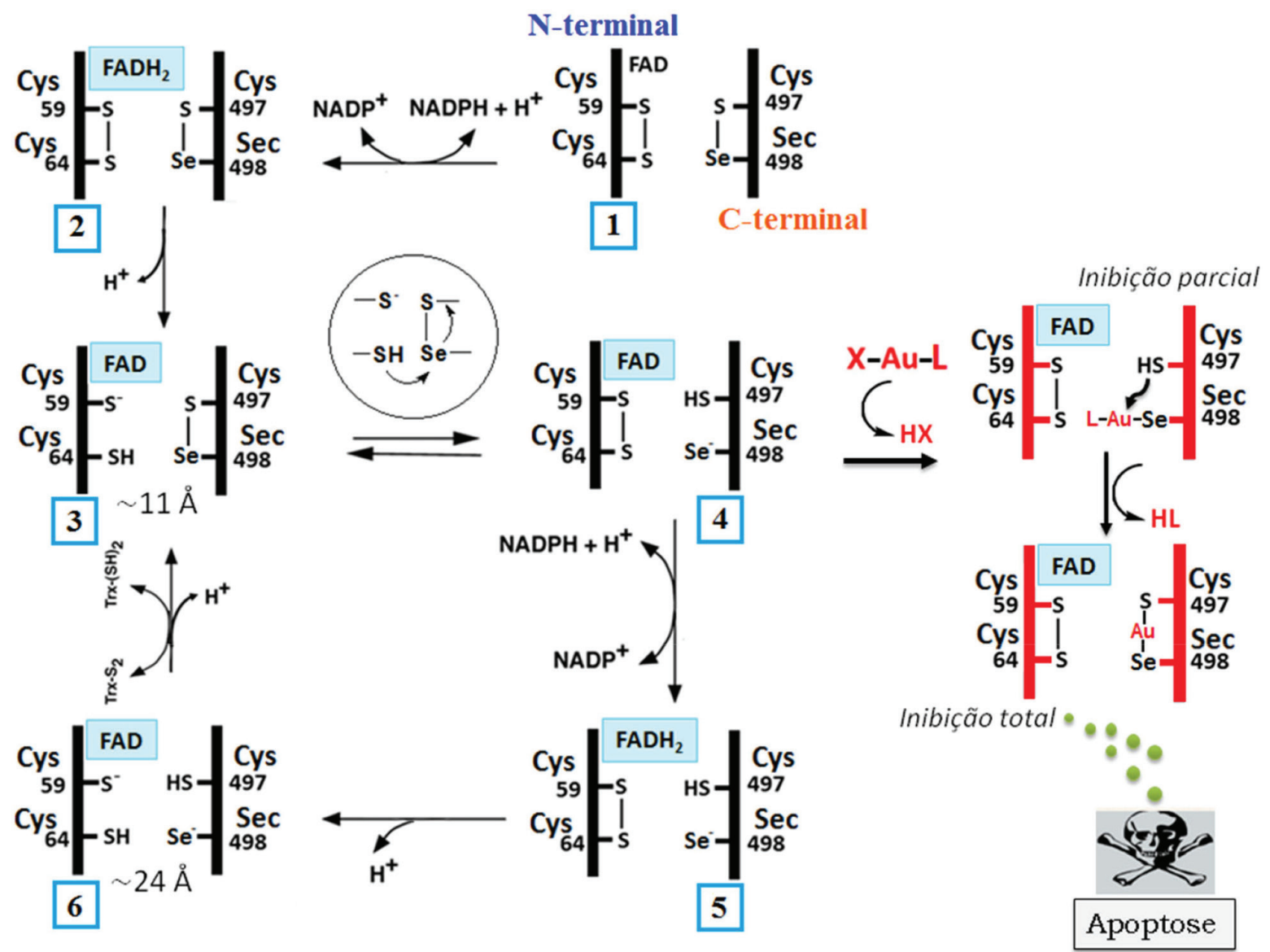

Figura 3. Mecanismo de reação proposto para a interação de complexos de Au(I) com a enzima TrxR reduzida (adaptado das referências ${ }^{17,18}$ ). No composto de ouro, X representa um ligante de caráter lábil como tetraacetil- $\beta$ - $D$-tioglucose ou cloreto e $L$ um ligante forte doador como PR $R_{3}$ ou $N H C$. $O$ ciclo se inicia com a enzima totalmente oxidada (etapa 1), onde o cofator FAD é reduzido pelo NADPH (etapa 2). Na etapa 3, o braço C-terminal dirige-se para o centro redox $N$-terminal para ser reduzido. A distância entre os grupos Cys497 e Sec498 (C-terminal) e Cys59 e Cys64 (N-terminal) é ao redor de 11 A. Uma vez, reduzidos a região C-terminal e o FAD (etapas 4 e 5 respectivamente), o braço $C$-terminal desloca-se para a superfície da enzima ficando longe da região $N$-terminal a uma distância de 24 Å como representado na etapa 6. Esta última posição tem importância no transporte dos elétrons para a superfície da enzima. Nesta etapa 6, a TrxR está pronta para reduzir a tiorredoxina (Trx), portanto é vantajoso manter o braço C-terminal próximo à superfície expondo o grupo selenato (Sec498). A interação covalente entre o composto de ouro e o braço C-terminal durante as etapas 4 ou 5 pode causar a inibição parcial ou total das atividades da $\operatorname{Tr} x$ o o que consequentemente poderia desencadear a liberação de sinalizadores de apoptose celular

de Au(III) são menos estáveis em condições fisiológicas, devido a seu alto potencial de redução e rápida taxa de hidrólise. Devido a isso, na última década, cresceu o interesse particular na síntese de estruturas mais estáveis para estes compostos. ${ }^{24}$

Sabe-se que em condições fisiológicas, a redução de $\mathrm{Au}^{3+} \mathrm{em}$ $\mathrm{Au}^{1+}$ ocorre rapidamente, e as espécies formadas de $\mathrm{Au}^{1+}$ podem sofrer reações de troca de ligantes. Complexos de $\mathrm{Au}(\mathrm{III})$ podem ser reduzidos por agentes redutores celulares como a glutationa (GSH), a qual é o tiol intracelular mais abundante, apresentando concentrações de 0,5 a $10 \mathrm{mmol} \mathrm{L}^{-1}$ em células cancerosas. Outros agentes como o ácido ascórbico também poderiam causar a redução dos complexos de $\mathrm{Au}(\mathrm{III}) .{ }^{4}$ Com base nessas observações, podemos propor duas possíveis vias de reação para um complexo de $\mathrm{Au}(\mathrm{III})$ uma vez que este ingresse na célula, como mostra a Figura 4. Como os complexos de $\mathrm{Au}(\mathrm{III})$ são geralmente tetracoordenados e complexos de $\mathrm{Au}(\mathrm{I}) / \mathrm{Au}(0)$ geralmente contém menos de quatro ligantes coordenados (geralmente são estruturas lineares), a redução do $\mathrm{Au}^{3+}$ será acompanhada pela liberação de ligantes..$^{4,23,25} \mathrm{Na}$ etapa [I], mostra-se a redução de um complexo de $\mathrm{Au}(\mathrm{III})$ tetra-coordenado até $\mathrm{Au}(\mathrm{I})$ di-coordenado, acompanhado da liberação de ligantes. Por outro lado, a etapa [II] representa a reação de troca de ligante com o nucleófilo através de um estado de transição trigonal plano. Considerando o caminho de reação na direção oposta, o complexo de $\mathrm{Au}(\mathrm{III})$ tetra-coordenado sofre primeiramente uma reação de substituição nucleofílica através de um estado de transição penta-coordenado (etapa [II]) e depois é reduzido $\mathrm{a} \mathrm{Au}^{1+}$ (2),(3), considerando duas reduções com liberação de ligantes (incluindo a liberação do nucleófilo). Dependendo do tipo de ligantes, a etapa $[\mathrm{I}]$ pode acontecer via uma reação de hidrólise prévia $\left(\mathrm{L}_{\mathrm{n}} / \mathrm{H}_{2} \mathrm{O}\right)$ e posterior substituição da água por um nucleófilo mais forte $\left(\mathrm{H}_{2} \mathrm{O} / \mathrm{Nu}\right)$. A via de reação a seguir dependerá da estabilidade do complexo de $\mathrm{Au}(\mathrm{III})$.

A estabilidade dos complexos metálicos é geralmente melhorada por ligantes quelantes multidentados, fazendo com que a maioria dos compostos de $\mathrm{Au}(\mathrm{III})$ desenvolvidos atualmente contenha ligantes bidentados $\mathrm{N}^{\wedge} \mathrm{N}, \mathrm{C}^{\wedge} \mathrm{N}$, tridentados $\mathrm{N}^{\wedge} \mathrm{N}^{\wedge} \mathrm{N}, \mathrm{C}^{\wedge} \mathrm{N}^{\wedge} \mathrm{N}, \mathrm{C}^{\wedge} \mathrm{N}^{\wedge} \mathrm{C}$, porfirinas, ditiocarbamatos, entre outros. A maioria destes complexos de $\mathrm{Au}(\mathrm{III})$ são estáveis em solução aquosa porque contêm átomos de carbono desprotonados doadores ( $\mathrm{C}^{-}$-carbânion) exibindo estabilidade redox contra agentes redutores celulares, como o ácido ascórbico e a glutationa (GSH).$^{4,24} \mathrm{Li}$ et al. ${ }^{26}$ mostraram que após o tratamento com GSH o complexo $\left[\mathrm{Au}\left(\mathrm{C}^{\wedge} \mathrm{N}^{\wedge} \mathrm{C}\right)(\text { meim- } 1)\right]^{+}($meim-1=1-metlimidazol $)$ não sofreu demetalação em um período de 24 horas demonstrando sua elevada estabilidade em solução. ${ }^{26}$ 


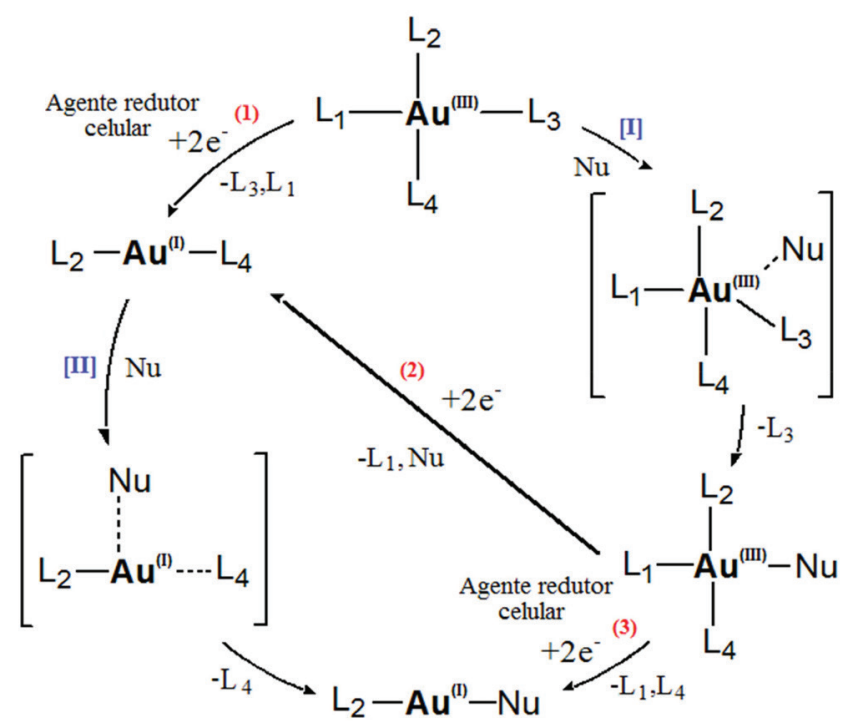

Figura 4. Possíveis caminhos de reação de complexos de Au(III) em ambiente celular ${ }^{23,25}$

Sabe-se há muito tempo que os complexos metálicos $\mathrm{d}^{8}$ quadráticos-planos possuem atividade devido a ligações covalentes cruzadas (crosslink) dos íons metálicos $\mathrm{d}^{8}$ ao $\mathrm{ADN}$, por intercalação dos complexos metálicos planares entre os pares de bases de ADN e/ou por inibição de atividades enzimáticas. ${ }^{424,26-36}$ Além de potentes inibidores de enzimas/proteínas contendo tióis e selenatos, complexos de $\mathrm{Au}$ (III) também têm mostrado afinidade pelo ADN. ${ }^{24,26,29,33} \mathrm{~A}$ busca de compostos mais estáveis levou a síntese de diversos complexos de $\mathrm{Au}(\mathrm{III})$ contendo ligantes quelantes planos que lhe atribuíram a característica de metalointercaladores. A interação dos complexos de ouro com vários alvos celulares importantes para diferentes doenças lhes confere um modo de ação diferente ao mecanismo convencional dos complexos de $\mathrm{Pt}(\mathrm{II})$, o que tem chamado a atenção dos pesquisadores nas últimas décadas.

A presente revisão descreve o desenvolvimento de complexos de $\mathrm{Au}(\mathrm{I})$ especialmente aqueles estabilizados por ligantes $\mathrm{PR}_{3}, \mathrm{NHCs}$ e complexos de $\mathrm{Au}$ (III) contendo diferentes ligantes multidentados, os quais têm mostrado uma excelente atividade como agentes antitumorais nos últimos anos. Mais detalhes sobre mecanismos de ação e a interação destes mesmos com diferentes alvos de interesse serão discutidos, juntamente com algumas abordagens gerais que têm sido utilizadas para tentar melhorar sua eficácia anticâncer.

\section{AURANOFINA COMO AGENTE ANTICÂNCER}

A AF (o antiartrítico conhecido comercialmente como Riadura ${ }^{\circledR}$, 3; Figura 1) é há muito tempo conhecida por inibir o crescimento de diferentes células cancerígenas in vitro. Porém, como já mencionado, sua atividade antitumoral in vivo tem sido limitada. A AF aumentou efetivamente o tempo de vida de camundongos inoculados com células de leucemia linfocítica P388 de maneira dependente da concentração e da dose. ${ }^{5}$ No entanto, estudos posteriores mostraram que quando a AF é administrada via injeção intraperitoneal (i.p), ela não inibe o crescimento nem prolonga a sobrevivência de vários modelos de tumores implantados nos camundongos. De fato, Mirabelli et al. ${ }^{37}$ relataram que, mesmo para camundongos portadores do modelo de leucemia P388, a AF só foi eficaz quando foi administrada via i.p., mas permaneceu inativa quando administrada por via intravenosa (i.v.) ou via subcutânea (s.c.). ${ }^{37}$ Estudos sobre o mecanismo de ação revelaram que a AF reage rapidamente com a Cys34 de albumina sérica, a qual é a proteína mais abundante no soro sanguíneo (concentração de 3,5 a

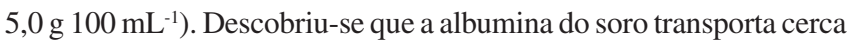
de $80-95 \%$ de ouro da AF adicionada ao sangue total. Na estrutura da forma principal da albumina está presente um resíduo de cisteína na posição 34 (Cys34) que transporta um grupo tiol ácido. ${ }^{38}$ Esse grupo é normalmente desprotonado em $\mathrm{pH}$ fisiológico $(\mathrm{pKa}<5,0)$ e oferece um potencial sítio de ligação para $\mathrm{Au}^{1+} .4$ Apesar do fato de que tiol-proteínas da membrana celular podem mediar a captação de íons de ouro que se ligam à albumina, a captação celular é muito mais lenta, tendo como resultado uma baixa citotoxicidade. ${ }^{4}$ Isso poderia explicar a baixa eficácia da $\mathrm{AF}$ em diferentes modelos tumorais in vivo. Apesar destas limitações mencionadas, a AF atualmente encontra-se em fase II de ensaios clínicos em pacientes com câncer de pulmão e de ovário na clínica Mayo em colaboração com o Instituto Nacional de Câncer (NCI) nos Estados Unidos de América. ${ }^{39}$

\section{COMPLEXOS Au(I)-FOSFINAS}

Complexos $\mathrm{Au}(\mathrm{I})-\mathrm{PR}_{3}$ têm sido estudados como agentes anticancerígenos por mais de três décadas. Berners-Price et $a l .{ }^{40} \mathrm{e}$ Humphreys et al. ${ }^{41}$ desenvolveram complexos tetracoordenados de $\mathrm{Au}(\mathrm{I})\left[\mathrm{Au}(\mathrm{dppe})_{2}\right] \mathrm{Cl}\left(\right.$ dppe $=$ bis(difenilfosfino)etano) e $\left[\mathrm{Au}(\mathrm{dppp})_{2}\right]$ $\mathrm{Cl}$ (dppe=bis(difenilfosfino)propano) representados como $\mathbf{4}$ e $\mathbf{5}$, respectivamente, na Figura 5, os quais mostraram alta lipofilicidade. ${ }^{40,41} \mathrm{O}$ complexo 4 se mostrou bastante estável quando comparado com seu análogo linear dicoordenado. Estudos de RMN de ${ }^{31} \mathrm{P}$ não revelaram reação deste com excesso de GSH após 8 dias de tratamento. Interessantemente, o composto 4 mostrou uma significativa atividade antitumoral in vivo contra uma gama de modelos de tumores de camundongos, incluindo leucemia e tumores sólidos. Esse foi selecionado para ensaios pré-clínicos, mas foi abandonado quando se evidenciou hepatotoxicidade grave em cães. Relações de estrutura-atividade mostraram que a maior atividade in vitro foi encontrada quando $\mathrm{R}=$ fenil e $\mathrm{n}=2$ e 3 (ver estruturas 4 e 5; Figura 5). Esse trabalho se mostrou particularmente marcante já que estudos posteriores se concentraram no desenvolvimento de complexos anticâncer de $\mathrm{Au}(\mathrm{I})$ de menor caráter lipofílico e mais reativos. O complexo análogo de 4 , $\left[\mathrm{Au}\left(\mathrm{d}_{2} \text { pype }\right)_{2}\right] \mathrm{Cl} \mathrm{d}$ pype $=(2-$ piridildifenilfosfino)etano (6; Figura 5), com lipofilicidade intermediária, foi ativo em tumores de cólon em camundongos. ${ }^{40}$ Por outro lado, o composto 7 [ $\left.\mathrm{Au}\left(\mathrm{d}_{2} \text { pypp }\right)_{2}\right] \mathrm{Cl} \mathrm{d} \mathrm{d}_{2}$ pypp=(2- piridildifenilfosfino) propano exibiu maior inibição da atividade de $\operatorname{TrxR}$ e foi mais seletivo para células de câncer de mama. ${ }^{41}$

Em 2003, Pillarsetty et l. $^{42}$ descreveram outro complexo tetracoordenado de $\left[\mathrm{Au}\left(\mathrm{PCH}_{2} \mathrm{OH}\right)_{4}\right] \mathrm{Cl}(\mathbf{8}$; Figura 5). Esse composto apresentou excelente atividade contra o câncer de próstata (LNCaP, PC-3), células do carcinoma gastrointestinal e do cólon (HCT-15) em experimentos in vitro e in vivo. A administração do composto $8 \mathrm{em}$ camundongos inoculados com células meth/A singênicas com 3 doses (doses totais de 75, 125 e $375 \mathrm{mg} \mathrm{kg}^{-1}$ ) prolongou significativamente o tempo de vida dos ratos, sendo esse dependente da dose aplicada. Além da eficácia terapêutica, não foi encontrada toxicidade aguda nos camundongos quando o composto $\mathbf{8}$ foi administrado em uma faixa de $0-125 \mathrm{mg} \mathrm{kg}^{-1}$ por três vezes. ${ }^{42}$

Em 2009, Chui et al..$^{43}$ estudaram a atividade antitumoral de uma série de compostos $\left[\mathrm{Au}\left(\mathrm{PPh}_{3}\right)(\right.$ dietinilfluorenos $\left.)\right]$. Entre eles, o complexo 9 da Figura 5 apresentou uma maior atividade citotóxica do que a cisplatina em estudos in vitro em três linhas celulares de câncer humano: Hep3B (hepatoma), MDA-MB231 (adenocarcinoma da mama) e SKHep-1 (adenocarcinoma do fígado), com valores de $\mathrm{IC}_{50}$ de $\sim 1,7 \sim 5,1 \mathrm{e} \sim 4,7 \mu \mathrm{mol} \mathrm{L}{ }^{-1}$, respectivamente (ver Tabela 1). O composto 9 induziu a geração de espécies reativas de oxigênio (ROS) em células de carcinoma hepatocelular Hep3B. Também exibe uma boa atividade antitumoral do modelo de xenoenxerto Hep3B 

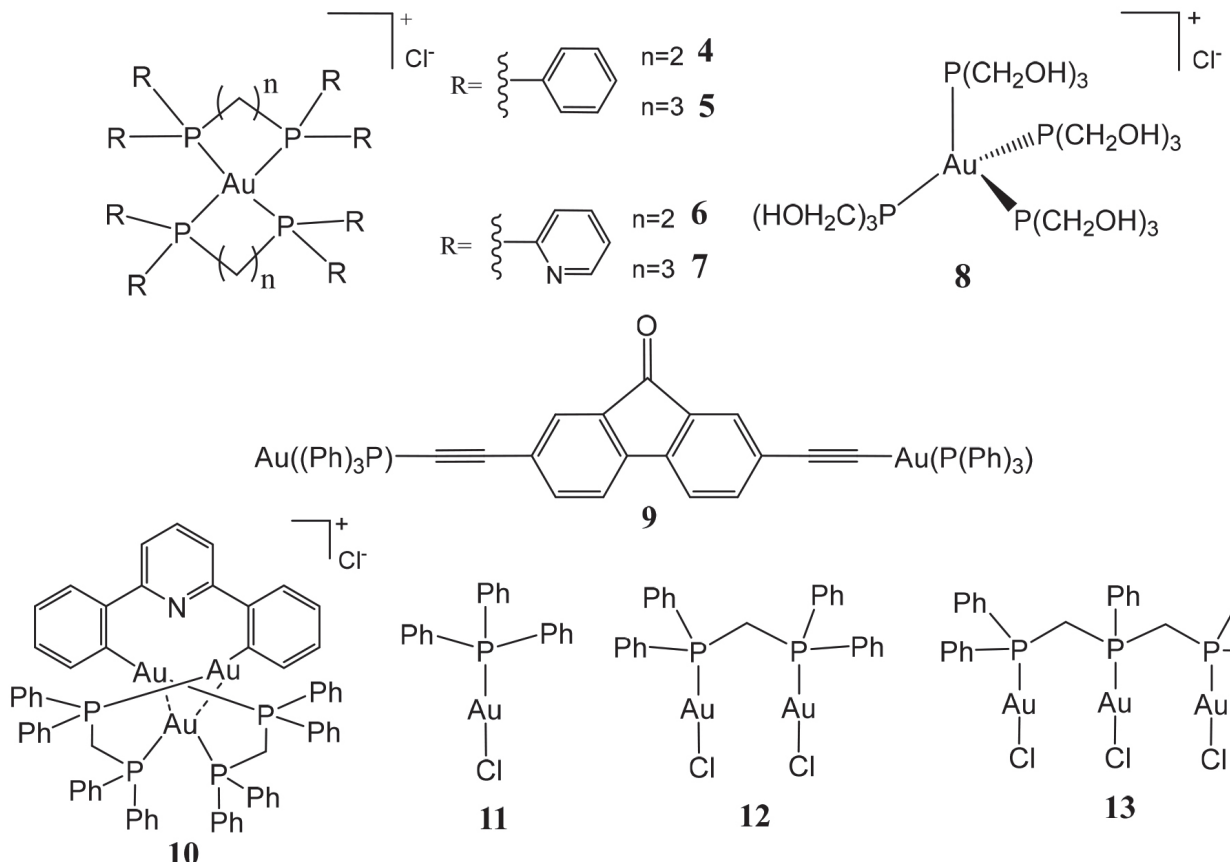<smiles>Cl[Al][PH](c1ccccc1)(c1ccccc1)c1ccccc1</smiles>

11<smiles>Cl[Ge]=P(C[PH](c1ccccc1)(c1ccccc1)[Al](Cl)Cl)(c1ccccc1)c1ccccc1</smiles>

12<smiles>Cl[Ge](Cl)[PH](CP(c1ccccc1)c1ccccc1)(C[Ge](Cl)(Cl)c1ccccc1)c1ccccc1</smiles>

13

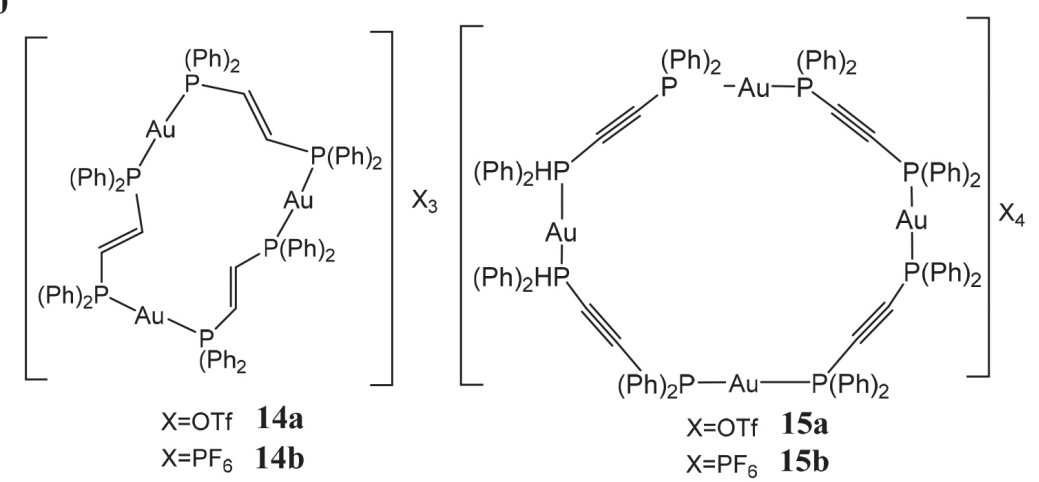

Figura 5. Estruturas químicas de complexos anticâncer de Au(I) contendo ligantes de fosfina

em camundongos após nove dias de tratamento. Porém, esse composto apresentou efeitos colaterais limitados em órgãos vitais como fígado e rim. Estudos de relações estrutura-atividade mostraram que a presença da carbonila em 9 parece determinar suas propriedades biológicas, uma vez que a mudança desse grupo carbonila por $\mathrm{CH}_{2}$ diminui completamente sua citotoxicidade. ${ }^{43}$

A autofagia é um processo catabólico celular que leva à degradação de componentes do citoplasma através dos lisossomas. Tian et al. ${ }^{44}$ relataram uma série de compostos $\mathrm{Au}(\mathrm{I})$-fosfina (10-13) com propriedades anticâncer que podem induzir a autofagia. Todos os compostos apresentaram valores $\mathrm{IC}_{50}$ na mesma ordem de magnitude que a cisplatina (ver Tabela 1). Os compostos 11-13 aumentaram o acúmulo de autofagossomas em células Hela, o qual está associado à morte celular. Os resultados sugerem que esses compostos modulam distintamente a autofagia através de uma acumulação de autofagossomas, que são os vacúolos intermediários na via para a autofagia. Complexos de $\mathrm{Au}(\mathrm{I})-\mathrm{PR}_{3}$ com propriedades indutoras de autofagia podem fornecer uma nova estratégia para o desenvolvimento de drogas anticâncer. ${ }^{44}$

Compostos de ouro contendo difosfinas quelantes tais como 4-7, discutidos anteriormente, continuaram sendo investigados. Estratégias para alterar o tamanho do anel quelato, variações no contra-íon e ligantes substituintes também têm sido testados para melhorar as propriedades desse tipo de compostos. ${ }^{45,46} \mathrm{Em} \mathrm{2017}$, Reddy et al. ${ }^{46}$ reportaram a atividade anticâncer de complexos metálicos trímeros e tetrâmeros cíclicos contendo a fração P-Au(I)-P. Os complexos
$\left[\mathrm{Au}_{3}(\mu \text {-dppen })_{3}\right] \mathrm{X}_{3}$, e $\left[\mathrm{Au}_{4}(\mu \text {-dppa })_{4}\right] \mathrm{X}_{4}\left[\mathrm{X}=\mathrm{OTf} ; \mathrm{X}=\mathrm{PF}_{6}\right]$ (14-15; Figura 5) apresentaram uma grande inibição do crescimento das células cancerosas de próstata (DU145), cervical (HeLa), mama (MDAMB231) e fibro sarcoma (HT1080) com valores de $\mathrm{IC}_{50}$ no intervalo de 0,04 a 4,7 $\mu \mathrm{mol} \mathrm{L}{ }^{-1}$ de citotoxicidade. Além disso, estes complexos exibiram uma alta seletividade entre as células tumorais e normais (HaCaT) em comparação com a cisplatina (ver Tabela 1). Todos os quatro compostos apresentaram atividade inibitória significativa da TrxR com valores de $\mathrm{EC}_{50}$ na faixa de 0,03 a $0,26 \mu \mathrm{mol} \mathrm{L}^{-1}$. O complexo 14a, que apresentou maiores efeitos inibidores do crescimento celular em comparação com os outros compostos, também apresentou maior atividade inibitória da TrxR in vitro. Estudos sobre o mecanismo antitumoral em células de fibro sarcoma (HT1080) foram investigados. O tratamento de células com estes compostos resultou na condensação de polímeros de actina (ensaio actin staining) e em uma inibição potente da migração das células do local inicial do tumor (ensaio healing). Resultados de citometria de fluxo indicam que o tratamento com estes compostos leva ao bloqueio do ciclo celular da fase G0/G1. Além disso, os complexos poderiam induzir a apoptose em células HT1080 por meio de disfunção mitocondrial e aumento da produção de espécies reativas de oxigênio $(R O S) .{ }^{46}$ Subsequentemente, o mesmo grupo de pesquisa investigou o efeito da inclusão de grupos metoxibenzeno na fosfina, sobre a atividade biológica de uma série de compostos de ouro. ${ }^{47} \mathrm{~A}$ atividade anticâncer para esse tipo de compostos foi avaliada nas linhas tumorais de ovário (SKOV-3), fibrossarcoma (HT1080), glioblastoma (U87MG), próstata (PC-3) e cervical (HeLa). De forma 
Tabela 1. Valores de $\mathrm{IC}_{50}$ para complexos selecionados de $\mathrm{Au}(\mathrm{I})$ contendo ligantes $\mathrm{PR}_{3}$ em linhagens celulares cancerosas. As respectivas referências são dadas em colchetes

\begin{tabular}{|c|c|c|c|c|c|c|c|c|c|c|c|c|c|c|c|c|}
\hline \multicolumn{17}{|c|}{$\mathrm{IC}_{50}, \mu \mathrm{mol} \mathrm{L} \mathrm{L}^{-1}$} \\
\hline Composto & HeLa & Нер3В & SKHep-1 & $\begin{array}{l}\text { MDA- } \\
\text { MB231 }\end{array}$ & NCI-H460 & SUNE1 & HepG2 & SW 480 & PLC & HL-60 & DU 145 & HT 1080 & B16-F10 & $\begin{array}{c}\text { CT26- } \\
\text { WT }\end{array}$ & A2780/R & $\begin{array}{c}\text { CCRF- } \\
\text { CEM }\end{array}$ \\
\hline $\mathbf{9}^{[43]}$ & & $\begin{array}{c}1,7 \pm \\
1,4\end{array}$ & $\begin{array}{c}4,7 \pm \\
1,5\end{array}$ & $\begin{array}{c}5,1 \pm \\
2,6\end{array}$ & & & & & & & & & & & & \\
\hline${ }^{\mathrm{a}} \mathbf{C D D P} \mathbf{P}^{[43]}$ & & $\begin{array}{c}38 \pm \\
4,2\end{array}$ & $\begin{array}{c}41 \pm \\
2,8\end{array}$ & $\begin{array}{c}78,0 \pm \\
4,6\end{array}$ & & & & & & & & & & & & \\
\hline $10^{[44]}$ & $\begin{array}{c}10,7 \pm \\
2,5\end{array}$ & & & $\begin{array}{c}28,1 \pm \\
2,7\end{array}$ & $\begin{array}{c}57 \pm \\
1,8\end{array}$ & $\begin{array}{c}39,7 \pm \\
1,6\end{array}$ & $\begin{array}{c}63,9 \pm \\
2,1\end{array}$ & $\begin{array}{c}52,5 \pm \\
3,5\end{array}$ & $>100$ & $\begin{array}{c}39,4 \pm \\
0,6\end{array}$ & & & & & & \\
\hline $11^{[44]}$ & $\begin{array}{c}4,9 \pm \\
0,6\end{array}$ & & & $\begin{array}{c}4,5 \pm \\
0,4\end{array}$ & $\begin{array}{c}11,0 \pm \\
1,8\end{array}$ & $\begin{array}{c}5,2 \pm \\
0,8\end{array}$ & $\begin{array}{c}13,7 \pm \\
1,5\end{array}$ & $\begin{array}{c}8,1 \pm \\
1,5\end{array}$ & $\begin{array}{c}7,0 \pm \\
2,0\end{array}$ & $\begin{array}{c}3,5 \pm \\
0,5\end{array}$ & & & & & & \\
\hline $12^{[44]}$ & $\begin{array}{c}3,4 \pm \\
0,9\end{array}$ & & & $\begin{array}{c}5,8 \pm \\
2,3\end{array}$ & $\begin{array}{c}19,6 \pm \\
1,1\end{array}$ & $\begin{array}{c}5,2 \pm \\
1,9\end{array}$ & $\begin{array}{c}22,0 \pm \\
2,1\end{array}$ & $\begin{array}{c}4,6 \pm \\
0,3\end{array}$ & $\begin{array}{c}23,8 \pm \\
2,5\end{array}$ & $\begin{array}{c}4,1 \pm \\
1,1\end{array}$ & & & & & & \\
\hline $13^{[44]}$ & $\begin{array}{c}10,6 \pm \\
0,1\end{array}$ & & & $\begin{array}{c}11,2 \pm \\
3,1\end{array}$ & $\begin{array}{c}27,3 \pm \\
1,8\end{array}$ & $\begin{array}{c}18,8 \pm \\
2,9\end{array}$ & $\begin{array}{c}33,5 \pm \\
1,2\end{array}$ & $\begin{array}{c}9,9 \pm \\
1,4\end{array}$ & $\begin{array}{c}24,8 \pm \\
0,3\end{array}$ & $\begin{array}{c}9,4 \pm \\
1,0\end{array}$ & & & & & & \\
\hline${ }^{\mathrm{a}} \mathbf{C D D P} \mathbf{P}^{[44]}$ & $\begin{array}{c}5,1 \pm \\
0,9\end{array}$ & & & $\begin{array}{c}52,1 \pm \\
2,5\end{array}$ & $\begin{array}{c}31,8 \pm \\
2,2\end{array}$ & $\begin{array}{c}25,6 \pm \\
1,5\end{array}$ & $\begin{array}{c}80,0 \pm \\
2,6\end{array}$ & $\begin{array}{c}63,7 \pm \\
3,2\end{array}$ & $>100$ & $>100$ & & & & & & \\
\hline $14 a^{[46]}$ & $\begin{array}{c}0,5 \pm \\
0,08\end{array}$ & & & $\begin{array}{c}0,36 \pm \\
0,19\end{array}$ & & & & & & & $\begin{array}{c}0,58 \pm \\
0,1\end{array}$ & $\begin{array}{c}0,04 \pm \\
0,02\end{array}$ & & & & \\
\hline $14 b^{[46]}$ & $\begin{array}{l}1,4 \pm \\
0,25\end{array}$ & & & $\begin{array}{c}0,76 \pm \\
0,27\end{array}$ & & & & & & & $\begin{array}{c}4,65 \pm \\
0,64\end{array}$ & $\begin{array}{c}0,42 \pm \\
0,19\end{array}$ & & & & \\
\hline $15 \mathbf{a}^{[46]}$ & $\begin{array}{c}2,9 \pm \\
0,73\end{array}$ & & & $\begin{array}{c}1,23 \pm \\
0,15\end{array}$ & & & & & & & $\begin{array}{c}3,92 \pm \\
0,66\end{array}$ & $\begin{array}{c}0,29 \pm \\
0,09\end{array}$ & & & & \\
\hline $15 b^{[46]}$ & $\begin{array}{l}3,1 \pm \\
0,43\end{array}$ & & & $\begin{array}{c}0,91 \pm \\
0,26\end{array}$ & & & & & & & $\begin{array}{c}2,8 \pm \\
0,59\end{array}$ & $\begin{array}{c}0,15 \pm \\
0,04\end{array}$ & & & & \\
\hline${ }^{\mathrm{a}} \mathbf{C D D P}^{[46]}$ & $\begin{array}{c}3,0 \pm \\
0,62\end{array}$ & & & $\begin{array}{c}6,35 \pm \\
1,65\end{array}$ & & & & & & & $\begin{array}{c}1,64 \pm \\
0,39\end{array}$ & $\begin{array}{c}0,54 \pm \\
0,11\end{array}$ & & & & \\
\hline $16 \mathbf{a}^{[51]}$ & & & & & & & & & & & & & $\begin{array}{c}1,2 \pm \\
0,2\end{array}$ & $\begin{array}{c}1,8 \pm \\
0,8\end{array}$ & & \\
\hline $16 b^{[51]}$ & & & & & & & & & & & & & $\begin{array}{c}5,7 \pm \\
0,5\end{array}$ & $\begin{array}{c}5,7 \pm \\
0,9\end{array}$ & & \\
\hline $17 \mathbf{a}^{[51]}$ & & & & & & & & & & & & & $\begin{array}{c}1,0 \pm \\
0,1\end{array}$ & $\begin{array}{c}0,9 \pm \\
0,1\end{array}$ & & \\
\hline $17 b^{[51]}$ & & & & & & & & & & & & & $\begin{array}{c}1,8 \pm \\
0,5\end{array}$ & $\begin{array}{c}1,8 \pm \\
0,3\end{array}$ & & \\
\hline${ }^{\mathrm{a}} \mathbf{C D D P}{ }^{[51]}$ & & & & & & & & & & & & & $\begin{array}{c}6,0 \pm \\
1,0\end{array}$ & $\begin{array}{c}5,0 \pm \\
1,7\end{array}$ & & \\
\hline${ }^{\mathrm{b}} \mathbf{A} \mathbf{F}^{[51]}$ & & & & & & & & & & & & & $\begin{array}{c}0,5 \pm \\
0,4\end{array}$ & $\begin{array}{c}0,5 \pm \\
0,4\end{array}$ & & \\
\hline $27^{[56]}$ & & & & & & & & & & & & & & & $\begin{array}{c}4,1 \pm \\
2,5\end{array}$ & \\
\hline${ }^{\mathrm{a}} \mathbf{C D D P}{ }^{[56]}$ & & & & & & & & & & & & & & & $\begin{array}{c}18,2 \pm \\
1,0\end{array}$ & \\
\hline $\mathbf{2 8}^{[61]}$ & & & & & & & & & & & & & & & & $\begin{array}{c}4,2 \pm \\
0,9\end{array}$ \\
\hline${ }^{\mathrm{b}} \mathbf{A} \mathbf{F}^{[61]}$ & & & & & & & & & & & & & & & & $\begin{array}{c}6,0 \pm \\
1,2\end{array}$ \\
\hline
\end{tabular}

${ }^{a} \mathrm{CDDP}=$ cis-diamino dicloro platina (cis-platina), ${ }^{\mathrm{b}} \mathrm{AF}=$ Auranofina.

geral, os compostos contendo ligantes halogênio $\left[\mathrm{AuX}\left\{\mathrm{P}\left(\mathrm{C}_{6} \mathrm{H}_{4}-4-\right.\right.\right.$ $\left.\left.\mathrm{OMe})_{3}\right\}\right]$ e $\left[\mathrm{AuX}\left\{\mathrm{P}\left(\mathrm{C}_{6} \mathrm{H}_{3}-2,6-\{\mathrm{OMe}\}_{2}\right)_{3}\right\}\right](\mathrm{X}=\mathrm{Cl}, \mathrm{Br}, \mathrm{I})$ se mostraram menos ativos que os compostos a base de difosfinas $\left[\mathrm{Au}\left\{\mathrm{P}\left(\mathrm{C}_{6} \mathrm{H}_{4}-4-\right.\right.\right.$ $\left.\left.\mathrm{OMe})_{3}\right\}_{2}\right] \mathrm{PF}_{6}, \mathrm{e}\left[\mathrm{Au}\left\{\mathrm{P}\left(\mathrm{C}_{6} \mathrm{H}_{3}-2,6-\{\mathrm{OMe}\}_{2}\right)_{3}\right\}_{2}\right] \mathrm{PF}_{6}$, confirmando que os substituintes metoxibenzeno na fosfina são cruciais para a atividade biológica. O complexo $\left[\mathrm{Au}\left\{\mathrm{P}\left(\mathrm{C}_{6} \mathrm{H}_{3}-2,6-\{\mathrm{OMe}\}_{2}\right)_{3}\right\}_{2}\right] \mathrm{PF}_{6}$ exibiu uma potente atividade anticâncer para todas as linhas celulares testadas com valores de $\mathrm{IC}_{50}$ entre 0,19 e $0,77 \mu \mathrm{mol} \mathrm{L}{ }^{-1}$. Esse último composto exibiu melhor atividade em relação à cisplatina, a qual apresentou valores $\mathrm{IC}_{50}=0,63-8,22 \mu \mathrm{mol} \mathrm{L}-1$. Tal composto também mostrou a maior inibição de crescimento de células 3D HeLa. Ensaios mostraram que o mecanismo de ação para este tipo de compostos é dado pela inibição da TrxR, causando o aumento da produção de ROS e subsequentemente indução de apoptose. ${ }^{47}$
De forma geral, as difosfinas são uma classe interessante de ligantes que oferecem diferentes modos de coordenação em torno do ouro, modulando a lipoficidade e a atividade anticâncer dos compostos obtidos. Uma ampla série de compostos anticâncer de ouro contendo ligantes difosfina, incluindo aqueles nos tipos quelante e ponte, têm sido desenvolvidos nos últimos 30 anos. Mais estratégias adotadas para melhorar as propriedades biológicas de compotos de ouro, a partir de difosfinas, podem ser consultadas na recente revisão de Mirzadeh e colaboradores. ${ }^{48}$

Alguns compostos orgânicos como tiazolidinas (TZD), oxadiazolinas (ODZ) e tiossemicarbazonas (TSC) exibem um amplo espectro de atividade farmacológica. De fato, alguns deles estão presentes em muitos produtos naturais e medicamentos. A coordenação deste tipo de ligantes aos íons metálicos como $\mathrm{Au}^{1+} \mathrm{e} \mathrm{Au}^{3+}$, tem 
dado origem a diversos compostos de ouro com atividades notáveis especialmente contra doenças tropicais e câncer. ${ }^{49-52}$ Nos últimos anos, pesquisadores têm tomado vantagem das propriedades de compostos $\mathrm{Au}-\mathrm{TZD} / \mathrm{ODZ} / \mathrm{TSC}$ e $\mathrm{Au}-\mathrm{PR}_{3}$ para criar uma nova classe de complexos de $\mathrm{Au}(\mathrm{I})$ que combinasse estes dois tipos de ligantes. Garcia et al. ${ }^{51}$ descreveram a atividade citotóxica contra linhas células tumorais B16-F10 (melanoma de pele) e CT26-WT (carcinoma colorretal) e a inibição da TrxR para quatro novos complexos de $\mathrm{Au}(\mathrm{I}) \mathrm{com}$ ligantes derivados de adamantano-1,3,4-oxadiazolinas ou 1,3-tiazolidinas heterocíclicas em conjunto com as fosfinas $\mathrm{PEt}_{3}$ ou $\mathrm{PPh}_{3}$ (16-17; Figura 6). Os complexos de $\mathrm{Au}(\mathrm{I})$-tiazolidina (17) foram mais ativos que os complexos $\mathrm{Au}(\mathrm{I})$-oxadiazol (16) e o uso da trietilfosfina como ligante auxiliar melhorou a atividade dos compostos em comparação à trifenilfosfina; este mesmo efeito foi observado para os análogos $\left[\mathrm{Au}\left(\mathrm{PEt}_{3}\right) \mathrm{Cl}\right]$ e $\left[\mathrm{Au}\left(\mathrm{PPh}_{3}\right) \mathrm{Cl}\right]$. Os compostos $\mathbf{1 7}$ mostraram-se mais ativos e seletivos em comparação à cisplatina contra ambas células tumorais (Tabela 1). Em particular, o complexo 17 a e apresentou valores de $\mathrm{IC}_{50}$ próximos à auranofina; no entanto, possui uma maior seletividade. O composto mais citotóxico da série (17a) também apresentou a melhor inibição da TrxR quando comparado à auranofina. Cálculos quânticos mostraram que os compostos de tiazolidina reagem com $\mathrm{Sec}$ muito mais rápido que os compostos de oxadiazol. Os autores sugerem que a maior resposta biológica para estes dois complexos pode ser devida à rápida troca de ligantes após a interação com o sítio de ligação à TrxR. De fato, a análise de docking indica que a flexibilidade deste tipo de estrutura favorece o ingresso do composto no sítio ativo da enzima e, além disso, pode alocar o complexo em uma posição mais favorável ao ataque nucleofílico dos grupos Sec/Cys. ${ }^{51}$ Em 2017, Tavares et al. ${ }^{52}$ adotaram uma estratégia similar, usando ligantes tiossemicarbazonas em conjunto com ligantes de fosfina para o desenho de compostos anticâncer de $\mathrm{Au}(\mathrm{I})$. Os complexos metálicos do tipo [Au(aryl-TSC) $\left.\left(\mathrm{PPh}_{3}\right)\right]^{+}$(18a-f; Figura 6) foram mais citotóxicos e seletivos do que seus respectivos análogos $\left[\mathrm{Au}(\operatorname{aryl}-\mathrm{TSC})_{2}\right]^{+}$sem a presença da fosfina contra as células tumorais de B16-F10 e CT26-WT. Apesar disso, 18a-f exibiram uma capacidade moderada para inibir a TrxR (entre 56-78\%) em comparação aos compostos [Au(aryl-TSC) $\left.]_{2}\right]^{+}$, os quais inibiram quase completamente a enzima. A discussão anterior é contraditória com o resultado de citotoxicidade observado para ambas séries de compostos, no entanto, os autores discutem que as condições do teste com a enzima isolada excluem a captação celular a qual é altamente promovida pelos grupos fosfina. A análise de docking sugeriu que a inibição da TrxR é dada principalmente pela interação entre o ligante TSC com o resíduo de tirosina (Y116) do $\mathrm{N}$-terminal, o qual é considerado chave para o mecanismo catalítico da enzima. Em relação à cisplatina, os compostos 18a-f mostraram similar citotoxicidade $\left(\mathrm{IC}_{50}<2 \mu \mathrm{mol} \mathrm{L} \mathrm{L}^{-1}\right)$, porém, se mostraram menos seletivos. ${ }^{52}$

Complexos de ouro têm se mostrado promissores agentes antimaláricos após a coordenação de diferentes compostos orgânicos, como o fármaco cloroquina (CQ) ${ }^{6,7,53} \mathrm{~A}$ atividade anticâncer do composto antimalárico $\left[\mathrm{Au}(\mathrm{CQ})\left(\mathrm{PPh}_{3}\right)\right] \mathrm{PF}_{6}(\mathbf{1 9}$; Figura 6) também foi testada em diferentes linhagens celulares tumorais humanas. A citotoxicidade de $\mathbf{1 9}$ foi testada em conjunto com os análogos [Au(CQ)Cl] e [Au(CQ)tgta] (tgta=tetraacetato de $\beta$-tioglucosa), sem a presença da fosfina. De forma geral, a atividade destes dois últimos foi maior do que a mostrada pela CQ livre e a cisplatina, mas não tão acentuada como a exibida pelo composto 19. Este último exibiu valores de $\mathrm{GI}_{50}$ de 0,03 e $0,04 \mu \mathrm{mol} \mathrm{\textrm {L } ^ { - 1 }}$ nas células de câncer de cólon (HT-29) e melanoma (B16/BL6). O composto 19 se mostrou como potente inibidor da $\operatorname{TrxR}\left(\mathrm{IC}_{50}=8,75 \mathrm{nmol} \mathrm{L}-1\right)$, entretanto, em menor proporção em relação ao composto de controle $\left[\mathrm{Au}\left(\mathrm{PEt}_{3}\right) \mathrm{Cl}\right]\left(\mathrm{IC}_{50}=2,58 \mathrm{nmol} \mathrm{L}-1\right) .53$
Recentemente, Gambini et al. ${ }^{54}$ relataram que os compostos $\mathrm{Au}(\mathrm{I})$-azolato/fofanos, [Au(4,5-dicloro-1H-imidazolato-1-il)(trifenilfosfano)] e [Au(4,5-dicianil-1H-imidazolato-1-il)- (trifenilfosfano)] (20a e 20b respectivamente; Figura 6) mostraram maior citotoxicidade entre a série estudada, principalmente nas células de câncer de mama HMLE/FoxQ1, com valores de $\mathrm{IC}_{50}$ de 7,41 e $9,27 \mu \mathrm{mol} \mathrm{L} \mathrm{L}^{-1}$. Os compostos $\mathbf{2 0 a}, \mathbf{b}$ foram testados em tumores A17 transplantados em camundongos singênicos. Após 19 dias de tratamento, estes compostos inibiram o crescimento do tumor similarmente à cisplatina, porém, nos últimos 5 dias de tratamento a cisplatina mostrou-se mais efetiva na supressão do tumor. Apesar disso, 20a,b exibiram baixa nefrotoxicidade em relação à cisplatina devido ao aumento da hidrofilicidade deste tipo de compostos permitindo uma boa excreção de ouro dos rins. Estudos sobre o mecanismo de ação sugerem que ambos os complexos de Au(I) inibiram a proteína desubiquitinase (DUBs) USP14 associada ao proteassoma 19S (responsável pelo controle das quantidades de várias proteínas reguladoras e proteínas danificadas) e induziram apoptose. Adicionalmente, o composto 20a também depende de sua capacidade de reduzir moléculas chave como STAT3 e Cox-2 que governam o crescimento e a progressão do câncer. ${ }^{54}$

A coordenação de peptídeos a íons metálicos pode ajudar na liberação de complexos metálicos, conseguindo cruzar eficientemente as membranas celulares e se acumular nas mitocôndrias das células cancerígenas. Köster et al. ${ }^{55}$ relataram a atividade anticâncer de uma série de compostos de fórmula $\mathrm{Au}(\mathrm{I})$-fosfina contendo ligantes di e tetrapeptídeos (compostos 21-26; Figura 6). A citotoxicidade dos compostos variou de 2 a $50 \mu \mathrm{mol} \mathrm{L} \mathrm{L}^{-1}$ quando testados contra células tumorais HT-29 e MCF-7 e está correlacionada com a lipofilicidade dos mesmos. Verificou-se também que os compostos inibem a TrxR, o que levou a níveis elevados de $R O S$, a perda da função mitocondrial da membrana e, finalmente, apoptose. Em particular, foi observado um efeito na taxa de respiração de células de câncer de mama MDA-MB231 mutantes de p53 altamente agressivas e resistentes à cisplatina. ${ }^{55}$

O uso de ligantes do tipo PTA (1,3,5-triaza-7-fosfadamantane) tem levado à obtenção de complexos de $\mathrm{Au}(\mathrm{I})$ solúveis em água com interessantes propriedades antitumorais contra células de câncer de ovário e cólon. ${ }^{56-59}$ Vergara et al. ${ }^{56}$ relatam a atividade anticâncer e a inibição da TrxR de uma série de análogos da AF contendo um tiolato e um ligante fosfina solúvel em água, como PTA. Os valores de $\mathrm{IC}_{50}$ desses compostos nas células A2780, resistentes e sensíveis à cisplatina, variam de 4 a $30 \mu \mathrm{mol} \mathrm{L}{ }^{-1}$, sendo o composto 27 (Figura 6, Tabela 1) o mais ativo. As concentrações nanomolares destes compostos inibem a TrxR citosólica e mitocondrial. Os valores de $\mathrm{IC}_{50}$ para a inibição da isoforma mitocondrial são aproximadamente quatro vezes mais altos que os da forma citosólica, fenômeno também observado em outros complexos de $\mathrm{Au}(\mathrm{I})$ e atribuído a variações de sequência que tornam o local ativo citosólico mais ácido. No entanto, a inibição da isoforma citosólica e mitocondrial da TrxR interrompe a homeostase redox celular e altera o estado de oxidação dos tióis mitocondriais, o que por sua vez afeta a permeabilidade da membrana mitocondrial, de modo que, em qualquer caso, o complexo metálico provoca atividade antimitocondrial ${ }^{56}$ Recentemente, compostos similares foram estudados usando a fosfina $\mathrm{P}\left(\mathrm{NMe}_{2}\right)_{3}$, que é mais solúvel do que PTA, e incluindo uma maior variedade de grupos tiolatos. ${ }^{60}$ Os resultados revelaram que a inclusão da fosfina $\mathrm{P}\left(\mathrm{NMe}_{2}\right)_{3}$ aumenta a atividade antiproliferativa nas células A2780, resistentes e sensíveis à cisplatina, comparada com a atividade observada com PTA. Adicionalmente, os complexos de $\mathrm{Au}(\mathrm{I})$ contendo os tióis 2-tiobenzimidazole e 2-tiouroacil exibiram uma alta seletividade específica para células Caco- 2 de câncer de cólon, sendo considerados como promissores candidatos a drogas anticâncer. A inibição da TrxR e 


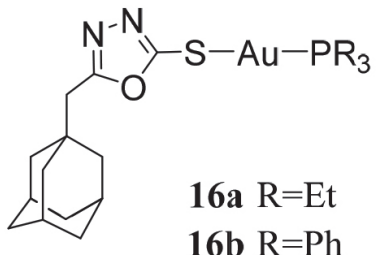

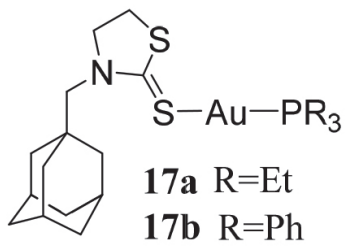<smiles></smiles>

19<smiles>[R]c1ncn(C#[Te][PH](c2ccccc2)(c2ccccc2)c2ccccc2)c1[R]</smiles>

20a $\mathrm{R}=\mathrm{Cl}$ 20b $\mathrm{R}=\mathrm{CN}$

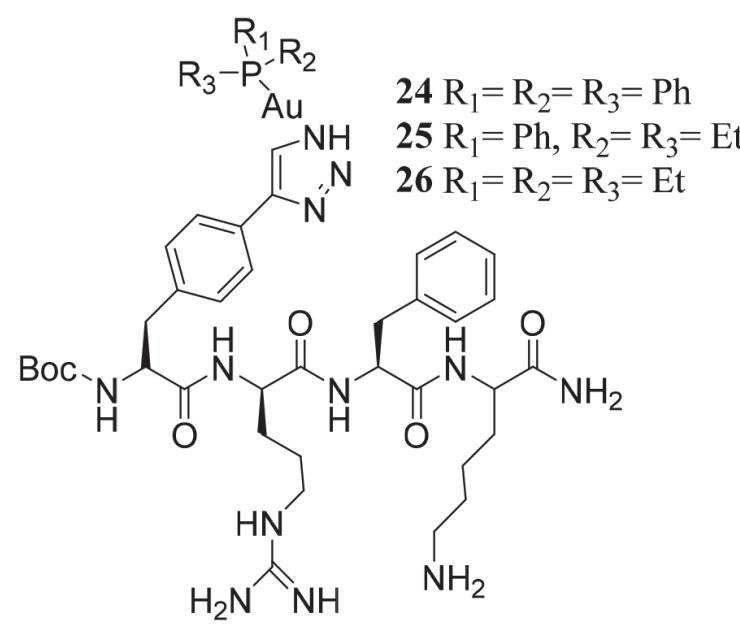<smiles>c1cnc(S[Al]2CN3CN4CN(C3)C42)nc1</smiles>

27

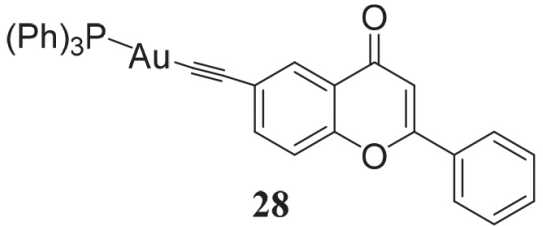<smiles>[W]=P(c1ccccc1)(c1ccccc1)c1ccccc1</smiles><smiles></smiles>

29

Figura 6. Estruturas químicas de complexos $A u(I)-P R_{3}$ com atividade anticâncer

danos oxidativos nos lipídios da membrana foram evidenciados como modo de ação deste tipo de compostos. ${ }^{60}$

Os complexos de $\mathrm{Au}(\mathrm{I})$ contendo ligantes fosfina e grupos alcinil também representam candidatos promissores a drogas anticâncer. O composto 28 (Figura 6, Tabela 1), reportado por Hikisz et al., ${ }^{61}$ no qual um ligante flavona está ligado à fração $\mathrm{Au}\left(\mathrm{PPh}_{3}\right)$ por meio de um ligante alcinil, apresentou atividade inibitória contra a TrxR. A TrxR celular é inibida pelo complexo $\mathbf{2 8}$, mas não foi observada uma correlação entre inibição e citotoxicidade. Em vez disso, foram obtidas evidências de que outros modos de ação, incluindo danos ao ADN e distúrbios do ciclo celular, também são atuantes. ${ }^{61}$

Diversas evidências experimentais têm mostrado que as enzimas deubiquitinases (DUBs) desempenham um papel importante em vários estágios do câncer. Tal fato fez com que recentemente fosse desenvolvida uma nova classe de compostos direcionados aos DUBs para inibir o crescimento tumoral. ${ }^{54,62} \mathrm{Li}$ et al.${ }^{63}$ reportaram em 2019 a síntese de um novo complexo de $\mathrm{Au}(\mathrm{I}),\left[\mathrm{Au}\left(\mathrm{PPh}_{3}\right) \mathrm{PT}\right]$ (29, Figura 6). A atividade inibitória de $\left[\mathrm{Au}\left(\mathrm{PPh}_{3}\right) \mathrm{PT}\right](\mathrm{PT}=$ piritiona) no sistema ubiquitina-proteassoma (UPS) e o crescimento de múltiplos tipos de células cancerígenas foram testados in vitro, ex vivo e in vivo. Tal composto induziu apoptose em duas linhas celulares de câncer de pulmão A549 e NCI/H1299; essa atividade anticâncer foi atribuída em parte à inibição seletiva das DUBs associadas ao proteassoma
19S e à diminuição da atividade de outras DUBs citoplasmáticos não proteasomais (USP7, USP10, USP15 e USP25). Além disso, o composto 29 induziu apoptose em células cancerígenas de pacientes com leucemia mielóide aguda, suprimiu efetivamente o crescimento de xenoenxertos de adenocarcinoma de pulmão em camundongos nus e provocou menos citotoxicidade em células normais do que vários outros complexos metálicos. Após a análise de tais resultados, concluiu-se que tal complexo é um inibidor eficaz das DUBs e potencial quimioterápico. ${ }^{63}$ Estudos prévios têm mostrado que a AF inibe algumas DUBs-proteasomais como UCHL5 e USP $14 .{ }^{64}$ De fato, como já mencionado, os compostos 20a,b também mostraram capacidade de inibir a USP14, o que leva a inferir que o ligante fosfina tem um papel importante na inibição destas enzimas.

\section{COMPLEXOS Au(I)-NHC}

Carbenos N-heterocíclicos (NHCs) são compostos de última geração e atualmente não há dúvida de que eles têm causado um impacto significativo na ciência e na química em geral. Os NHCs são relativamente não-tóxicos, possuem fortes propriedades doadoras de elétrons e suas variações estruturais são essencialmente ilimitadas, permitindo-se ajustar sua lipoficidade e reatividade. ${ }^{14}$ Complexos de metais de transição-NHC são facilmente preparados partindo-se de 
sais de imidazol. Assim, complexos Au(I)-NHC têm sido extensivamente investigados nas últimas duas décadas.

Em 2006, uma série de complexos catiônicos de fórmula geral $\left[\mathrm{Au}(\mathrm{R}-\mathrm{NHC})_{2}\right]^{+}$(30; Figura 7), foram preparados e elucidados por Baker et al. ${ }^{65}$ Os substituintes alquila dos ligantes NHC foram variados para modular as propriedades lipofílicas dos complexos resultantes. Os valores do logaritmo decimal do coeficiente de partição octanol/ água $\left(\log P_{\mathrm{ow}}\right)$ para estes compostos variaram entre $-1,09$ a $1,73 \mathrm{e}$ aumentaram conforme o esperado: $\mathrm{R}=\mathrm{Me}<\mathrm{i}-\mathrm{Pr}<\mathrm{t}-\mathrm{Bu}<\mathrm{n}-\mathrm{Bu}<\mathrm{Cy}$. Os compostos induzem à permeabilização da membrana mitocondrial do fígado de rato, a qual pode ser atribuída por ambas características catiônicas e lipofílicas. De fato, os resultados mostraram que existe uma relação direta entre a atividade antimitocondrial e a lipoficidade do complexo metálico. ${ }^{65}$ Estudos subsequentes focaram-se na inibição da enzima TrxR. ${ }^{66}$ Para entender o mecanismo de inibição da TrxR com os compostos $\left[\mathrm{Au}(\mathrm{R}-\mathrm{NHC})_{2}\right]^{+}$, estudaram-se reações de troca de ligante R-NHC/Cys,Sec em duas etapas consecutivas, utilizando-se RMN de ${ }^{1} \mathrm{H}$. Os valores das constantes de velocidade estimadas indicaram que a reação de troca de $\left[\mathrm{Au}(\mathrm{R}-\mathrm{NHC})_{2}\right]^{+}$com substituintes mais volumosos no NHC diminui a velocidade da reação, onde a reação com $\mathrm{Sec}$ mostrou-se mais rápida do que com Cys. Os compostos 30b, 30c e 30d se mostraram seletivamente tóxicos em células de câncer de mama (MDA-MB-231 e MDA-MB-468), mas não para as células normais. $\mathrm{O}$ grau de seletividade se correlaciona com seus valores de $\log P_{\text {ow }}$. O composto 30c inibiu a atividade da $\operatorname{TrxR}\left(\mathrm{IC}_{50}=\sim 5 \mu \mathrm{mol} \mathrm{L}{ }^{-1}\right)$, porém, não houve inibição da atividade intracelular da GR nas mesmas condições. ${ }^{66}$ Mais recentemente, foi descrita uma análise cinética mais detalhada da mesma reação de troca R-NHC/Cys em compostos $\left[\mathrm{Au}(\mathrm{R}-\mathrm{NHC})_{2}\right]^{+}$usando cálculos DFT. ${ }^{67}$ Para a primeira etapa da reação, a qual se mostrou como

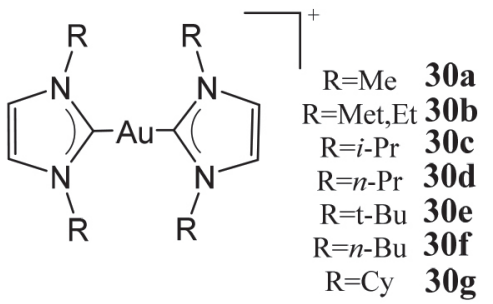<smiles>CCn1c(=O)n(CC)c2ccccc21</smiles><smiles>CCN1C(=C2N(CC)c3ccccc3N2CC)N(CC)c2ccccc21</smiles><smiles>[B-][C+](Br)CC</smiles><smiles>CCC=C(CC)C(C)C</smiles>
$\mathrm{P}(n-\mathrm{Bu})_{3}$<smiles>Cn1c(=O)c2c(n(C)c1=O)n(C)c(=O)n2C</smiles>

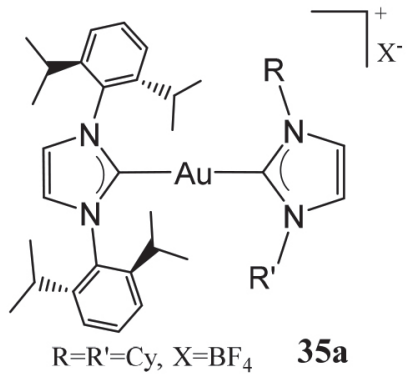

$\mathrm{R}=\mathrm{Me}, \mathrm{R}^{\prime}=n-\mathrm{Bu}, \mathrm{X}=\mathrm{Cl}$ 35b

$\mathrm{R}=\mathrm{Me}, \mathrm{R}^{\prime}=n-\mathrm{Bu}, \mathrm{X}=\mathrm{PF}_{6} 35 \mathrm{c}$

$\mathrm{R}=\mathrm{Me}, \mathrm{R}^{\prime}=n-\mathrm{Bu}, \mathrm{X}=\mathrm{BF}_{4} 35 \mathrm{~d}$ $\mathrm{R}=\mathrm{R}^{\prime}=t-\mathrm{Bu}, \mathrm{X}=\mathrm{BF}_{4} \quad 35 \mathrm{e}$ $\mathrm{R}=\mathrm{R}^{\prime}=\mathrm{Mes}, \mathrm{X}=\mathrm{BF}_{4} \quad \mathbf{3 5 f}$

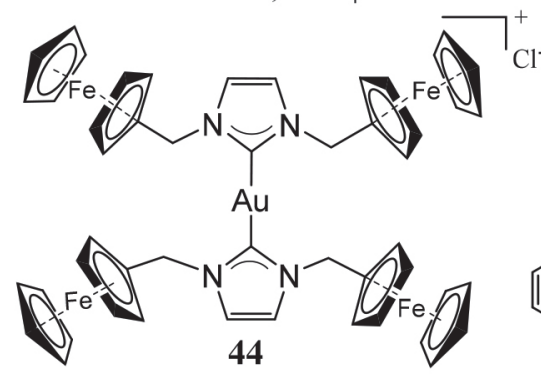

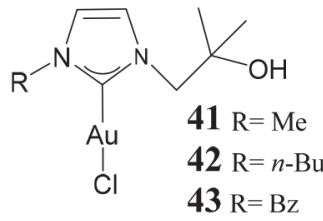

44<smiles></smiles>

36

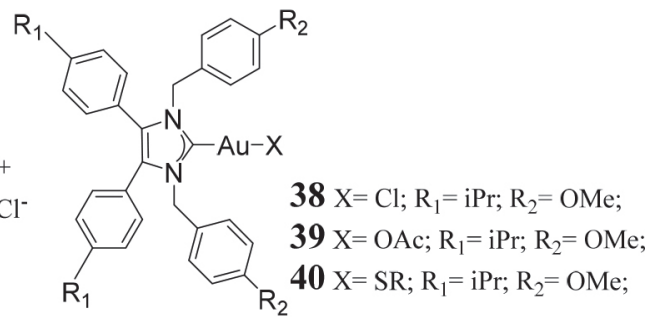

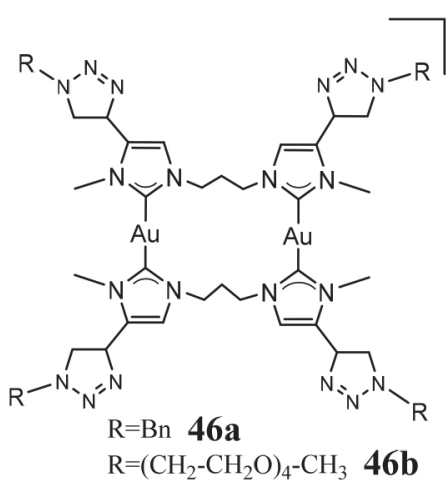

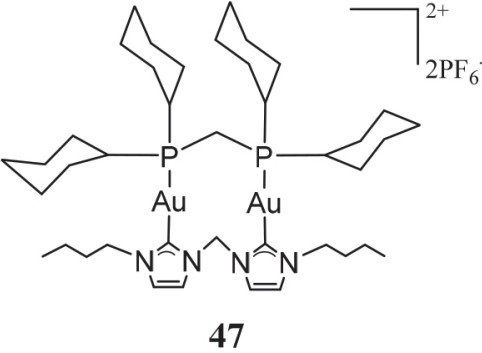

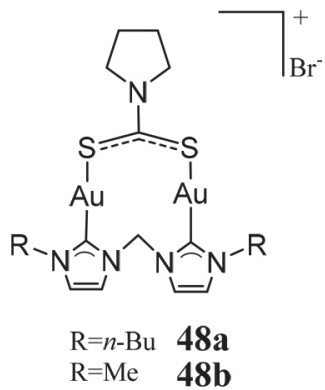

Figura 7. Estruturas químicas de complexos anticâncer de Au(I) contendo ligantes NHC 
a etapa limitante da reação total, a entalpia de ativação seguiu a ordem $\mathrm{Me}<\mathrm{Me}, \mathrm{Et}<n$ - $\mathrm{Bu}<i-\mathrm{Pr}<\mathrm{Cy}<t$ - $\mathrm{Bu}$, que pode ser explicada por características estéricas e eletrônicas. Os resultados sugerem que o derivado $\mathrm{R}-\mathrm{NHC}(\mathrm{R}=\mathrm{Me})$ leva a uma rápida reação com nucleófilos, em que o estado de transição é menos estabilizado pela $\sigma$-doação do carbeno. A segunda etapa de reação também mostrou relações similares de estrutura, porém, as energias de ativação foram menos sensíveis à estrutura. ${ }^{67}$

Rubbiani et al. ${ }^{68}$ descreveram uma série de complexos $[\mathrm{Au}(\mathrm{NHC}) \mathrm{L}]^{\mathrm{n}+}$ (em que o NHC é 1,3-dietilbenzimidazol-2-ilideno) como potentes inibidores da TrxR. $\mathrm{O}[\mathrm{Au}(\mathrm{NHC}) \mathrm{Cl}]$ inibiu a respiração mitocondrial, aumentou a formação de $R O S$ e induziu a apoptose afetando fortemente o metabolismo celular. ${ }^{68} \mathrm{O}$ estudo de propriedades farmacodinâmicas com a variação do ligante $\mathrm{L}\left(\mathrm{L}=\mathrm{Cl}, \mathrm{PPh}_{3}\right.$ e NHC; 31-33, Figura 7) foi avaliado posteriormente. ${ }^{69} \mathrm{~A}$ espectrometria de absorção atômica revelou que as velocidades de reação de troca do ligante L com a Cys34 da albumina sérica foram dadas na ordem 31 >32>33. Como esperado, a reação de troca é mais rápida para o composto 31, o qual contém o ligante lábil cloreto. As atividades de inibição de TrxR destes complexos seguiram a mesma ordem com valores de $\mathrm{EC}_{50} 0,36,0,66,4,89 \mu \mathrm{mol} \mathrm{L} \mathrm{L}^{-1}$ respectivamente. A substituição do cloro no composto $\mathbf{3 1}$ pelos ligantes fosfina e NHC levou a um aumento de aproximadamente 5 vezes na potência antiproliferativa em células de câncer de mama (MCF-7), bem como um aumento de aproximadamente 15 vezes nas células de câncer de cólon (HT-29). Com relação à biosseletividade, apenas o composto $\mathbf{3 3}$ apresentou alguma preferência por células tumorais sobre as não tumorigênicas HEK-293 (ver Tabela 2) ${ }^{69}$ Anteriormente, Weaver e colegas haviam reportado uma ampla série de complexos de ouro cationicos similares do tipo $\left[\mathrm{Au}(\mathrm{R}-\mathrm{NHC}) \mathrm{PR}_{3}\right]^{+} \mathrm{e}\left[\mathrm{Au}(\mathrm{R}-\mathrm{NHC})_{2}\right]^{+}$com o ligante NHC substituído com grupos volumosos (34-36, Figura 7). ${ }^{70}$ Esses compostos mostraram uma alta citotoxicidade em células de câncer de mama e próstata com valores de $\mathrm{IC}_{50}$ entre 0,21 e $1,0 \mu \mathrm{mol} \mathrm{L} \mathrm{L}^{-1}$. Tais valores são incluídos na Tabela 2. A inclusão de fragmentos biocompatíveis, tais como tioglicose, sacarina, aminoácidos e esteroides como ligantes (L) para formar compostos neutros do tipo [Au(R-NHC)L], resultou em uma diminuição significativa da atividade para o mesmo grupo de células cancerosas. Provavelmente, o caráter lipofílico é um importante parâmetro o qual está associado ao acúmulo mitocondrial. ${ }^{70} \mathrm{De}$ fato, a inibição da função mitoncondrial tem sido uma das principais

Tabela 2. Valores de $\mathrm{IC}_{50}$ para complexos selecionados de $\mathrm{Au}(\mathrm{I})$ contendo ligantes NHC em linhagens celulares cancerosas. As respectivas referências são dadas em colchetes

\begin{tabular}{|c|c|c|c|c|c|c|c|c|c|c|c|c|c|c|}
\hline \multicolumn{15}{|c|}{$\mathrm{IC}_{50}, \mu \mathrm{mol} \mathrm{L}-1$} \\
\hline Composto & MCF-7 & HT-29 & HEK-293 & LNCap & $\begin{array}{l}\text { MDA- } \\
\text {-MB231 }\end{array}$ & A549 & A2780 & A2780 cis & PC-3 & НCТ 116 & SKOV3 & MRC5 & HepG2 & $\mathrm{U}-87 \mathrm{MG}$ \\
\hline $31^{[69]}$ & $\begin{array}{c}4,57 \pm \\
0,03\end{array}$ & $\begin{array}{c}6,41 \pm \\
1,97\end{array}$ & $\begin{array}{c}10,3 \pm \\
1,10\end{array}$ & & & & & & & & & & & \\
\hline $32^{[69]}$ & $\begin{array}{c}0,89 \pm \\
0,40\end{array}$ & $\begin{array}{c}0,40 \pm \\
0,18\end{array}$ & $\begin{array}{c}0,41 \pm \\
0,18\end{array}$ & & & & & & & & & & & \\
\hline $\mathbf{3 3}^{[69]}$ & $\begin{array}{c}0,81 \pm \\
0,13\end{array}$ & $\begin{array}{c}0,44 \pm \\
0,13\end{array}$ & $\begin{array}{c}3,13 \pm \\
0,54\end{array}$ & & & & & & & & & & & \\
\hline $\mathbf{3 4} \mathbf{a}^{[70]}$ & & & & 0,73 & 0,38 & & & & & & & & & \\
\hline $\mathbf{3 4} \mathbf{b}^{[70]}$ & & & & 0,41 & 0,40 & & & & & & & & & \\
\hline $\mathbf{3 4} \mathbf{c}^{[70]}$ & & & & 0,38 & 0,35 & & & & & & & & & \\
\hline $35 \mathbf{a}^{[70]}$ & & & & 0,75 & 0,21 & & & & & & & & & \\
\hline $\mathbf{3 5} \mathbf{b}^{[70]}$ & & & & 0,41 & 0,48 & & & & & & & & & \\
\hline $35 \mathbf{c}^{[70]}$ & & & & 0,43 & 1,00 & & & & & & & & & \\
\hline $35 d^{[70]}$ & & & & 0,63 & 0,82 & & & & & & & & & \\
\hline $35 e^{[70]}$ & & & & 0,48 & 0,46 & & & & & & & & & \\
\hline $35 f^{170]}$ & & & & 0,42 & 0,38 & & & & & & & & & \\
\hline $36^{[70]}$ & & & & 0,37 & 0,37 & & & & & & & & & \\
\hline $44^{[75]}$ & & & & & & $\begin{array}{c}0,14 \pm \\
0,03\end{array}$ & $\begin{array}{c}0,19 \pm \\
0,01\end{array}$ & $\begin{array}{c}0,12 \pm \\
0,01\end{array}$ & $\begin{array}{c}0,48 \pm \\
0,15\end{array}$ & & & & & \\
\hline $45^{[76]}$ & & & & & & $\begin{array}{c}0,07 \pm \\
0,016\end{array}$ & $\begin{array}{c}0,03 \pm \\
0,007\end{array}$ & $\begin{array}{c}0,05 \pm \\
0,006\end{array}$ & $\begin{array}{l}0,1 \pm \\
0,017\end{array}$ & & & & & \\
\hline${ }^{\mathrm{a}} \mathbf{D} \mathbf{x}^{[76]}$ & & & & & & $\begin{array}{c}0,10 \pm \\
0,023\end{array}$ & & & & & & & & \\
\hline${ }^{\mathbf{b}} \mathbf{A} \mathbf{F}^{[75,76]}$ & & & & & & $\begin{array}{c}1,67 \pm \\
0,05\end{array}$ & & & & & & & & \\
\hline${ }^{\mathrm{c}} \mathrm{CDDP}^{[76]}$ & $>10$ & & & & & & & & 5,1 & 3,3 & 4,4 & 8,5 & & \\
\hline $46 a^{[77]}$ & $\begin{array}{c}2,2 \pm \\
0,2\end{array}$ & & & & & & & & $\begin{array}{c}3,6 \pm \\
1,0\end{array}$ & $\begin{array}{c}2,8 \pm \\
0,8\end{array}$ & $\begin{array}{c}12,0 \pm \\
0,8\end{array}$ & $\begin{array}{c}2,8 \pm \\
0,1\end{array}$ & & \\
\hline $46 b^{[77]}$ & $\begin{array}{c}0,09 \pm \\
0,01\end{array}$ & & & & & & & & $\begin{array}{c}0,25 \pm \\
0,14\end{array}$ & $\begin{array}{c}0,26 \pm \\
0,12\end{array}$ & $\begin{array}{c}4,4 \pm \\
1,3\end{array}$ & $\begin{array}{c}0,39 \pm \\
0,02\end{array}$ & & \\
\hline $48 a^{[80]}$ & & & & & & & $\begin{array}{c}2,0 \pm \\
0,68\end{array}$ & $\begin{array}{c}0,83 \pm \\
0,08\end{array}$ & & & & & $\begin{array}{c}2,4 \pm \\
1,0\end{array}$ & $\begin{array}{c}2,1 \pm \\
0,5\end{array}$ \\
\hline $48 b^{[80]}$ & & & & & & & $\begin{array}{l}4,2 \pm \\
0,83\end{array}$ & $\begin{array}{l}7,5 \pm \\
2,2\end{array}$ & & & & & $\begin{array}{c}3,0 \pm \\
0,7\end{array}$ & $\begin{array}{c}7,2 \pm \\
0,8\end{array}$ \\
\hline${ }^{\mathrm{c}} \mathrm{CDDP}^{[80]}$ & & & & & & & $\begin{array}{l}3,2 \pm \\
0,61\end{array}$ & $\begin{array}{c}34 \pm \\
2,4\end{array}$ & & & & & $\begin{array}{c}12 \pm \\
1,3\end{array}$ & $\begin{array}{c}5,5 \pm \\
0,97\end{array}$ \\
\hline
\end{tabular}

${ }^{\mathrm{a}} \mathrm{Dx}=$ Doxorrubucina, ${ }^{\mathrm{b}} \mathrm{AF}=$ Auranofina, ${ }^{\mathrm{c}} \mathrm{CDDP}=$ cis-diamino dicloro platina (cis-platina). 
características relatadas para esse tipo de compostos antitumorais $[\mathrm{Au}(\mathrm{NHC}) \mathrm{L}]^{\mathrm{n}+}$ (em que L é um ligante doador de 2 elétrons), o qual tem atraído o interesse dos pesquisadores nas últimas duas década. ${ }^{13}$

Em 2012, um estudo descreveu pela primeira vez um composto catiônico do tipo $[\mathrm{Au}(\mathrm{bis}-\mathrm{NHC})]^{+}$contendo um ligante à base de cafeína (37; Figura 7), seletivo para G-quadruplexes do ADN. ${ }^{71}$ G-quadruplexes são sequências de ácidos nucleicos ricas em guanina, capazes de formar estruturas de quatro cadeias. Estas estruturas consistem num arranjo em quadrado de guaninas (tetrada) estabilizado por ligações de hidrogênio. São também estabilizadas pela existência de cátions monovalentes, especialmente potássio, no centro das tetradas. A cafeína é um derivado das guaninas e, portanto, poderia imitar melhor a montagem original de guaninas $/ \mathrm{K}^{+}$. G-quadruplexes estão sendo bastante estudadas atualmente, já que se perfilam como outra classe de alvos na quimioterapia de câncer, uma vez que se suspeita que tais compostos desempenham papéis chaves, tais como a regulação da transcrição do ADN. Dessa maneira, o desenvolvimento de drogas visando os quadruplexes parece muito promissor. ${ }^{24,71}$

Em 2013, Hackenberg et al. ${ }^{72}$ sintetizaram, caracterizaram e avaliaram biologicamente as atividades anticâncer, em linhas de células tumorais de Caki-1 (renal) e MCF-7 (mama), de uma série de compostos de $\mathrm{Ru}(\mathrm{III})$ e $\mathrm{Au}(\mathrm{I})$ com ligantes NHC. Complexos de fórmula $[\mathrm{Au}(\mathrm{R}-\mathrm{NHC}) \mathrm{L}]^{\mathrm{n}+}$ foram obtidos utilizando-se clorodimetilssulfeto de ouro(I) $\left(\left[\mathrm{Au}(\mathrm{SMe})_{2} \mathrm{Cl}\right]\right)$ como agente transmetalante para gerar os compostos do tipo [Au(NHC)SR] e do tipo [Au(NHC)OAc]. De maneira geral, os complexos [Au(NHC)SR] exibiram melhor atividade ou igual à dos compostos $[\mathrm{Au}(\mathrm{NHC}) \mathrm{Cl}]$ contra as duas linhas celulares citadas anteriormente. Os mesmos compostos também apresentaram melhor atividade do que seus análogos [Au(NHC)OAc]. As únicas exceções são encontradas para os compostos 38, 39 e 40 (Figura 7), onde aquele que contém o grupo acetato (39) mostra melhor atividade contra Caki-1 (18 $\left.\pm 1 \mu \mathrm{mol} \mathrm{L}^{-1}\right)$ do que seus análogos contendo cloro $(41 \pm 1 \mu \mathrm{mol} \mathrm{L}-1)$ e SR $\left(58 \pm 2 \mu \mathrm{mol} \mathrm{L}^{-1}\right)$. Valores mais baixos de $\mathrm{IC}_{50}$ dos complexos [Au(NHC)SR] são provavelmente atribuídos à maior solubilidade dos complexos de ouro, bem como possível captação celular aprimorada devido à porção tioglucopiranose. ${ }^{72}$

Karaca et $a l .{ }^{73}$ relataram a síntese de compostos mono e dinucleares de $\mathrm{Au}(\mathrm{I})$ contendo ligantes bis(NHC) sulfonados e compostos mononucleares $\mathrm{Au}(\mathrm{I})$-(NHC) hidroxilados. Tanto os complexos de $\mathrm{Au}(\mathrm{I})$ quanto os ligantes foram testados contra células de câncer de ovário humano OV2008, e foram também estudados os mecanismos de ação dos complexos de Au(I) frente a TrxR e GR. Com base nos resultados obtidos com os ensaios iniciais de viabilidade celular, os compostos 41, 42 e 43 (Figura 7) mononucleares Au(I)-(NHC) hidroxilados, apresentaram fortes atividades antiproliferativas contra células de câncer utilizadas nesse estudo, mesmo após 1 hora de incubação. Tais compostos também apresentaram forte atividade inibitória seletiva da TrxR. Informações valiosas sobre a reatividade molecular dos compostos de ouro com TrxR foram obtidas por meio do ensaio BIAM (iodoacetamida conjugada com biotina) e por meio da análise de experimentos de competição por espectrometria de massas (MS). Ambas as técnicas sugerem a afinidade dos complexos mononucleares $\mathrm{Au}(\mathrm{I})-(\mathrm{NHC})$ por selenóis e tióis. ${ }^{73}$

Complexos de $\mathrm{Au}(\mathrm{I})$ contendo ligantes R-NHC têm sido recentemente desenvolvidos com o objetivo de inibir a TrxR e ao mesmo tempo aumentar o estresse celular oxidativo (níveis mais altos de ROS) esperando-se, consequentemente, uma redução no crescimento celular. Esta é uma característica que tem sido apreciada há muito tempo no contexto da terapia do câncer. ${ }^{74-76}$ Arambula et al..$^{75}$ reportaram compostos $\left[\mathrm{Au}(\mathrm{R}-\mathrm{NHC})_{2}\right]^{+}$contendo grupos ferroceno como substituintes (44; Figura 7). A incorporação de ferrocenos geradores de ROS nos compostos Au(I)-NHC aumentou consideravelmente as propriedades antiproliferativas que foram correlacionadas positivamente com o número de unidades de ferroceno incorporadas. O tratamento de células de câncer de pulmão A549 com 44 mostrou um valor de $\mathrm{IC}_{50}=0,14 \mu \mathrm{mol} \mathrm{L} \mathrm{L}^{-1} \mathrm{e}$ um aumento de 13,7 vezes o número de $R O S$ intracelulares. Esse é um aumento significativo em relação ao composto de controle, a $\mathrm{AF}\left(\mathrm{IC}_{50}=1,67 \mu \mathrm{mol} \mathrm{L}{ }^{-1}, 2,7\right.$ vezes-ROS) (ver Tabela 2$)$. Porém, a AF mostrou uma maior inibição da TrxR do que o composto 44 e seus análogos. ${ }^{75} \mathrm{~A}$ busca de compostos $\mathrm{Au}(\mathrm{I})$-NHC que induzem um estresse oxidativo é contínua. Mais recentemente, o mesmo grupo de pesquisa reportou outro composto com tais caraterísticas. ${ }^{76}$ As quinonas são agentes fortemente oxidantes. Muitas quinonas podem ser seletivamente reduzidas em ambientes hipóxicos como no caso de células cancerosas, aumentando a produção de ROS. O composto 45 dicoordenado com duas unidades de 1,4-naftoquinona, causou uma alta proliferação de células cancerígenas (Tabela 2), muito maior do que seu análogo $[\mathrm{Au}($ naftoq- $\mathrm{NHC})(\mathrm{Cl})]$ e o ligante de naftoquinona livre. O composto $\mathbf{4 5}$ também mostrou maior citotoxidade do que a AF e a doxorrubicina. De fato, o tratamento de células A549 com o composto 45 produziu um aumento de aproximadamente 27 vezes na expressão de $R O S$, as quais foram localizadas nas mitocôndrias. A inibição de TrxR do composto $\mathbf{4 5}$ foi semelhante à da $\mathrm{AF}$ e foi confirmado um mecanismo apoptótico na morte celular. ${ }^{76}$

Tendo em vista as propriedades eletro-doadoras de ligantes NHC para formar fortes ligações Metal-NHC, diversos pesquisadores continuam testando as propriedades anticâncer de complexos de $\mathrm{Au}(\mathrm{I})$ dinucleares, contendo ligantes NHC. Baron et al. ${ }^{77}$ sintetizaram e caracterizaram complexos dinuclerares de $\mathrm{Au}(\mathrm{I})$, estabilizados por ligantes funcionalizados de NHC (46; Figura 7). Os precursores dos azóis foram obtidos utilizando-se a cicloadição de azida/alcino catalisada por cobre (I). Atividades antiproliferativas foram testadas em um grupo de diferentes linhagens celulares tumorais humanas (MCF7, HCT116, PC3 e SKOV3) e em duas células não cancerígenas (MRC5 e EPC). O composto 46b foi muito mais ativo do que o $46 \mathrm{a}$ em todas as linhagens celulares, ao qual foi atribuído o maior caráter hidrofílico conferido pelo substituinte de polietilenoglicol $\left(\mathrm{CH}_{2}-\mathrm{CH}_{2} \mathrm{O}\right)_{4}-\mathrm{CH}_{3}$ em 46b comparado com o benzil em 46a $\left(\log P_{\text {ow }}=-0,6\right.$ e - 0,9 para 46a e 46b, respectivamente). O composto 46b mostrou uma potente atividade anticâncer, especialmente nas células MCF7 de câncer de mama $\left(\mathrm{IC}_{50}=0,09 \mu \mathrm{mol} \mathrm{L}{ }^{-1}\right)$. Ambos os compostos mostraram uma alta seletividade frente às células normais endoteliais ECP, mas não para os fibroblastos derivados do pulmão MRC5 (Tabela 2). ${ }^{77}$

Sabendo que vários complexos de $\mathrm{Au}(\mathrm{I})$ dinucleares contendo ligantes NHC bidentados em ponte, $\left[\mathrm{Au}_{2}(\mathrm{bis}(\mathrm{NHC}))_{2}\right]^{2+}$, não são reativos contra tióis, Zou et al. ${ }^{78}$ prepararam um composto com essas características e adicionaram um ligante difosfina $\left[\mathrm{Au}_{2}(\mathrm{dcpm})\right.$ (bisNHC $\left.\left.{ }^{2 \mathrm{C} 4}\right)\right]\left(\mathrm{PF}_{6}\right)_{2}[\mathrm{dcpm}=$ bis(diciclohexilfosfina)metano] (47; Figura 7). A análise por espectrometria de massas de ionização por electrospray ESI-MS, combinada com experimentos de ICP-MS (espectrometria de massas por plasma acoplado indutivamente) revelou que a AF foi altamente reativa a GSH $\left(1-10 \mu \mathrm{mol} \mathrm{L}^{-1}\right)$ e a albumina sérica (35-50 $\mathrm{mg} \mathrm{mL}^{-1}$ ) presentes no sangue. Por outro lado, o complexo dinuclear 47 não reagiu com os tióis em iguais condições, sugerindo que essa estabilidade lhe permite inibir a atividade da TrxR sem ser atacado previamente por tióis do sangue. Utilizando-se o modelo de peptídeo do braço C-terminal da TrxR GCSG (glicina-cisteína-selenocisteína-glicina), ensaios ESI-MS em conjunto com RMN revelaram um aduto 1:1 formado entre a porção GCSG e o complexo 47, indicando a coordenação simultânea da unidade dinuclear $\left[\mathrm{Au}_{2}(\mathrm{dcpm})\right]$ com os respectivos átomos $\mathrm{S}(\mathrm{Cys})$ e $\mathrm{Se}(\mathrm{Sec})$ e a liberação do ligante bis(NHC) ${ }^{78}$ Alguns estudos anteriores relataram a ligação de duas unidades de $\left[\mathrm{Au}\left(\mathrm{PEt}_{3}\right)\right]^{+}$de $\mathrm{AF}$ a $\sim \mathrm{Se}^{-}$e $\sim \mathrm{SH}$ do peptídeo GCSG. ${ }^{79} \mathrm{O}$ tratamento de camundongos portadores de xenoenxertos HeLa ( $5 \mathrm{mg}$ $\mathrm{kg}^{-1}$, i.p) e tumores altamente agressivos de melanoma B16-F10 de camundongo (15 mg kg-1, i.p) com o composto 47 , resultou na inibição 
significativa do tumor em $81 \%$ e $62 \%$, respectivamente. A dosagem do tratamento, que variou de 0,6 a $15 \mathrm{mg} \mathrm{kg}^{-1}$, não mostrou morte nem perda de peso corporal dos ratos. ${ }^{78}$ Subsequentemente, Sun et al..$^{80}$ relataram uma série de compostos dinucleares $\mathrm{Au}(\mathrm{I})$-bis(NHC) similares aos de Zou et al. ${ }^{78}$ contendo um ligante pirrolidinodiocarbamato. As atividades anticancerígenas foram determinadas in vitro para um grupo de células humanas de carcinoma de ovário (A2780 e a sua variante resistente a cisplatina A2780cis, HepG2, U-87 MG) e em células epiteliais renais normais Madin-Darby (MDCK). Os valores de $\mathrm{IC}_{50}$ são incluídos na Tabela 2. O complexo 48a (Figura 7) apresentou resultados promissores citotóxicos e antimigratórios in vitro em células cancerosas A2780cis. Devido à estrutura rígida do composto 48a foi possível testá-lo em conjunto com uma estrutura metalorgânica baseada em Zn(II) (Zn-MOF), um material biocompatível para facilitar sua captação e liberação em soluções. Os resultados indicam a viabilidade do uso do Zn-MOF com o complexo $48 \mathbf{a}$ em estudos anticâncer e podem abrir caminho para estudos futuros de outros materiais biocompatíveis para melhorar a atividade anticâncer de complexos de ouro. ${ }^{80}$ Discussões adicionas de outros complexos de $\mathrm{Au}(\mathrm{I})-\mathrm{NHC}$ anticancerígenos podem ser encontrados nas recentes revisões de 2018 e 2019. . $^{15,81}$

Dada et al. ${ }^{82}$ reportaram a síntese e a atividade biológica de vários complexos de $\mathrm{Au}(\mathrm{I})$ contendo ligantes NHC com estrutura similar aos complexos 38-40 já discutidos. Foram obtidos os complexos 49-54 (Figura 8), pseudo-halogenatos e tiolatos de $\mathrm{Au}(\mathrm{I})$ contendo ligantes NHC. Tais compostos foram testados quanto à sua potencial citotoxicidade em linhagens celulares tumorais MCF-7, SN12C, K-562 e NCI/COLO205. Os compostos 49, 50 e 53 apresentaram atividade média a baixa, enquanto os complexos 51, 52 e 54 mostraram atividade promissora no painel de células cancerígenas NCI 60. Além disso, os compostos 51 e 54 mostraram inibição de crescimento celular médio de $50 \%\left(\mathrm{GI}_{50}\right)$ em concentrações de $1,78 \mathrm{e} 1,95 \mu \mathrm{mol} \mathrm{L}{ }^{-1}$ respectivamente, enquanto o complexo $\mathbf{5 2}$ mostrou atividade superior com um valor $\mathrm{GI}_{50}$ médio de $0,47 \mu \mathrm{mol} \mathrm{L} \mathrm{L}^{-1}$. $^{82}$ Foi também relatado por Schmidt e colegas o estudo do potencial citotóxico contra células de carcinoma HT-29, bem como em linhagens celulares de câncer de mama MCF-7 e MDA-MB231, de uma série de compostos de fórmula

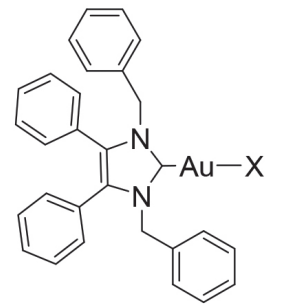

$49 \mathrm{X}=$ tiofenolato

$50 \mathrm{X}=P$-tiometoxifenolato

$51 \mathrm{X}=$ ciclohexanotioxifenolato

$52 \mathrm{X}=$ tiocianato

$53 \mathrm{X}=$ isocianato

$54 \mathrm{X}=$ azida<smiles>[R2]N1c2ccccc2N([R2])C1[AlH2]Sc1ncccn1</smiles>

58e $\mathrm{R}=$ 2,6-dimetilfenil; $\mathrm{X}=\mathrm{H} ; \mathrm{Y}=\mathrm{H}$;

58f $\mathrm{R}=$ 2,4,6-trimetilfenil; $\mathrm{X}=\mathrm{H} ; \mathrm{Y}=\mathrm{H}$;

58g R $1=\mathrm{CH}\left(\mathrm{CH}_{3}\right)_{2} ; \mathrm{R}_{2}=\mathrm{CH}\left(\mathrm{CH}_{3}\right)_{2}$;

58h $\mathrm{R}_{1}=\mathrm{CH}_{3} ; \mathrm{R}_{2}=\mathrm{CH}_{2}-\mathrm{Fc}$; geral [Au(R-NHC)Cl] (55-57; Figura 8). ${ }^{83}$ Essa série de compostos apresentou uma certa tendência para maior citotoxicidade, indicando o forte efeito antiproliferativo contra todas as células cancerígenas mencionadas. Estudos realizados com tais compostos revelaram que a atividade citotóxica dos mesmos foi fortemente influenciada pela estabilidade e eficiência destes para se acumular nas células. Além disso, a biodisponibilidade celular dos mesmos também foi afetada pela ligação destes à albumina, apresentando valores acima de $80 \%$. A efetiva inibição da TrxR de mamíferos e bactérias também foi confirmada para todos os compostos. ${ }^{83}$

Schuh et al. ${ }^{84}$ relatam a síntese de uma série de complexos de $\mathrm{Au}(\mathrm{I})$ contendo um ligante imidazol ou benzimidazol-2-ilideno substituído com 1,3 e 2-mercaptopirimidina (compostos 58a-h, Figura 8). Os compostos apresentaram valores de $\mathrm{IC}_{50}$ na faixa de 2 a $30 \mu \mathrm{mol} \mathrm{L} \mathrm{L}^{-1}$ em células A2780, resistentes e sensíveis à cisplatina, sendo mais ativos do que seus pares com um ligante clorido mais lábil, em vez do ligante tiolato. O direcionamento preferencial da selenocisteína da TrxR1 foi confirmado pelo ensaio BIAM. Curiosamente, os complexos 58e, $\mathbf{5 8 f}$ e $\mathbf{5 8 g}$ inibem seletivamente a TrxR nas células A2780S, enquanto esses não apresentam efeito na TrxR das células HEK-293T não cancerígenas. Isso contrasta acentuadamente com as propriedades inibidoras da AF que não mostram seletividade da linha celular. No entanto, 58e-g ainda são bastante citotóxicos contra células HEK-293T não cancerígenas $\left(\mathrm{IC}_{50} 12-16 \mu \mathrm{mol} \mathrm{L}^{-1}\right){ }^{84}$

O complexo 59 (Figura 8) reduz o tamanho do tumor em camundongos portadores de melanoma $\mathrm{B} 16 \mathrm{~F} 10 .{ }^{85}$ Os estudos celulares indicaram uma perda de potencial de membrana mitocondrial $(\Delta \psi \mathrm{m})$ dependente da dose, geração de $R O S$, regulação negativa das proteína Bcl-2 e regulação positiva de Bax, p53 e p21, de acordo com o envolvimento da via mitocondrial de apoptose. Embora não tenham sido estudados experimentalmente, os autores sugeriram a inibição da TrxR por analogia com outros complexos $\mathrm{Au}(\mathrm{I})-\mathrm{NHC}{ }^{85}$

\section{COMPLEXOS DE Au(III) CONTENDO LIGANTES MULTIDENTADOS COM PROPRIEDADES ANTICÂNCER}

A inclusão de diferentes ligantes quelantes multidentados tem<smiles>[X]C1=C([Y])N([R])C([Al]Sc2ncccn2)N1[R]</smiles>

58a $\mathrm{R}=\mathrm{CH}_{3} ; \mathrm{X}=\mathrm{H} ; \mathrm{Y}=\mathrm{H}$;

$\mathbf{5 8 b} \mathrm{R}=\mathrm{CH}_{3} ; \mathrm{X}=\mathrm{Cl} ; \mathrm{Y}=\mathrm{Cl}$;

58c $\mathrm{R}=\mathrm{CH}_{3} ; \mathrm{X}=\mathrm{H} ; \mathrm{Y}=\mathrm{CH}_{3} \mathrm{OC}(=\mathrm{O}) \mathrm{CH}=\mathrm{CH}$

58d $\mathrm{R}=\mathrm{CH}_{3} ; \mathrm{CHPh}_{2} ; \mathrm{X}=\mathrm{H} ; \mathrm{Y}=\mathrm{H}$<smiles>C/C=C\N1C=CN(CCNC(C)=O)C1[Al]C1N(CCNC(C)=O)C=C2C=CC=CN21</smiles>

Figura 8. Estruturas químicas de complexos anticâncer $\mathrm{Au}(\mathrm{I})$-NHC 
sido uma estratégia eficaz para o desenvolvimento de complexos de Au(III) mais estáveis. Como já mencionado, a maioria dos agentes anticâncer de $\mathrm{Au}^{3+}$ atualmente desenvolvidos contém ligantes multidentados do tipo $\mathrm{N}^{\wedge} \mathrm{N}, \mathrm{N}^{\wedge} \mathrm{N}^{\wedge} \mathrm{N}, \mathrm{C}^{\wedge} \mathrm{N}, \mathrm{C}^{\wedge} \mathrm{N}^{\wedge} \mathrm{N}, \mathrm{C}^{\wedge} \mathrm{N}^{\wedge} \mathrm{C}$, porfirinas e ditiocarbamatos. Compostos de coordenação formados com ligantes tridentados também são conhecidos como complexos metálicos pincer. Dessa maneira, os complexos de $\mathrm{Au}$ (III) contendo ligantes, tais como $\mathrm{N}^{\wedge} \mathrm{N}^{\wedge} \mathrm{N}, \mathrm{C}^{\wedge} \mathrm{N}^{\wedge} \mathrm{N}$ e $\mathrm{C}^{\wedge} \mathrm{N}^{\wedge} \mathrm{C}$, são considerados complexos pincer de ouro. Nos últimos tempos, uma grande variedade de complexos de $\mathrm{Au}$ (III) tem exibido alta toxicidade para diferentes células tumorais in vitro e também alguns poucos resultados in vivo têm sido reportados. O resumo e discussão sobre esses resultados serão apresentados a seguir.

\section{Complexos de $\mathrm{Au}(\mathrm{III})$ contendo ligantes $\mathrm{C}^{\wedge} \mathrm{N}$ e $\mathrm{C}^{\wedge} \mathrm{N}^{\wedge} \mathrm{N}$}

Em 1996, Buckley et al. ${ }^{86}$ e Parish et al. ${ }^{87}$ descreveram uma série de complexos de $\mathrm{Au}(\mathrm{III})$ do tipo $\left[\mathrm{AuX}_{2}(\mathrm{damp})\right]$ (damp $=O-\mathrm{C}_{6} \mathrm{H}_{4} \mathrm{CH}_{2} \mathrm{NMe}_{2} ; \mathrm{X}=\mathrm{Cl}, \mathrm{SCN}$, OAc, oxalato ou malonato) representados como 60 na Figura 9. ${ }^{86,87}$ Esses complexos metálicos apresentaram citotoxicidade semelhante à da cisplatina contra várias linhas de células tumorais humanas, sendo que os complexos metálicos com acetato e malonato geralmente mostraram melhor atividade e seletividade in vitro e uma moderada atividade antitumoral in vivo contra xenoenxerto de carcinoma humano. A administração de $12,5 \mathrm{mg} \mathrm{kg}^{-1}$ (via i.p.) destes compostos provocou uma inibição de até $60 \%$ do crescimento do tumor em um modelo de xenoenxerto

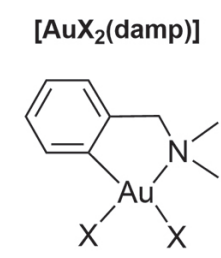

$\mathrm{X}=\mathrm{Cl}, \mathrm{SCN}$, acetato $\mathrm{X}_{2}=$ oxalato, malonato

60

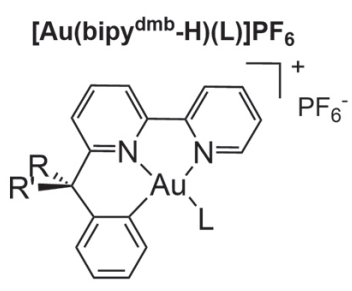

61a $\mathrm{L}=\mathrm{OH}, \mathrm{R}=\mathrm{R}^{\prime}=\mathrm{Me}$

61b $\mathrm{L}=\mathrm{NHC}_{6} \mathrm{H}_{3} \mathrm{Me}_{2}-2,6, \mathrm{R}=\mathrm{R}^{\prime}=\mathrm{Me}$ 61c $\mathrm{L}=\mathrm{HC}_{2} \mathrm{ArNHCOQ}, \mathrm{R}=\mathrm{R}^{\prime}=\mathrm{Me}$

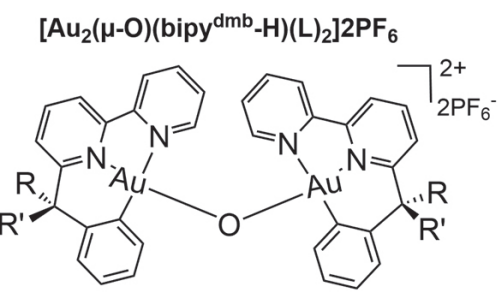

62a $\mathrm{R}=\mathrm{R}^{\prime}=\mathrm{Me}$

62b $\mathrm{R}=\mathrm{H}, \mathrm{R}^{\prime}=\mathrm{Me}$
$\left[\mathrm{Au}_{2}\left(\mathrm{bipy}^{2 \mathrm{Me}}-\mathrm{H}\right)(\mu-\mathrm{O})_{2}\right] 2 \mathrm{PF}_{6}$

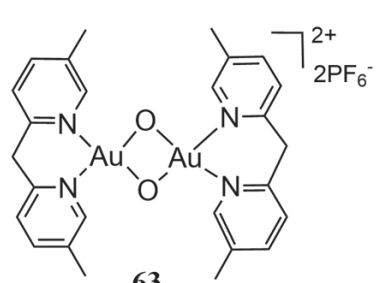

63

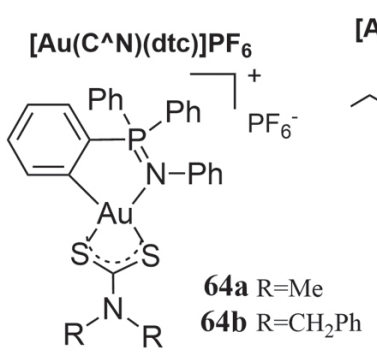

[Au( $\left({ }^{\mathrm{nBu}} \mathrm{C}^{\wedge} \mathrm{N}\right)($ biguanida) $] \mathrm{Cl}$

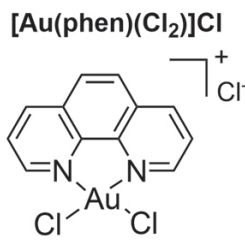

66<smiles></smiles>

67
[Au(IPI)(NHC)]OTf<smiles></smiles>

68a $\mathrm{R}=\mathrm{Me}$,

$68 b \quad R={ }^{n} B u t$

68c $\mathrm{R}=-\left(\mathrm{CH}_{2}\right)_{5} \mathrm{CH}_{3}$
[Au(BPB)(NHC)]OTf

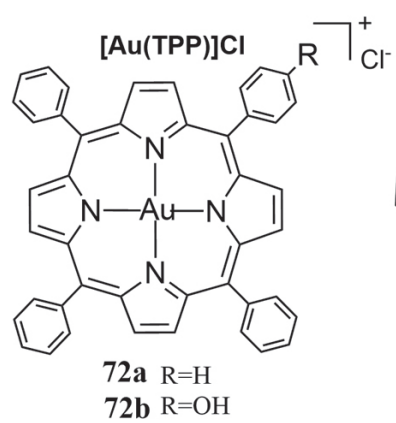

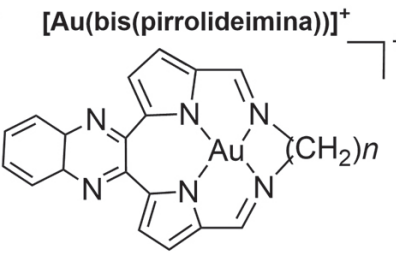

73

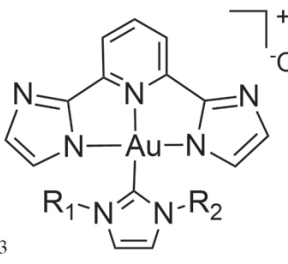

69a $\mathrm{R}_{1}=\mathrm{R}_{2}=\mathrm{Me}$

Tf $69 \mathrm{~b} \mathrm{R}_{1}=\mathrm{Me}, \mathrm{R}_{2}={ }^{\mathrm{n}} \mathrm{But}$

69c $\mathrm{R}_{1}=\mathrm{Me}, \mathrm{R}_{2}=-\left(\mathrm{CH}_{2}\right)_{7} \mathrm{CH}_{3}$

$69 d \mathrm{R}_{1}=\mathrm{Me}, \mathrm{R}_{2}=-\left(\mathrm{CH}_{2}\right)_{9} \mathrm{CH}_{3}$

69e $\mathrm{R}_{1}=\mathrm{Me}, \mathrm{R}_{2}=-\left(\mathrm{CH}_{2}\right)_{15} \mathrm{CH}_{3}$

69 f $\mathrm{R}_{1}=\mathrm{R}_{2}={ }^{\mathrm{n}} \mathrm{But}$

$69 \mathrm{~g} \mathrm{R}_{1}=\mathrm{R}_{2}=-\left(\mathrm{CH}_{2}\right)_{5} \mathrm{CH}_{3}$

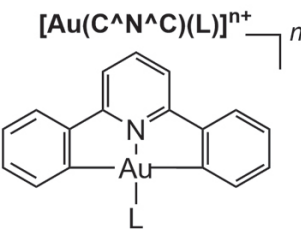

74a $\mathrm{L}=\mathrm{Cl}^{-}$

74b $\mathrm{L}=1$-metilimidazol

74c $\mathrm{L}=\mathrm{Py}$

74d $\mathrm{L}=\mathrm{PPh}_{3}$

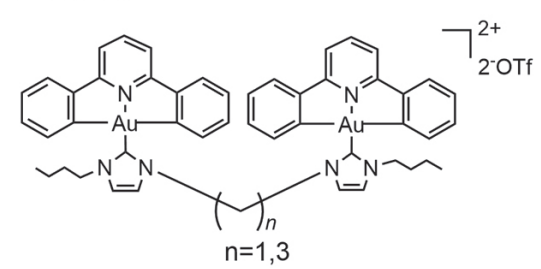

76

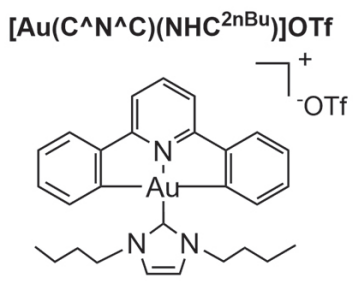

77
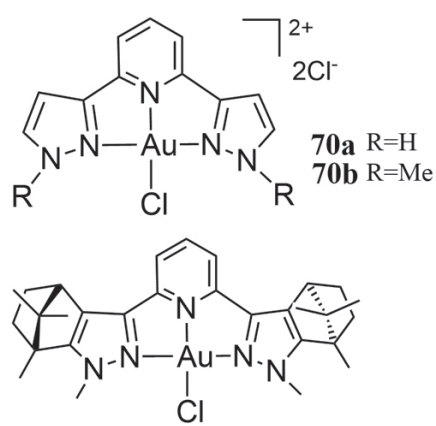

71

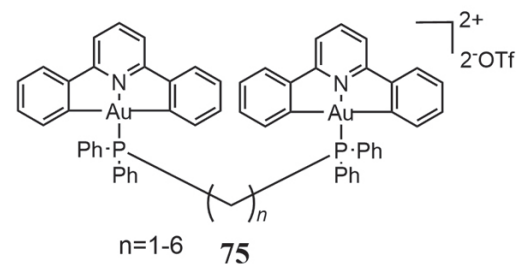<smiles>CN1c2ccccc2N(C)C1[Al](Cl)[n+]1c(-c2ccc(C(C)(C)C)cc2Cl)cncc1-c1ccc(C(C)(C)C)cc1C(F)(F)F</smiles>

78

Figura 9. Complexos de Au(III) contendo ligantes multidentados com propriedades anticâncer 
de ratos após 28 dias de tratamento. ${ }^{86} \mathrm{O}$ composto $\left[\mathrm{AuCl}_{2}\right.$ (damp)] (60) e os análogos de acetato e malonato inibem as cisteínas proteases catepsina $\mathrm{B}$ e $\mathrm{K}$, com valores de $\mathrm{IC}_{50}$ de $0,6-1,36 \mu \mathrm{mol} \mathrm{L}{ }^{-1}$ e 1,3-3,3 $\mu \mathrm{mol} \mathrm{L} \mathrm{L}^{-1}$, respectivamente, e, além disso, são potenciais inibidores da TrxR. ${ }^{88,89}$ Esses resultados despertaram novamente o interesse em complexos de $\mathrm{Au}(\mathrm{III})$ como potenciais agentes antineoplásicos. Assim, foi desenvolvida uma série de complexos de $\mathrm{Au}(\mathrm{III})$ ciclometalados, contendo outros ligantes do tipo $\mathrm{C}^{\wedge} \mathrm{N}$ e $\mathrm{C}^{\wedge} \mathrm{N}^{\wedge} \mathrm{N}$ mostrando interessantes propriedades anticâncer., ${ }^{4,24}$ Alguns análogos de $\mathbf{6 0}(\mathrm{C}, \mathrm{N})$ foram avaliados adicionando uma, duas ou três ligações $\mathrm{C}$-Au. Em geral, a introdução de um número crescente de ligações C-Au torna os compostos mais lipofílicos, facilitando a captação intracelular. No entanto, a capacidade de interagir com os tióis ou grupos selenol de proteínas pareceu ser reduzida. ${ }^{24,89}$

Em 2002, Marcon et al. ${ }^{90}$ desenvolveram complexos de ouro com ligantes tipo pincer $\left(\mathrm{C}^{\wedge} \mathrm{N}^{\wedge} \mathrm{N}\right)$, [(bipy $\left.\left.{ }^{\mathrm{dmb}}-\mathrm{H}\right) \mathrm{Au}(\mathrm{L})\right] \mathrm{PF}_{6}$ (bipy $^{\mathrm{dmb}}=6-(1,1-$ dimetilbenzil) $)-2,2^{\prime}$-bipiridina) (61; Figura 9). O composto 61a mostrou relevantes efeitos citotóxicos em células tumorais de câncer de ovário sensíveis e resistentes à cisplatina como reportado na Tabela $3 .{ }^{90} \mathrm{Na}$ Tabela 3 encontra-se resumida a atividade anticâncer de complexos de $\mathrm{Au}(\mathrm{III})$ com valores $\mathrm{IC}_{50}$ menores a $14 \mu \mathrm{mol} \mathrm{L} \mathrm{L}^{-1}$ em diferentes linhagens celulares cancerosas. Em um estudo sistemático mais recente, o composto 61a foi testado em um amplo painel de células cancerígenas e mostrou moderado efeito antiproliferativo e escassa seletividade. ${ }^{91}$ Porém, o análogo contendo um ligante de 2,6-xilidina, (61b), foi marcadamente mais citotóxico e teve um alto grau de seletividade contra um grupo de 36 linhas de células tumorais humanas. A inibição da síntese da proteína quinase mTOR, do proteassoma e/ou do ADN tem sido sugerida como um possível mecanismo de ação. ${ }^{92}$ Já o composto 61c, que apresenta uma cumarina como ligante auxiliar e é dotado de alta estabilidade redox em solução, exibe efeitos antiproliferativos, sendo este o mais ativo nas linhas celulares testadas (Tabela 3). Para estudar a reatividade desse último composto com biomoléculas, a interação do complexo

Tabela 3. Valores de $\mathrm{IC}_{50}$ para complexos selecionados de $\mathrm{Au}(\mathrm{III})$ em linhagens celulares cancerosas. As respectivas referências são dadas em colchetes

\begin{tabular}{|c|c|c|c|c|c|c|c|}
\hline $\begin{array}{l}\text { Complexo de } \\
\mathrm{Au}(\mathrm{IIII})\end{array}$ & $\begin{array}{c}\text { Linhagem celular } \\
\text { cancerosa }\end{array}$ & $\begin{array}{c}\text { Atividade } \\
\left(\mathrm{IC}_{50} / \mu \mathrm{mol} \mathrm{L} \mathrm{L}^{-1}\right)\end{array}$ & 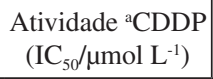 & $\begin{array}{c}\text { Complexo de } \\
\mathrm{Au}(\mathrm{III})\end{array}$ & $\begin{array}{c}\text { Linhagem celular } \\
\text { cancerosa }\end{array}$ & $\begin{array}{c}\text { Atividade } \\
\left(\mathrm{IC}_{50} / \mu \mathrm{mol} \mathrm{L} \mathrm{L}^{-1}\right)\end{array}$ & $\begin{array}{c}\text { Atividade a }{ }^{\text {CDDP }} \\
\left(\mathrm{IC}_{50} / \mu \mathrm{mol} \mathrm{L} \mathrm{L}^{-1}\right)\end{array}$ \\
\hline \multirow{4}{*}{$61 \mathbf{a}^{[90]}$} & A2780 & $3,3 \pm 1,4$ & $1,3 \pm 0,2$ & \multirow{2}{*}{$\mathbf{7 2} \mathbf{a}^{[29]}$} & CNE1 & $0,17 \pm 0,02$ & $40,8 \pm 2,17$ \\
\hline & A2780cis & $8,2 \pm 1,5$ & $15,3 \pm 1,9$ & & HepG2 & $0,34 \pm 0,02$ & $13,5 \pm 1,82$ \\
\hline & SKOV3 & $13,3 \pm 1,6$ & $21,6 \pm 4,1$ & \multirow{5}{*}{$\mathbf{7 2} \mathbf{b}^{[106]}$} & MDA-MB231 & $0,007 \pm 0,002$ & $7,37 \pm 1,19$ \\
\hline & CCRF-CEM & $11,9 \pm 2,1$ & $1,0 \pm 0,3$ & & MCF7 & $0,08 \pm 0,04$ & $14,3 \pm 1,46$ \\
\hline \multirow{5}{*}{$\mathbf{6 1} \mathbf{c}^{[91]}$} & A549 & $4,5 \pm 0,8$ & $11,5 \pm 0,9$ & & BT474 & $0,49 \pm 0,17$ & $49,0 \pm 0,50$ \\
\hline & MCF-7 & $2,3 \pm 0,8$ & $20 \pm 3$ & & SKBR3 & $0,02 \pm 0,01$ & $65,9 \pm 25,5$ \\
\hline & SKOV-3 & $2,6 \pm 0,8$ & $13 \pm 4$ & & T47D & $0,04 \pm 0,01$ & $66,5 \pm 12,4$ \\
\hline & A375 & $1,46 \pm 0,8$ & $3,10 \pm 1,59$ & \multirow{3}{*}{$\mathbf{7 4} \mathbf{a}^{[26]}$} & HeLa & $3,4 \pm 0,6$ & $11 \pm 1,0$ \\
\hline & HEK-293 & $0,55 \pm 0,01$ & $8,15 \pm 0,47$ & & SUNE1 & $4,0 \pm 0,5$ & $1,0 \pm 0,1$ \\
\hline \multirow{2}{*}{$\mathbf{6 3}^{[94]}$} & A2780 & $1,79 \pm 0,17$ & $2,1 \pm 0,2$ & & CNE1 & $3,1 \pm 0,4$ & $3,3 \pm 0,5$ \\
\hline & A2780cis & $4,81 \pm 0,5$ & $24,4 \pm 0,1$ & \multirow{3}{*}{$\mathbf{7 4} b^{[26]}$} & HeLa & $8,0 \pm 0,5$ & $11 \pm 1,0$ \\
\hline \multirow{2}{*}{$\mathbf{6 4} \mathbf{a}^{[95]}$} & HeLa-GPF & 6,2 & 14,9 & & SUNE1 & $12 \pm 1,3$ & $1,0 \pm 0,1$ \\
\hline & Jurkat-GFP & 1,0 & 31 & & CNE1 & $6,7 \pm 1,5$ & $3,3 \pm 0,5$ \\
\hline \multirow{2}{*}{$\mathbf{6 4} b^{[95]}$} & Hela-GPF & 7,75 & 14,9 & \multirow{3}{*}{$\mathbf{7 4} c^{[26]}$} & HeLa & $8,2 \pm 0,4$ & $11 \pm 1,0$ \\
\hline & Jurkat-GFP & 2,5 & 31 & & SUNE1 & $4,0 \pm 0,4$ & $1,0 \pm 0,1$ \\
\hline \multirow{5}{*}{$\mathbf{6 5}^{[97]}$} & HeLa & $7,7 \pm 0,1$ & $5,2 \pm 0,1$ & & CNE1 & $2,6 \pm 0,4$ & $3,3 \pm 0,5$ \\
\hline & B16 & $10,5 \pm 0,3$ & $8,7 \pm 1,0$ & \multirow{2}{*}{$\mathbf{7 4} \mathbf{d}^{[26,108]}$} & HeLa & $7,2 \pm 0,6$ & $0,084 \pm 0,007$ \\
\hline & PLC & $8,8 \pm 0,3$ & $46,4 \pm 1,8$ & & CNE1 & $11 \pm 2,0$ & - \\
\hline & MDA-MB231 & $8,7 \pm 0,2$ & $66,7 \pm 1,3$ & \multirow{4}{*}{$\mathbf{7 5}^{[108]} n=3$} & HeLa & $0,043 \pm 0,006$ & $0,084 \pm 0,007$ \\
\hline & SUNE1 & $2,1 \pm 0,1$ & $12,0 \pm 1,3$ & & PLC & $0,17 \pm 0,07$ & $0,24 \pm 0,01$ \\
\hline \multirow{2}{*}{$\mathbf{6 6}^{[98]}$} & A2780 & $3,8 \pm 1,1$ & $1,22 \pm 0,43$ & & CCD-19Lu (normal) & $1,6 \pm 0,1$ & $1,9 \pm 0,1$ \\
\hline & A2780cis & $3,49 \pm 0,91$ & $14,16 \pm 2,72$ & & HepG2 & $0,21 \pm 0,09$ & $1,1 \pm 0,09$ \\
\hline \multirow{2}{*}{$67^{[98]}$} & $\mathbf{A 2 7 8 0}$ & 0,2 & $1,22 \pm 0,43$ & \multirow{4}{*}{$\mathbf{7 6}^{[108]} n=3$} & HeLa & $0,35 \pm 0,01$ & $0,084 \pm 0,007$ \\
\hline & A2780cis & $0,37 \pm 0,032$ & $14,16 \pm 2,72$ & & PLC & $7,8 \pm 0,8$ & $0,24 \pm 0,01$ \\
\hline $69 e^{[28]}$ & HeLa & $1,4 \pm 0,2$ & - & & CCD-19Lu (normal) & $12 \pm 0,8$ & $1,9 \pm 0,1$ \\
\hline${ }^{\mathrm{b}} \mathbf{A} \mathbf{F}^{[28]}$ & Hela & $1,8 \pm 0,1$ & - & & HepG2 & $7,5 \pm 0,08$ & $1,1 \pm 0,09$ \\
\hline \multirow{5}{*}{$72 \mathbf{a}^{[29]}$} & HeLa & $0,28 \pm 0,02$ & $11,2 \pm 0,96$ & \multirow{5}{*}{$7^{(108]}$} & HeLa & $11 \pm 1,0$ & $0,084 \pm 0,007$ \\
\hline & SUNE1 & $0,11 \pm 0,02$ & $12,6 \pm 0,92$ & & PLC & $7,6 \pm 0,6$ & $0,24 \pm 0,01$ \\
\hline & KB-3-1 & $0,20 \pm 0,03$ & $13,2 \pm 1,24$ & & CCD-19Lu (normal) & $>100$ & $1,9 \pm 0,1$ \\
\hline & HL-60 & $0,73 \pm 0,02$ & $16,8 \pm 1,42$ & & HepG2 & $13 \pm 0,9$ & $1,1 \pm 0,09$ \\
\hline & KB-V1 & $0,11 \pm 0,02$ & $12,6 \pm 0,78$ & & - & - & - \\
\hline
\end{tabular}

${ }^{\mathrm{a}} \mathrm{CDDP}$ (cis-platina), ${ }^{\mathrm{b}} \mathrm{AF}$ (auranofina). 
com a proteína citocromo $c$ e os aminoácidos Cys e His foi analisada por espectrometria de massas de ionização por eletropulverização (ESI MS), mostrando a formação de adutos somente com Cys após pelo menos 1 hora de incubação. No geral, os resultados obtidos apontam para a possibilidade de atingir seletivamente o ADN com complexos organometálicos de $\mathrm{Au}(\mathrm{III}) .{ }^{91}$

Em 2011, Gabbiani et al..$^{93}$ apresentaram dois complexos oxo dinucleares catiônicos $\left[\left(\mathrm{N}^{\wedge} \mathrm{N}^{\wedge} \mathrm{C}\right)_{2}-\mathrm{Au}_{2}(\mu-\mathrm{O})\right]\left(\mathrm{PF}_{6}\right)_{2}$ representados como 62a e 62b, na Figura 9. Esses compostos revelaram uma estabilidade redox marcada mesmo na presença de fortes agentes redutores biológicos, tais como ácido ascórbico e glutationa. A atividade citotóxica destes dois compostos dinucleares foi avaliada em um painel representativo de 12 linhagens celulares tumorais, em conjunto com seus respectivos compostos mononucleares $\left[\mathrm{Au}\left(\mathrm{N}^{\wedge} \mathrm{N}^{\wedge} \mathrm{C}\right)(\mathrm{OH})\right] \mathrm{PF}_{6}$, apresentando uma citotoxicidade moderada para a maioria delas. O complexo 62b é particularmente ativo contra células 401NL de câncer de mama, enquanto o 62a foi fracamente seletivo. Devido a sua estabilidade, possivelmente seus efeitos biológicos são causados pelo $\mathrm{Au}^{3+}$, já que após reação com os agentes redutores, esses compostos permanecem no estado de oxidação 3+ conservando seu ligante orgânico. De fato, estudos de espectrometria de massas após reação de 62a,b com lisozima de clara de ovo de galinha (HEWL) e citocromo c de coração de cavalo (cyt $c$ ) utilizados como proteínas modelo, evidenciou-se que os adutos de proteína-Au resultantes ainda continham íons de ouro no estado de oxidação $3+$ em conjunto com seus ligantes multidentados. ${ }^{93}$ Tais resultados diferem dos dados relatados anteriormente para outros compostos dinucleares de fórmula geral $\left[\mathrm{Au}_{2}\left(\mathrm{~N}^{\wedge} \mathrm{N}\right)_{2}(\mu-\mathrm{O})_{2}\right]\left(\mathrm{PF}_{6}\right)_{2}(63$; Figura 9), contendo exclusivamente ligantes $\mathrm{N}$-doadores ${ }^{94}$ A reatividade com proteínas facilita a clivagem da ponte de oxigênio para a conversão dos complexos bimetálicos em espécies monometálicas. ${ }^{24} \mathrm{O}$ composto 63 apresentou melhor atividade do que o complexo 61a contra as células de câncer de ovário A2780cis resistentes à cisplatina (4,8 e $8,2 \mu \mathrm{mol} \mathrm{L}{ }^{-1}$ respectivamente, ver Tabela 3 ).

Recentemente, as propriedades citotóxicas dos complexos do tipo $\left[\mathrm{Au}\left(\mathrm{C}^{\wedge} \mathrm{N}\right)(\mathrm{dtc})\right] \mathrm{PF}_{6}\left(\mathrm{HC}^{\wedge} \mathrm{N}=\mathrm{N}, 1,1,1\right.$-tetrafenil- $\lambda^{5}$-fosfanimina, $\mathrm{dtc}=$ ligante de ditiocarbamato, $\mathrm{S}$ doador) (64a,b; Figura 9) foram avaliadas in vitro contra células de carcinoma cervical (Hela) e células de leucemia linfoblástica aguda Jurkat-T. ${ }^{95}$ Ambos os compostos mostraram uma alta citotoxicidade, especialmente para células Jurkat de leucemia (Tabela 3). Esses efeitos podem ser atribuídos à disfunção mitocondrial induzida por espécies $R O S$ e pela ativação das proteínas Bax/Bak. ${ }^{96}$ As proteínas Bax e Bak são capazes de perfurar a membrana externa mitocondrial para mediar a morte celular por apoptose. Nos últimos anos, Zhang et al. ${ }^{97}$ desenvolveram um complexo de $\mathrm{Au}(\mathrm{III})$ contendo outro tipo de ligante $\left(\mathrm{HC}^{\wedge} \mathrm{N}=2\right.$-fenilpiridina) e biguanida como ligante auxiliar o qual é solúvel em água $\left(\left[\mathrm{Au}\left({ }^{\mathrm{nBu}} \mathrm{C}^{\wedge} \mathrm{N}\right)\right.\right.$ (biguanida)]Cl, 65; Figura 9). Interessantemente, ensaios de ESI-MS revelaram que este composto é capaz de formar o aduto $\mathrm{Au}^{3+}$-GSH, como os complexos 62a,b. O composto $\mathbf{6 5}$ apresentou maior citotoxicidade para diferentes linhagens celulares de câncer $\left(2,1-17,1 \mu \mathrm{mol} \mathrm{L} \mathrm{L}^{-1}\right)$ do que em células fibroblásticas pulmonares normais $(C C D-19 \mathrm{Lu}$, valor $\mathrm{IC}_{50}$ de $\left.32,8 \mu \mathrm{mol} \mathrm{L}{ }^{-1}\right)$. Verificou-se que esse complexo metálico induz estresse celular relacionado ao retículo endoplasmático (stress ER), regulando positivamente marcadores dele, como as proteínas $\mathrm{CHOP}$ e HSP70 e subsequentemente a morte celular. ${ }^{97}$

\section{Complexos de $\mathrm{Au}$ (III) contendo ligantes multidentados N-doadores}

Messori et al. ${ }^{98}$ relataram as atividades anticâncer de uma série de complexos de $\mathrm{Au}$ (III) contendo ligantes de bipiridina e terpiridina (66 e 67; Figura 9). Esses complexos são eficazes na inibição do crescimento de células de câncer de ovário (A2780) sensíveis ou resistentes à cisplatina, apresentando valores de $\mathrm{IC}_{50}$ entre 0,2 e 3,8 $\mu \mathrm{mol} \mathrm{L}{ }^{-1}$ (Tabela 3). Em comparação com os complexos organometálicos de Au(III) discutidos anteriormente, esses complexos são menos estáveis na presença de agentes redutores, como a glutationa ou ácido ascórbico, e podem causar danos oxidativos às biomoléculas. ${ }^{98}$

Em 2013, Martins et al. ${ }^{99}$ reportaram os efeitos inibitórios seletivos sobre aquaporinas AQP3 para estes mesmos compostos (66 e 67). ${ }^{99}$ Aquaporinas são "o sistema de encanamento para as células". A água se move através das células de forma organizada, mais rapidamente nos tecidos que possuem canais de água de aquaporina. Especificamente, AQP3 medeiam a maioria do movimento do glicerol através das membranas hRBC. Além de sua expressão em hRBC, a AQP3 tem uma ampla distribuição tecidual nas células epiteliais do rim, das vias aéreas e da pele, sugerindo um papel na reabsorção de água para este tipo de células. Estudos demonstraram uma expressão anormal de AQP3 em células tumorais de diferentes origens, particularmente em tumores agressivos, portanto, as aquaporinas estão se perfilando como alvos importantes para o tratamento do câncer. ${ }^{99,100}$ Tendo isso em conta, é possível que a inibição da AQP3 possa influenciar nos efeitos biológicos dos complexos de $\mathrm{Au}(\mathrm{III}) \mathrm{em}$ relação às células cancerosas. O composto $\mathbf{6 6}$ chamado Au(phen), é um dos mais eficazes na inibição da permeação do glicerol via AQP3 mostrando-se como um potente inibidor da AQP3 com um valor de $\mathrm{IC}_{50}$ na faixa micromolar baixa $\left(0,8 \mu \mathrm{mol} \mathrm{L} \mathrm{L}^{-1}\right)$. Resultados obtidos usando-se dinâmica molecular em conjunto com cálculos DFT, mostraram que o sítio de interação entre o composto 66 e AQP3 é dado com o resíduo Cys40 devido a sua maior acessibilidade comparado com outros grupos tióis. ${ }^{101}$ Recentemente, o ligante fenantrolina (phen) no composto $\mathbf{6 6}$ foi modificado em diferentes posições, obtendo-se uma série de seis complexos de $\mathrm{Au}(\mathrm{III}){ }^{102} \mathrm{O}$ composto $\left[\mathrm{Au} \text { (bipy) } \mathrm{Cl}_{2}\right]^{+}$(bipy=bipiridina), (Au(bipy)), também foi incluído neste estudo. Cálculos teóricos e experimentos foram realizados buscando melhorar a ligação com as proteínas e entender relações de estrutura-atividade. Os novos derivados contendo $\mathrm{Cl}^{-}$e grupos fenil sobre o anel fenantrolina mostraram uma leve melhora na inibição da AQP3 quando comparados aos compostos 66 e Au(bipy). Cálculos quânticos revelaram algumas importantes diferenças entre esses dois últimos. Em condições fisiológicas, os compostos do tipo $\mathrm{Au}$ (phen) são mais estáveis e tendem a hidrolisar em menor taxa quando comparados a $\mathrm{Au}$ (bipy). Essa diferença afeta principalmente a interação não coordenada com o AQP3, permitindo o acesso a outros resíduos em diferentes orientações. ${ }^{102}$

Devido à fácil redução $\mathrm{Au}^{3+} / \mathrm{Au}^{1+}$ de compostos contendo ligantes $\mathrm{N}$-doadores, Zou et al., ${ }^{28}$ desenvolveram uma classe de complexos catiônicos de $\mathrm{Au}(\mathrm{III})$ contendo ligantes $\mathrm{N}^{\wedge} \mathrm{N}^{\wedge} \mathrm{N}$ do tipo 2,6-bis(imidazol-2-il)piridina ( $\left.\mathrm{H}_{2} \mathrm{IPI}\right)$ e 2,6-bis(benzimidazol-2-il)piridina $\left(\mathrm{H}_{2} \mathrm{BPB}\right)$ e ligantes NHC (68 e 69; Figura 9). Esse tipo de ligantes $\left(\mathrm{H}_{2} \mathrm{IPI}\right)$ e $\left(\mathrm{H}_{2} \mathrm{BPB}\right)$ são altamente fluorescentes e apresentam menor toxicidade do que a terpiridina (terpy). A estratégia de Zou baseou-se no seguinte: a redução $\mathrm{Au}^{3+} \rightarrow \mathrm{Au}^{1+}$ seria acompanhada da liberação do ligante $\mathrm{N}^{\wedge} \mathrm{N}^{\wedge} \mathrm{N}$ devido a sua labilidade, seguida da ligação da fração $\mathrm{Au}(\mathrm{I})-\mathrm{NHC}$ ao tiol celular. Os ligantes $\mathrm{HN}^{\wedge} \mathrm{N}^{\wedge} \mathrm{NH}$ emitem luz visível. Portanto, esse tipo de compostos pode atuar como marcadores fluorescentes de tióis resultantes da emissão após a redução $\mathrm{Au}^{3+} \rightarrow \mathrm{Au}^{1+}$. $\mathrm{O}$ ligante NHC é bem conhecido por estabilizar $\mathrm{Au}^{1+}$ contra a redução a $\mathrm{Au}^{0}$. Dessa maneira, o derivado de $\mathrm{Au}^{1+}$ poderia inibir a TrxR produzindo a atividade anticâncer. Experimentos de RMN mostraram que, uma vez que se adiciona GSH ou Cys (que contém tiol), os sinais de emissão são detectados em apenas um minuto devido aos ligantes $\mathrm{HN}^{\wedge} \mathrm{N}^{\wedge} \mathrm{NH}$ livres. Também foi revelada a oxidação dos dois equivalentes de GSH levando à formação da espécie GSSG e o restante equivalente a GSH coordenado ao complexo de $\mathrm{Au}(\mathrm{I})$, formando a 
espécie [Au(R-NHC)(GS)]. A captação e distribuição intracelular do complexo 68a em células cancerosas foi seguida por microscopia de fluorescência. Após a incubação de células HeLa com este complexo de $\mathrm{Au}(\mathrm{III})$, foi detectada significativa fluorescência no citoplasma, mas não no núcleo ou no ambiente extracelular. Após redução, a espécie formada de $\mathrm{Au}(\mathrm{I})$-NHC pode inibir a atividade da TrxR celular $\left(\mathrm{IC}_{50}=5,5 \mu \mathrm{mol} \mathrm{\textrm {L } ^ { - 1 }}\right)$ sendo citotóxica para as células HeLa. $\mathrm{O}$ composto 69a foi o mais ativo da série contra células Hela com uma citotoxicidade similar à da $\mathrm{AF}$ (ver Tabela 3). Interessantemente, estudos adicionais in vivo revelaram que o tratamento com o composto $69 \mathrm{e}\left(3 \mathrm{mg} \mathrm{kg}^{-1}\right)$ pode suprimir significativamente o crescimento tumoral em camundongos portadores de xenoenxertos $\mathrm{HeLa}(76 \%$ de inibição) sem morte ou perda de peso corporal dos ratos. ${ }^{28}$

Três novos compostos tipo pincer $\left[\mathrm{Au}\left(\mathrm{N}^{\wedge} \mathrm{N}^{\wedge} \mathrm{N}\right) \mathrm{Cl}\right] \mathrm{Cl}_{2}\left(\mathrm{~N}^{\wedge} \mathrm{N}^{\wedge} \mathrm{N}=\right.$ 2,6-bis-pirazolilpiridina) (70 e 71; Figura 9) foram preparados e caracterizados por Radisavljević et al. ${ }^{103}$ em 2018. A análise de espectroscopia UV/visível mostrou que estes compostos são estáveis em soluções buffer de fosfato, nas quais o Au manteve o estado de oxidação $3+$ dentro de um período de observação de 24 horas. Tendo em vista o ADN como alvo principal, estudos cinéticos para a reação de troca de ligante $\mathrm{Cl} / \mathrm{L}$, em que $\mathrm{L}$ representa pequenas biomoléculas derivadas de guanina (guanosina e guanosina 5' monofosfato), foram abordados através da técnica do fluxo interrompido. Os resultados mostraram que a reação depende da natureza do ligante tridentado $\mathrm{N}^{\wedge} \mathrm{N}^{\wedge} \mathrm{N}$, sendo que a presença de substituintes eletrodoadores relativamente volumosos (70b e 71) sobre o anel pirazol afeta a velocidade de reação de troca. Estudos de interação dos compostos 70a,b e 71 com o ADN extraído do timo de bezerro revelaram que estes compostos se ligam ao ADN com afinidade moderada. Os valores da constante de ligação intrínseca $\left(K_{\mathrm{b}}\right)$ foram estimados na faixa $10^{3}-10^{4} \mathrm{~L} \mathrm{~mol}^{-1}$. Estudos de docking molecular indicaram que todos os compostos interagem com o ADN através da intercalação entre os pares de base. Tanto os resultados experimentais como o docking mostraram que o composto 70a exibe a maior afinidade ao ADN. A atividade citotóxica de 70a e do seu correspondente ligante livre $\mathrm{HN}^{\wedge} \mathrm{N}^{\wedge} \mathrm{NH}$ foi testada nas linhas celulares de câncer de pulmão A549, melanoma A375 e cólon LS-174. Tal composto exibiu valores de $\mathrm{IC}_{50}$ entre 11,2 e 20,1 $\mu \mathrm{mol} \mathrm{L} \mathrm{L}^{-1}$, sendo mais ativo que o ligante $\mathrm{HN}^{\wedge} \mathrm{N}^{\wedge} \mathrm{NH}$ e a cisplatina em todas as células cancerígenas avaliadas. A indução a apoptose, por parte do composto $\mathbf{7 0 a}$, em células A375 foi confirmada por citometria de fluxo. ${ }^{103}$

Em 2003, Che et al. ${ }^{29}$ reportaram alguns complexos porfirínicos de $\mathrm{Au}(\mathrm{III}),[\mathrm{Au}(\mathrm{TPP})] \mathrm{Cl}$, (TPP=5,10,15,20-tetrafenilporfirina) (72; Figura 9), eles foram relatados como estáveis no ambiente fisiológico na presença de GSH e apresentaram citotoxicidade in vitro em níveis micromolares ou nanomolares em diferentes linhagens celulares de câncer. ${ }^{29} \mathrm{O}$ complexo 72a também é ativo em linhagens celulares resistentes à cisplatina, o que indica um mecanismo molecular diferente daquele proposto (Tabela 3 ). Estudos sobre o mecanismo de ação revelaram que o composto 72a induz a apoptose através da disfunção mitocondrial e da supressão da proteína Bcl-2, a qual regula a permeabilidade da membrana externa da mitocôndria. Esse composto também tem sido testado in vivo mostrando ser um agente anticâncer promissor para o tratamento do carcinoma nasofaríngeo (NPC), metástase de NPC, carcinoma hepatocelular (HCC), câncer de cólon, neuroblastoma e melanoma. ${ }^{4,29} \mathrm{Em} 2012$, foi mostrado que o composto 72a também é capaz de inibir a capacidade de auto-renovação de células tumorais CSCs (Cancer stem cells) U-87 MG. ${ }^{104}$ Experimentos de toxicidade aguda indicaram uma dosagem segura deste complexo (via i.v.) abaixo de $3 \mathrm{mg} \mathrm{kg}^{-1}$. Testes subsequentes de irritação de vasos sanguíneos usando coelhos e testes de mutagenicidade in vivo (o micronúcleo da medula óssea) em camundongos revelaram que o composto 72a não causa irritação nos vasos sanguíneos ou genotoxicidade significativa. ${ }^{104}$ Posteriormente, esse mesmo grupo de pesquisa testou a utilidade deste tipo de compostos em modelos de camundongo portando tumores de ovário humano A2780 resistentes e sensíveis à cisplatina, simultaneamente. $\mathrm{O}$ tratamento com 72a inibiu significativamente ambos os tipos de tumores resistentes e sensíveis enquanto a cisplatina foi apenas eficaz na supressão de tumores sensíveis. ${ }^{105}$ Entretanto, Chow et al. ${ }^{106}$ prepararam o análogo $72 \mathrm{~b}$ com um grupo hidroxil em R (ver Figura 9). Esse composto mostrou-se altamente citotóxico para várias células de carcinoma de mama, principalmente para MDA-MB-231 $\left(\mathrm{IC}_{50}=7,0 \mathrm{nmol} \mathrm{L}^{-1}\right)$ (Tabela 3) e suprimiu significativamente o crescimento do tumor de mama em camundongos nus. O mecanismo de ação do composto 72b envolve a atenuação da sinalização de Wnt/b-catenina através da inibição da atividade da histona desacetilase de classe I (HDAC). ${ }^{106}$ HDACs são classificadas como enzimas capazes de remover grupos acetil $(\mathrm{O}=\mathrm{C}$ $\mathrm{CH}_{3}$ ) de uma lisina $\varepsilon-\mathrm{N}$-acetil em uma histona, permitindo às histonas a capacidade de enovelar o ADN. Interessantemente, os resultados sugerem que os dois compostos, embora possuam estruturas químicas similares, podem não compartilhar mecanismos citotóxicos comuns no nível molecular.

Akerman et al. ${ }^{107}$ relataram uma série de complexos de $\mathrm{Au}(\mathrm{III})$ estabilizados por um ligante macrocíclico ([Au(bis(pirrolideimina) $\left.)]^{+}\right)$. $\mathrm{O}$ complexo de ouro com uma ligação - $\left(\mathrm{CH}_{2}\right)_{4}-(n=4,73$; Figura 9$)$ foi identificado como inibidor catalítico específico da topoisomerase 1 (TopoI) já que a inibição da TopoII se mostrou muito mais fraca. Foi revelado que o íon $\mathrm{Au}(\mathrm{III})$ desempenha um papel crucial na intercalação do ADN e na inibição da TopoI. O estudo do mecanismo de inibição usando mecânica molecular mostrou que o complexo 73 se liga a uma sequência específica de TopoI através do sulco principal do ADN “major groove”, e tal ligação com o ADN possivelmente bloqueia o reconhecimento do substrato pela TopoI, contribuindo assim para o mecanismo de inibição. Os valores de $\mathrm{IC}_{50}$ para todas as linhagens de câncer testadas estiveram entre 5 e $27 \mu \mathrm{mol} \mathrm{L} \mathrm{L}^{-1}$. Leucemia, câncer no sistema nervoso central e câncer de cólon foram os tipos de câncer mais sensíveis ao composto $73 .{ }^{107}$

\section{Complexos de $\mathrm{Au}(\mathrm{III})$ contendo ligantes $\mathrm{C}^{\wedge} \mathrm{N}^{\wedge} \mathrm{C}$}

Como uma alternativa aos ligantes de porfirina para estabilizar o íon $\mathrm{Au}^{3+}$, Li et al. ${ }^{26}$ introduziram um ligante tridentado do tipo $\mathrm{C}^{\wedge} \mathrm{N}^{\wedge} \mathrm{C}$ $\left(\mathrm{C}^{\wedge} \mathrm{N}^{\wedge} \mathrm{C}=2\right.$,6-difenilpiridina) para coordenação ao sítio de $\mathrm{Au}(\mathrm{III})$. Exemplos de complexos de $\mathrm{Au}(\mathrm{III})$ contendo este tipo de ligante são representados na Figura 9 (74-78). Nenhum destes complexos sofre redução a $\mathrm{Au}^{1+}$ facilmente na presença de agentes redutores celulares, embora, a troca do ligante auxiliar (L) possa ocorrer. Estudos mostraram que o mecanismo de ação dos complexos de ouro com ligantes tipo pincer $\left[\mathrm{Au}\left(\mathrm{C}^{\wedge} \mathrm{N}^{\wedge} \mathrm{C}\right) \mathrm{L}\right]^{\mathrm{n+}}$ (74; Figura 9) são fortemente dependentes da substituição do ligante L. Os complexos 74b,c atuam como agentes metalo-intercaladores e potenciais inibidores da telomerase por meio da ligação do ligante $\mathrm{C}^{\wedge} \mathrm{N}^{\wedge} \mathrm{C} .{ }^{26} \mathrm{~A}$ estabilidade em solução para esse tipo de compostos aumenta ao usar fosfinas como ligantes auxiliares (74d). Diferentes ligantes de fosfina foram usados, obtendo complexos do tipo mono, bi e trinucleares. De fato, em estudos posteriores de 2013, foi observado que a atividade anticâncer aumenta significativamente com complexos análogos binucleares. ${ }^{108}$ O complexo binuclear, $\left[\mathrm{Au}_{2}\left(\mathrm{C}^{\wedge} \mathrm{N}^{\wedge} \mathrm{C}\right)_{2}(\mathrm{dppp})\right](\mathrm{OTf})_{2}$, com um ligante em ponte bis(difenilfosfino)propano ( $\mu$-dppp) ( $n=3$ em 75; Figura 9 ), exibiu a maior citotoxicidade in vitro entre os complexos dinucleares testados $(\mathrm{n}=1-6)$ incluindo o análogo de NHC (76) nas células cancerosas HeLa, HepG2, SUNE1 e CNE1. Os valores de $\mathrm{IC}_{50}$ para o composto $75(n=3)$ variaram entre 0,043 e $0,21 \mu \mathrm{mol} \mathrm{L}^{-1}$ e esse foi menos citotóxico para a linhagem de fibroblastos pulmonares nor-

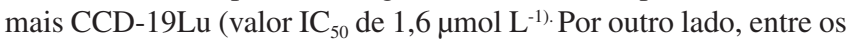


compostos mononucleares $\left[\mathrm{Au}\left(\mathrm{C}^{\wedge} \mathrm{N}^{\wedge} \mathrm{C}\right) \mathrm{PPh}_{3}\right]^{+}(\mathbf{7 4 d})$ e $\left[\mathrm{Au}\left(\mathrm{C}^{\wedge} \mathrm{N}^{\wedge} \mathrm{C}\right)\right.$ $\left.\mathrm{NHC}^{2 \mathrm{nBu}}\right]^{+}(\mathbf{7 7})$, o composto 75 mostrou uma atividade anticâncer in vitro muito maior do que a do composto $\mathbf{7 4 d}$ (ver Tabela 3 ). ${ }^{108}$

Sun et al. ${ }^{108}$ também realizaram testes in vivo do complexo $\mathbf{7 5}$ $(n=3)$ assim como estudos sobre os mecanismos de ação do mesmo. A administração de 2 a $10 \mathrm{mg} \mathrm{kg}^{-1}$ (via i.p.) deste composto binuclear duas vezes por semana provocou uma inibição de $77 \%$ do crescimento tumoral em camundongos portadores de xenoenxertos de PLC (carcinoma hepatocelular) e sua eficácia é ainda maior do que a da cisplatina e da doxorrubicina na supressão do crescimento do tumor em condições experimentais semelhantes. O composto $75(n=3)$ foi também mais eficaz na inibição tumoral do que a cisplatina (28\% de inibição) e doxorrubicina ( $60 \%$ de inibição). Estudos de toxicidade aguda, subcrônica e genotoxicidade foram realizados em camundongos e cães beagle. Os valores encontrados para cada um destes testes indicam que o composto $75(\mathrm{n}=3)$ pode inibir o crescimento tumoral in vivo em uma dosagem relativamente segura. Observaram-se alguns sinais clínicos, como fezes mucóides, depressão do segmento ST e redução do consumo de alimentos nas três primeiras administrações do composto, porém, esses sinais foram desaparecendo gradualmente. Para métodos comparativos, também foram testadas as propriedades inibitórias da TrxR purificada com $76(n=3)$ e com compostos análogos dinucleares e mononucleares, dentre os quais, o complexo 76 $(\mathrm{n}=3)$ mostrou-se o inibidor mais potente com um valor de $\mathrm{IC}_{50} \mathrm{de}$ 2,7 nmol L-1. Entre os compostos análogos mononucleares, apenas os complexos mononucleares 74a e 74d inibiram efetivamente a TrxR em uma concentração menor que $100 \mathrm{nmol} \mathrm{L}{ }^{-1}$, com valores de $\mathrm{IC}_{50}$ de 7,0 e 19,0 nmol L-1 , respectivamente. De forma geral, análises transcriptômicas e de mapa de conectividade indicaram que a inibição da TrxR, a indução do estresse $E R$ e uma via apoptótica dependente de receptor de morte DR5, podem estar envolvidos nos mecanismos anticâncer do composto $\mathbf{7 5}(\mathrm{n}=3){ }^{108}$

Duas diferentes vias para a redução (como as descritas na Figura 4) do complexo 74a ao derivado de $\mathrm{Au}(\mathrm{I})$ foram estudadas em solução aquosa. ${ }^{23}$ Água $\left(\mathrm{H}_{2} \mathrm{O}\right)$, e metanotiol $\left(\mathrm{CH}_{3} \mathrm{SH} /\right.$ $\mathrm{CH}_{3} \mathrm{~S}^{-}$), metanoselenol $\left(\mathrm{CH}_{3} \mathrm{Se}-\right)$ e 4 metilimidazol (meim-4-H) foram tomados como nucleófilos representando a cadeia lateral de aminoácidos de Cys, Sec e His, respectivamente. Levando em consideração os primeiros passos de ambas as rotas, foi encontrado que a energia de ativação para a troca do cloro $(7,1-24,2 \mathrm{kcal}$ $\mathrm{mol}^{-1}$ ) foi muito menor do que a energia requerida para a redução direta do $\mathrm{Au}^{3+} \rightarrow \mathrm{Au}^{1+}\left(47,8 \mathrm{kcal} \mathrm{mol}^{-1}\right)$. Além disso, a estabilidade redox do metabólito formado $\left[\mathrm{Au}\left(\mathrm{C}^{\wedge} \mathrm{N}^{\wedge} \mathrm{C}\right) \mathrm{Nu}\right]^{+n}$ foi menor do que no composto original (74a). Esses resultados sugerem que 74a poderia atuar como pró-droga, sendo ativado por reações de troca de ligantes com os nucleófilos disponíveis no organismo, incluindo a água, e subsequentemente reduzido a derivados de $\mathrm{Au}^{1+}$. Entre os nucleófilos testados, a reação de troca de ligantes do composto $\mathbf{7 4 a}$ com $\mathrm{CH}_{3} \mathrm{Se}^{-}$foi muito rápida $\left(k_{I}=\sim 10^{7} \mathrm{~L} \mathrm{~mol}^{-1} \mathrm{~s}^{-1}\right)$ e espontânea $\left(\Delta \mathrm{G}^{\circ}=-20,69 \mathrm{kcal} \mathrm{mol}^{-1}\right)$, seguida por $\mathrm{CH}_{3} \mathrm{SH} / \mathrm{CH}_{3} \mathrm{~S}$. Também foi analisado o processo de redução $\mathrm{Au}^{3+} \rightarrow \mathrm{Au}^{1+}$ do metabólito formado e o potencial de redução foi positivo. Esse resultado poderia ser interpretado com base em evidências experimentais para a interação de $\mathrm{Au}-\mathrm{TrxR}$, em que o íon $\mathrm{Au}^{1+}$ é coordenado por resíduos de enxofre e selênio no sítio ativo (RS-Au-SeR). Três etapas de reação que poderiam fazer parte do mecanismo de ação do complexo 74a foram propostas: (1) reação de troca de ligante: $\mathrm{Cl}^{-} / \mathrm{RSe}^{-}$(1a) ou $\mathrm{H}_{2} \mathrm{O} / \mathrm{RSe}^{-}(1 \mathrm{~b})$, sendo que essa última acontece através de uma reação inicial de hidrólise (A-B); (2) redução com abertura do quelato $\left(\varepsilon^{\circ}=+0,15 \mathrm{~V}\right)$ e (3) reação de troca e liberação do ligante $\mathrm{HC}^{\wedge} \mathrm{N}^{\wedge} \mathrm{CH}$, como representado na Figura $10 .{ }^{23}$

Bertrand et al., ${ }^{109}$ reportaram a atividade antiproliferativa contra várias linhagens celulares de câncer de um complexo Au(III)-NHC ciclometalado à base de pirazina (78; Figura 9). As propriedades antiproliferativas do complexo $\mathbf{7 8}$ foram testadas contra as células câncer HL60, MCF-7 A549 e MRC-5. Tal composto exibiu excelentes valores de $\mathrm{IC}_{50}$ na faixa submicromolar $\left(0,31 ; 0,15 ; 7,8 \mu \mathrm{mol} \mathrm{L} \mathrm{L}^{-1}\right.$, respectivamente) em todas as linhagens celulares. Os experimentos de captação celular confirmaram que a concentração intracelular de ouro desse composto era quase 11 vezes maior em comparação ao derivado de cafeína, obtido após substituir o grupo 1,3-dimetilbenzimidazol-2-ilideno pela estrutura da cafeína. Além disso, os estudos de reatividade do complexo $\mathbf{7 8}$ com glutationa sugeriram que é improvável que esta espécie desencadeie seus efeitos antiproliferativos via coordenação direta de enzimas contendo doadores de enxofre, como TrxR ou PARP-1. Finalmente, o estudo das propriedades de

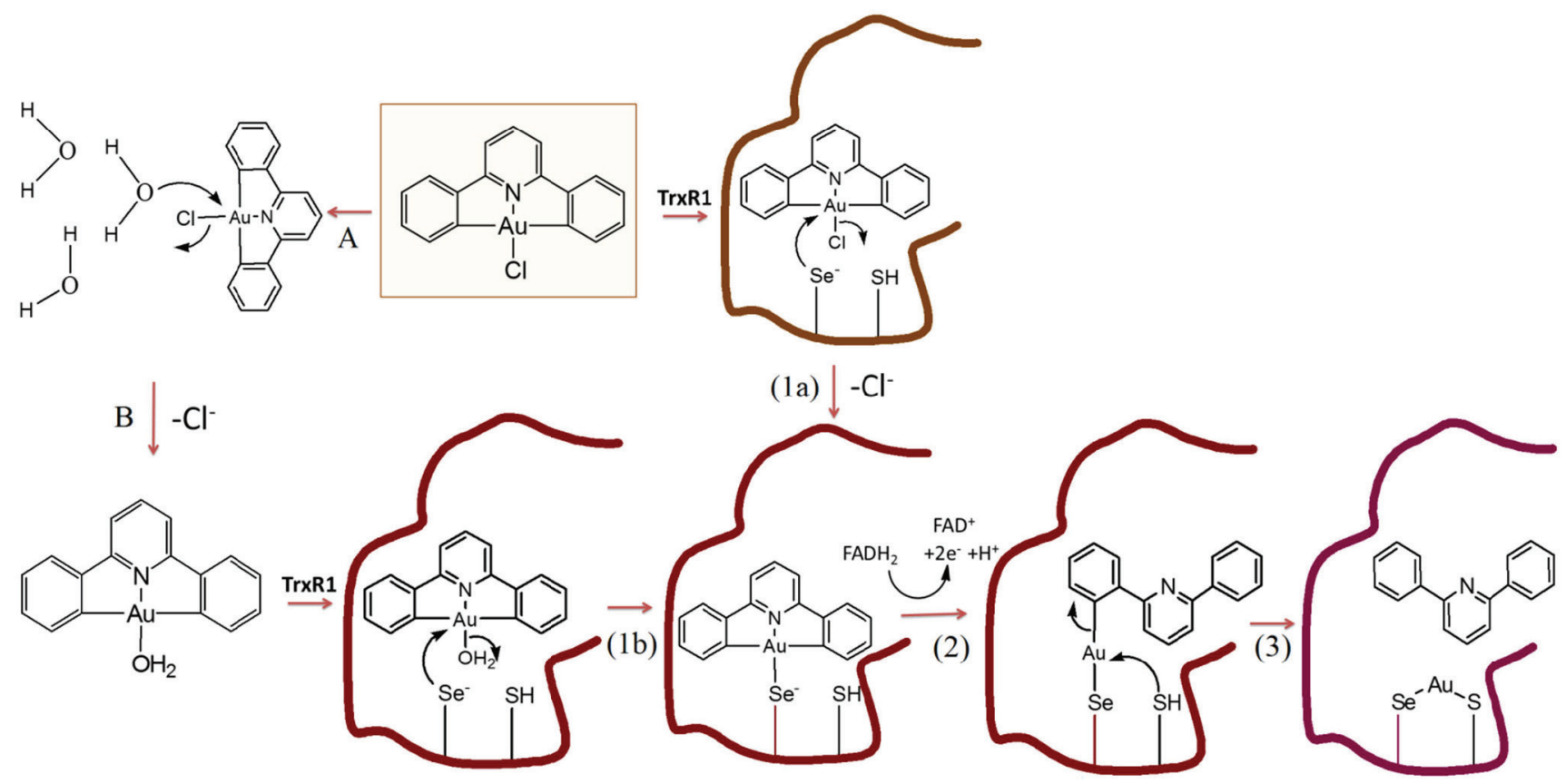

Figura 10. Possíveis mecanismos de ação do complexo $\left[\mathrm{Au}\left(\mathrm{C}^{\wedge} N^{\wedge} \mathrm{C}\right) \mathrm{Cl}\right]$ (74a) como inibidor da TrxR, de acordo aos resultados da referência ${ }^{23}$ 
ligação ao ADN indicou que o composto à base de NHC interage de maneira dependente da dose com todas as estruturas de ADN. Particularmente, o composto $\mathbf{7 8}$ interage fortemente com estruturas de G-quadruplexes e parece estabilizar a estrutura telomérica ADN de motivo I, mesmo em $\mathrm{pH}$ fisiológico. ${ }^{109}$

Interessantemente, o composto $\left[\mathrm{AuCl}_{3}\left(\mathrm{NHC}^{\mathrm{nBu}, \mathrm{CN}}\right)\right]$ reportado por Haque et al., ${ }^{110} \mathrm{em}$ 2016, o qual contém um ligante NHC sem a presença do ligante multidentado, exibiu uma significativa atividade antiproliferativa contra linhagens celulares de câncer de cólon humano (HCT 116, $\mathrm{IC}_{50}=0,05 \mu \mathrm{mol} \mathrm{L}-1$ ), carcinoma de mama (MCF-7, $\left.\mathrm{IC}_{50}=0,31 \mu \mathrm{mol} \mathrm{L}-1\right)$, câncer de próstata $\left(\mathrm{PC} 3, \mathrm{IC}_{50}=0,34 \mu \mathrm{mol} \mathrm{L} \mathrm{L}^{-1}\right) \mathrm{e}$ leucemia (U937, $\mathrm{IC}_{50}=0,19 \mu \mathrm{mol} \mathrm{L}{ }^{-1}$ ). Resultados do índice de seletividade revelaram que esse composto apresentou maior seletividade para todas as quatro linhas celulares de câncer em comparação com outros complexos de $\mathrm{Au}(\mathrm{I})$ já testados. ${ }^{110}$ Estudos mais detalhados dos mecanismos de ação de complexos de $\mathrm{Au}(\mathrm{III})$ com a presença e ausência de ligantes multidentados poderiam ajudar no desenho de compostos mais seletivos a células cancerosas, bem como o uso de ligantes auxiliares, tais como $\mathrm{PR}_{3}$ e $\mathrm{NHCs}$, os quais são chave na atividade anticâncer de complexos de $\mathrm{Au}(\mathrm{III})$.

\section{CONSIDERAÇÕES FINAIS}

Após várias décadas de desenvolvimento, os complexos de ouro têm se mostrado como promissores candidatos para resolver o problema da resistência da cisplatina no tratamento do câncer. Evidências experimentais reunidas até agora sugerem que os efeitos antiproliferativos causados pelos compostos de ouro provavelmente resultam de seus mecanismos de ação inovadores em comparação com drogas anticâncer já estabelecidas. Geralmente, enzimas/proteínas contendo tióis são consideradas alvos moleculares chave dos complexos de ouro devido à alta afinidade de ligação dos íons de ouro com os tióis. Existem estruturas cristalinas de raios $\mathrm{X}$ de adutos de proteína-Au relatadas na literatura. Essas evidências têm colocado enzimas como a GR, TrxR e TR como principais alvos dos compostos de ouro. No entanto, a Auranofina e alguns dos seus derivados têm se mostrado inibidores eficazes das enzimas DUBs as quais participam ativamente no controle de eventos celulares no câncer. Por outro lado, complexos de $\mathrm{Au}$ (III) têm exibido afinidade pelo ADN, sendo que a coordenação de ligantes planos tem lhe atribuído caraterísticas metalointercaladoras. Nos últimos anos, alguns complexos estáveis de $\mathrm{Au}(\mathrm{III})$ mostraram efeitos inibitórios seletivos para G-quadruplexes e aquaporinas (AQP3), direcionando o desenho de compostos de ouro a novos alvos.

Existem muitos estudos sobre a citotoxicidade e os mecanismos de ação in vitro para complexos de $\mathrm{Au}(\mathrm{I})$. De fato, a excelente inibição de tiol-enzimas e potentes citotoxicidades foram relatadas para complexos de $\mathrm{Au}(\mathrm{I})$ contendo ligantes $\mathrm{PR}_{3}$ e NHCs. Grande parte do sucesso deste tipo de compostos como agentes antitumorais é devido a sua capacidade de acumulação na mitocôndria a qual desempenha um papel crítico na regulação da apoptose celular. De maneira geral, os trabalhos mencionados na presente revisão mostram que compostos de $\mathrm{Au}(\mathrm{I})$ contendo ligantes NHC apresentam maior atividade antitumoral in vitro quando comparados àqueles que contém ligantes fosfina. No entanto, estudos sobre a atividade anticâncer in vivo e estudos de toxicidade aguda de complexos de $\mathrm{Au}(\mathrm{I})$ são bastante escassos, uma vez que ainda não é possível inferir com certeza que os ligantes NHC são melhores candidatos que os ligantes $\mathrm{PR}_{3}$ para o desenho de compostos quimioterápicos anticâncer de Au(I). Apesar de existirem várias informações sobre as relações estrutura-atividade, até o momento os compostos com as melhores relações não possuem informações suficientes de mecanismos de ação nem ensaios in vivo. Devido à ampla variação estrutural testada e a alta citotocixidade que todos estes têm exibido nas diferentes linhagens celulares cancerígenas, torna-se difícil definir um composto de $\mathrm{Au}(\mathrm{I})$ como o mais promissor para o tratamento do câncer.

Quanto aos complexos de Au(III), sua estabilidade frente a tióis celulares e sua seletividade para células tumorais têm melhorado significativamente com o uso de ligantes multidentados apropriados. Entre esses, a ciclometalação de íons $\mathrm{Au}^{3+}$ com ligantes $\mathrm{C}-\mathrm{N}$ bi e tridentados e com ligantes auxiliares adequados é certamente uma estratégia viável para a obtenção de complexos de $\mathrm{Au}$ (III) mais estáveis e eficazes. De fato, as propriedades luminescentes de alguns ligantes quelantes usados para se estabilizar o $\mathrm{Au}^{3+}$ têm ajudado na elucidação de seus mecanismos de ação. Outro aspecto que parece relevante é a escolha do ligante auxiliar, como $\mathrm{PR}_{3}$ e NHCs, que possam influenciar significativamente na atividade do complexo de $\mathrm{Au}(\mathrm{III})$, porém um entendimento mais detalhado do seu papel na atividade é necessário. Apesar disso, em relação a complexos de $\mathrm{Au}(\mathrm{I})$, poucos complexos de $\mathrm{Au}$ (III) têm sido testados in vivo. Estratégias como a sintonização coletiva da reatividade redox e as reações de troca de ligante de $\mathrm{Au}(\mathrm{III}) / \mathrm{Au}(\mathrm{I})$ com tióis são chaves para o desenvolvimento de complexos de $\mathrm{Au}$ (III) com potencial quimioterápico, especialmente para o tratamento de câncer de ovário, em que eles têm mostrado uma excelente atividade anticâncer. Porém, essa relação deve ser amplamente acompanhada de testes in vivo.

\section{LISTA DE ABREVIAÇÕES}

ADN: Ácido desoxirribonucleico.

AQP3: Aquaporine ativa.

Bcl-2: Proteínas pró-apoptóticas Bax e Bak (regulam a permeabilização da membrana externa mitocondrial durante a apoptose).

CHOP: do inglês, CCAAT/Enhancer-binding protein homologous protein (primeira proteína identificada que regula a apoptose induzida pelo estresse oxidativo do retículo endoplasmático).

Cox-2: Ciclo-oxigenase.

Cyp-3: Ciclofilina 3.

CypA: Peptidilprolil isomerase.

Cys: Cisteína.

DFT: Teoria do funcional da densidade.

DUBs: Deubiquitinases.

ESI-MS: do inglês, Electrospray Ionization Mass Spectrometry.

GCSG: Glicina-cisteína-selenocisteína-glicina.

GR: Glutationa redutase.

GSH: Glutationa.

HCT116: Linha celular de câncer de cólon humano.

HDAC: Histona desacetilase de classe I.

HEK-293: do inglês, "Human embryonic kidney 293 cells".

His: Histidina.

HL60: Linha celular de leucemia humana.

hRBC: Gel de celulose bacteriana esférica.

HSP70: Grupo de proteínas induzidas por choque térmico.

K-562: Linha celular de leucemia humana.

MOF: Estruturas metalorgânicas.

mTOR: do inglês, "mammalian Target of Rapamycin". Proteína envolvida com o crescimento, proliferação e manutenção das células. NCI/COLO205: Linhagem cancerosa de colon humano desenvolvida pelo Instituto Nacional de Câncer dos Estados Unidos.

NCI/H1299: Linha celular humana de carcinoma pulmonar desenvolvida pelo Instituto Nacional de Câncer dos Estados Unidos.

NHCs: Carbenos N-heterocíclicos.

OAc: Grupo acetoxi.

PARP-1: do inglês, "Poly [ADP-ribose] polymerase 1". É uma enzima essencial para iniciar várias formas de reparo do ADN.

RMN: Ressonância magnética nuclear 
ROS: do inglês, "Reactive Oxygen Species"

SCN: Tiocianato.

Sec: Seleniocisteina.

SIDA: Síndrome da Imunodeficiência Humana Adquirida.

SN12C: Carcinoma de células renais.

STAT3: do inglês, "signal transducers and activators of transcription".

UCHL5: do inglês, Ubiquitin C-Terminal Hydrolase L5.

USP14: do inglês, "Ubiquitin-specific protease 14".

TopoI: Topoisomerase I.

TGR: Tiorredoxina glutationa-redutase.

TrxR1: Tiorredoxina redutase citosólica.

VIH: Vírus da Imunodeficiência Humana.

\section{AGRADECIMENTOS}

Os autores agradecem às agências de fomento brasileiras FAPEMIG, CAPES e CNPq pelo apoio contínuo às atividades de pesquisa. GYSD e CASRC agradecem à CAPES (Finance Code 001) pela bolsa de doutoramento.

\section{REFERÊNCIAS}

1. Sadler, P. J.; Sue, R. E.; Met.-Based Drugs 1994, 1, 107.

2. Benedek, T. G.; J. Hist. Med. Allied Sci. 2004, 59, 50.

3. Berners-Price, S. J.; Filipovska, A.; Metallomics 2011, 3, 863.

4. Zou, T.; Lum, C. T.; Lok, C. N.; Zhang, J. J.; Che, C. M.; Chem. Soc. Rev. 2015, 44, 8786.

5. Wattenberg, L. W.; Cancer Res. 1985, 45, 1.

6. Navarro, M.; Coord. Chem. Rev. 2009, 253, 1619.

7. Navarro, M.; Castro, W.; Martínez, A.; Sánchez-Delgado, R. A.; J. Inorg. Biochem. 2011, 105, 276.

8. Glišić, B.; Djuran, M. I.; J. Chem. Soc. Dalton Trans. 2014, 43, 5950.

9. Bernardes, V. H. F.; Qu, Y.; Du, Z.; Beaton, J.; Vargas, M. D.; Farrell, N. P.; Inorg. Chem. 2016, 55, 11396.

10. De Paiva, R. E. F.; Du, Z.; Peterson, E. J.; Corbi, P. P.; Farrell, N. P.; Inorg. Chem. 2017, 56, 12308.

11. Ong, Y. C.; Roy, S.; Andrews, P. C.; Gasser, G.; Chem. Rev. 2019, 119, 730 .

12. Maia, P. I. da S.; Deflon, U.; Future Med. Chem. 2014, 6, 1515.

13. Barnard, P. J.; Berners-Price, S. J.; Coord. Chem. Rev. 2007, 251, 1889.

14. Huynh, H. V.; Chem. Rev. 2018, 118, 9457.

15. Mora, M.; Gimeno, M. C.; Visbal, R.; Chem. Soc. Rev. 2019, $48,447$.

16. Smith, A. D.; Guidry, C. A.; Morris, V. C.; Levander, O. A.; J. Nutr. 1999, 129, 194.

17. Angelucci, F.; Sayed, A. A.; Williams, D. L.; Boumis, G.; Brunori, M.; Dimastrogiovanni, D.; Miele, A. E.; Pauly, F.; Bellelli, A.; J. Biol. Chem. 2009, 284, 28977.

18. Cheng, Q.; Sandalova, T.; Lindqvist, Y.; Arnér, E. S. J.; J. Biol. Chem. 2009, 284, 3998.

19. Sengupta, S.; Chen, H.; Togawa, T.; DiBello, P. M.; Majors, A. K.; Büdy, B.; Ketterer, M. E.; Jacobsen, D. W.; J. Biol. Chem. 2001, 276, 30111.

20. Bhabak, K. P.; Bhuyana, B. J.; Mugesh, G.; Dalton Trans. 2011, 40, 2099.

21. Zou, J.; Taylor, P.; Dornan, J.; Robinson, S. P.; Walkinshaw, M. D.; Sadler, P. J.; Angew. Chem., Int. Ed. 2000, 39, 2931.

22. Dos Santos, H. F.; Comput. Theor. Chem. 2014, 1048, 95.

23. Sánchez Delgado, G. Y.; Paschoal, D.; Dos Santos, H. F.; J. Biol. Inorg. Chem. 2018, 23, 1283.

24. Bertrand, B.; Casini, A.; Dalton Trans. 2014, 43, 4209.

25. Sánchez Delgado, G. Y.; Paschoal, D.; Dos Santos, H. F.; Comput. Theor. Chem. 2017, 1108, 86.

26. Li, C. K. L.; Sun, R. W. Y.; Kui, S. C. F.; Zhu, N.; Che, C. M.; Chem. Eur. J. 2006, 12, 5253.
27. Navarro, M.; Betancourt, A.; Hernández, C.; Marchán, E.; J. Braz. Chem. Soc. 2008, 19, 1355.

28. Zou, T.; Lum, C. T.; Chui, S. S. Y.; Che, C. M.; Angew. Chemie Int. Ed. 2013, 52, 2930

29. Che, C. M.; Sun, R. W. Y.; Yu, W. Y.; Ko, C. B.; Zhu, N.; Sun, H.; Chem. Commun. 2003, 9, 1718.

30. Barolli, J. P.; Corrêa, R. S.; Miranda, F. S.; Ribeiro, J. U.; Bloch, C.; Ellena, J.; Moreno, V.; Cominetti, M. R.; Batista, A. A.; J. Braz. Chem. Soc. 2017, 28, 1879.

31. Pich, C. T.; Dos Santos, P. R.; Fortunato, T. V. O.; Chiarello, M.; De Oliveira, I. M.; Soares, B. Q.; Ghermani, N. E.; Machado, M.; RoeschEly, M.; Dumas, F.; Terenzi, H.; Henriques, J. A. P.; Moura, S.; J. Braz. Chem. Soc. 2019, 30, 597.

32. Martins, D. A.; Bomfim Filho, L. F.; Da Silva, C. M.; De Fátima, Â.; Louro, S. R. W.; Batista, D. G. J.; Soeiro, M. N. C.; De Carvalho, J. E.; Teixeira, L. R.; J. Braz. Chem. Soc. 2017, $28,87$.

33. Navarro, M.; Hernández, C.; Colmenares, I.; Hernández, P.; Fernández, M.; Sierraalta, A.; Marchán, E.; J. Inorg. Biochem. 2007, 101, 111.

34. Villarreal, W.; Colina-Vegas, L.; de Oliveira, C. R.; Tenorio, J. C.; Ellena, J.; Gozzo, F. C.; Cominetti, M. R.; Ferreira, A. G.; Ferreira, M. A. B.; Navarro, M.; Batista, A. A.; Inorg. Chem. 2015, 54, 11709.

35. Navarro, M.; Castro, W.; Higuera-Padilla, A. R.; Sierraalta, A.; Abad, M. J.; Taylor, P.; Sánchez-Delgado, R. A.; J. Inorg. Biochem. 2011, 105, 1684.

36. Navarro, M.; Higuera-Padilla, A. R.; Arsenak, M.; Taylor, P.; Transit. Met. Chem. 2009, 34, 869.

37. Mirabelli, C. K.; Johnson, R. K.; Sung, C. M.; Faucette, L.; Muirhead, K.; Crooke, S. T.; Cancer Res. 1985, 45, 32.

38. Kamal, J. K. A.; Zhao, L.; Zewail, A. H.; Proc. Natl. Acad. Sci. U. S. A. 2004, 101, 13411.

39. https://www.mayo.edu/research/clinical-trials/cls-20115754, acessada em Junho 2020.

40. Berners-Price, S. J.; Mirabelli, C. K.; Johnson, R. K.; Mattern, M. R.; McCabe, F. L.; Faucette, L. F.; Sung, C. M.; Mong, S. M.; Sadler, P. J.; Crooke, S. T.; Cancer Res. 1986, 46, 5486.

41. Humphreys, A. S.; Filipovska, A.; Berners-Price, S. J.; Koutsantonis, G. A.; Skelton, B. W.; White, A. H.; Dalton Trans. 2007, 4943.

42. Pillarsetty, N.; Katti, K. K.; Hoffman, T. J.; Volkert, W. A.; Katti, K. V.; Kamei, H.; Koide, T.; J. Med. Chem. 2003, 46, 1130.

43. Chui, C. H.; Wong, R. S. M.; Gambari, R.; Cheng, G. Y. M.; Yuen, M. C. W.; Chan, K. W.; Tong, S. W.; Lau, F. Y.; Lai, P. B. S.; Lam, K. H.; Ho, C. L.; Kan, C. W.; Leung, K. S. Y.; Wong, W. Y.; Bioorg. Med. Chem. 2009, 17, 7872 .

44. Tian, S.; Siu, F. M.; Kui, S. C. F.; Lok, C. N.; Che, C. M.; Chem. Commun. 2011, 47, 9318.

45. Berners-Price, S. J.; Girard, G. R.; Hill, D. T.; Sutton, B. M.; Jarrett, P. S.; Faucette, L. F.; Johnson, R. K.; Mirabelli, C. K.; Sadler, P. J.; J. Med. Chem. 1990, 33, 1386.

46. Reddy, T. S.; Privér, S. H.; Mirzadeh, N.; Bhargava, S. K.; J. Inorg. Biochem. 2017, 175, 1.

47. Reddy, T. S.; Privér, S. H.; Rao, V. V.; Mirzadeh, N.; Bhargava, S. K.; Dalton Trans. 2018, 47, 15312 .

48. Mirzadeh, N.; Reddy, T. S.; Bhargava, S. K.; Coord. Chem. Rev. 2019 , $388,343$.

49. Maia, P. I. da S.; Graminha, A.; Pavan, F. R.; Leite, C. Q. F.; Batista, A. A.; Back, D. F.; Lang, E. S.; Ellena, J.; De S. Lemos, S.; Salistre-Dearaujo, H. S.; Deflon, V. M.; J. Braz. Chem. Soc. 2010, 21, 1177.

50. Maia, P. I. da S.; Carneiro, Z. A.; Lopes, C. D.; Oliveira, C. G.; Silva, J. S.; De Albuquerque, S.; Hagenbach, A.; Gust, R.; Deflon, V. M.; Abram, U.; Dalton Trans. 2017, 46, 2559.

51. Garcia, A.; Machado, R. C.; Grazul, R. M.; Lopes, M. T. P.; Corrêa, C. C.; Dos Santos, H. F.; De Almeida, M. V.; Silva, H.; J. Biol. Inorg. Chem. 2016, 21, 275. 
52. Tavares, T. T.; Azevedo, G. C.; Garcia, A.; Carpanez, A. G.; Lewer, P. M.; Paschoal, D.; Müller, B. L.; Dos Santos, H. F.; Matos, R. C.; Silva, H.; Grazul, R. M.; Fontes, A. P. S.; Polyhedron 2017, 132, 95.

53. Navarro, M.; Castro, W.; González, S.; Abad, J.; Taylor, P.; J. Mex. Chem. Soc. 2013, 57, 220.

54. Gambini, V.; Tilio, M.; Maina, E. W.; Andreani, C.; Bartolacci, C.; Wang, J.; Iezzi, M.; Ferraro, S.; Ramadori, A. T.; Simon, O. C.; Pucciarelli, S.; Wu, G.; Dou, Q. P.; Marchini, C.; Galassi, R.; Amici, A.; Eur. J. Med. Chem. 2018, 155, 418.

55. Köster, S. D.; Alborzinia, H.; Can, S.; Kitanovic, I.; Wölfl, S.; Rubbiani, R.; Ott, I.; Riesterer, P.; Prokop, A.; Merz, K.; Metzler-Nolte, N.; Chem. Sci. 2012, 3, 2062.

56. Vergara, E.; Casini, A.; Sorrentino, F.; Zava, O.; Cerrada, E.; Rigobello, M. P.; Bindoli, A.; Laguna, M.; Dyson, P. J.; ChemMedChem 2010, 5, 96.

57. Garcia-Moreno, E.; Gascon, S.; Garcia de Jalon, J.; Romanos, E.; Rodriguez-Yoldi, M.; Cerrada, E.; Laguna, M.; Anticancer. Agents Med. Chem. 2015, 15, 773.

58. Vergara, E.; Cerrada, E.; Clavel, C.; Casini, A.; Laguna, M.; Dalton Trans. 2011, 40, 10927.

59. García-Moreno, E.; Gascón, S.; Atrián-Blasco, E.; Rodriguez-Yoldi, M. J.; Cerrada, E.; Laguna, M.; Eur. J. Med. Chem. 2014, 79, 164.

60. Abas, E.; Pena-Martinez, R.; Aguirre-Ramírez, D.; Rodriguez-Dieguez, A.; Laguna, M.; Grasa, L.; Dalton Trans. 2020, 49, 1915.

61. Hikisz, P.; Szczupak, Ł.; Koceva-Chyła, A.; Guśpiel, A.; Oehninger, L.; Ott, I.; Therrien, B.; Solecka, J.; Kowalski, K.; Molecules 2015, 20 , 19699

62. Wei, R.; Liu, X.; Yu, W.; Yang, T.; Cai, W.; Liu, J.; Huang, X.; Xu, G. T.; Zhao, S.; Yang, J.; Liu, S.; Oncotarget 2015, 6, 12872.

63. Li, X.; Huang, Q.; Long, H.; Zhang, P.; Su, H.; Liu, J.; EBioMedicine 2019, 39, 159 .

64. Liu, N.; Li, X.; Huang, H.; Zhao, C.; Liao, S.; Yang, C.; Liu, S.; Song, W.; Lu, X.; Lan, X.; Chen, X.; Yi, S.; Xu, L.; Jiang, L.; Zhao, C.; Dong, X.; Zhou, P.; Li, S.; Wang, S.; Shi, X.; Dou, P. Q.; Wang, X.; Liu, J.; Oncotarget 2014, 5, 5453.

65. Baker, M. V.; Barnard, P. J.; Berners-Price, S. J.; Brayshaw, S. K.; Hickey, J. L.; Skelton, B. W.; White, A. H.; Dalton Trans. 2006, 6, 3708.

66. Hickey, J. L.; Ruhayel, R. A.; Barnard, P. J.; Baker, M. V.; Berners-Price, S. J.; Filipovska, A.; J. Am. Chem. Soc. 2008, 130, 12570.

67. Dos Santos, H. F.; Vieira, M. A.; Sánchez Delgado, G. Y.; Paschoal, D.; J. Phys. Chem. A 2016, 120, 2250.

68. Rubbiani, R.; Kitanovic, I.; Alborzinia, H.; Can, S.; Kitanovic, A.; Onambele, L. A.; Stefanopoulou, M.; Geldmacher, Y.; Sheldrick, W. S.; Wolber, G.; Prokop, A.; Wölfl, S.; Ott, I.; J. Med. Chem. 2010, 53, 8608.

69. Rubbiani, R.; Can, S.; Kitanovic, I.; Alborzinia, H.; Stefanopoulou, M.; Kokoschka, M.; Mönchgesang, S.; Sheldrick, W. S.; Wölfl, S.; Ott, I.; J. Med. Chem. 2011, 54, 8646.

70. Weaver, J.; Gaillard, S.; Toye, C.; MacPherson, S.; Nolan, S. P.; Riches, A.; Chem. Eur. J. 2011, 17, 6620.

71. Stefan, L.; Bertrand, B.; Richard, P.; Le Gendre, P.; Denat, F.; Picquet, M.; Monchaud, D.; ChemBioChem 2012, 13, 1905.

72. Hackenberg, F.; Müller-Bunz, H.; Smith, R.; Streciwilk, W.; Zhu, X.; Tacke, M.; Organometallics 2013, 32, 5551.

73. Karaca, Ö.; Scalcon, V.; Meier-Menches, S. M.; Bonsignore, R.; Brouwer, J. M. J. L.; Tonolo, F.; Folda, A.; Rigobello, M. P.; Kühn, F. E.; Casini, A.; Inorg. Chem. 2017, 56, 14237.

74. Lima, B. A. V; Corrêa, R. S.; Graminha, A. E.; Kuznetsov, A.; Ellena, J.; Pavan, F. R.; Leite, C. Q. F.; Batista, A. A.; J. Braz. Chem. Soc. 2016, 27,30 .

75. Arambula, J. F.; McCall, R.; Sidoran, K. J.; Magda, D.; Mitchell, N. A.; Bielawski, C. W.; Lynch, V. M.; Sessler, J. L.; Arumugam, K.; Chem. Sci. 2016, 7, 1245.
76. McCall, R.; Miles, M.; Lascuna, P.; Burney, B.; Patel, Z.; Sidoran, K. J.; Sittaramane, V.; Kocerha, J.; Grossie, D. A.; Sessler, J. L.; Arumugam, K.; Arambula, J. F.; Chem. Sci. 2017, 8, 5918.

77. Baron, M.; Bellemin-Laponnaz, S.; Tubaro, C.; Basato, M.; Bogialli, S.; Dolmella, A.; J. Inorg. Biochem. 2014, 141, 94.

78. Zou, T.; Lum, C. T.; Lok, C. N.; To, W. P.; Low, K. H.; Che, C. M.; Angew. Chem., Int. Ed. 2014, 53, 5810 .

79. Pratesi, A.; Gabbiani, C.; Ginanneschi, M.; Messori, L.; Chem. Commun. 2010, 46, 7001.

80. Sun, R. W. Y.; Zhang, M.; Li, D.; Zhang, Z. F.; Cai, H.; Li, M.; Xian, Y. J.; Ng, S. W.; Wong, A. S. T.; Chem. - A Eur. J. 2015, 21, 18534.

81. Porchia, M.; Pellei, M.; Marinelli, M.; Tisato, F.; Del Bello, F.; Santini, C.; Eur. J. Med. Chem. 2018, 146, 709.

82. Dada, O.; Curran, D.; O'Beirne, C.; Müller-Bunz, H.; Zhu, X.; Tacke, M.; J. Organomet. Chem. 2017, 840, 30.

83. Schmidt, C.; Karge, B.; Misgeld, R.; Prokop, A.; Franke, R.; Brönstrup, M.; Ott, I.; Chem. - A Eur. J. 2017, 23, 1869.

84. Schuh, E.; Pflüger, C.; Citta, A.; Folda, A.; Rigobello, M. P.; Bindoli, A.; Casini, A.; Mohr, F.; J. Med. Chem. 2012, 55, 5518.

85. Nandy, A.; Dey, S. K.; Das, S.; Munda, R. N.; Dinda, J.; Saha, K. D.; Mol. Cancer 2014, 13, 1.

86. Buckley, R. G.; Elsome, A. M.; Fricker, S. P.; Henderson, G. R.; Theobald, B. R. C.; Parish, R. V.; Howe, B. P.; Kelland, L. R.; J. Med. Chem. 1996, 39, 5208.

87. Parish, R. V.; Howe, B. P.; Wright, J. P.; Mack, J.; Pritchard, R. G.; Buckley, R. G.; Elsome, A. M.; Fricker, S. P.; Inorg. Chem. 1996, 35, 1659.

88. Fricker, S. P.; Mosi, R. M.; Cameron, B. R.; Baird, I.; Zhu, Y.; Anastassov, V.; Cox, J.; Doyle, P. S.; Hansell, E.; Lau, G.; Langille, J.; Olsen, M.; Qin, L.; Skerlj, R.; Wong, R. S. Y.; Santucci, Z.; McKerrow, J. H.; J. Inorg. Biochem. 2008, 102, 1839.

89. Engman, L.; McNaughton, M.; Gajewska, M.; Kumar, S.; Birmingham, A.; Powis, G.; Anticancer. Drugs 2006, 17, 539.

90. Marcon, G.; Carotti, S.; Coronnello, M.; Messori, L.; Mini, E.; Orioli, P.; Mazzei, T.; Cinellu, M. A.; Minghetti, G.; J. Med. Chem. 2002, 45, 1672.

91. Carboni, S.; Zucca, A.; Stoccoro, S.; Maiore, L.; Arca, M.; Ortu, F.; Artner, C.; Keppler, B. K.; Meier-Menches, S. M.; Casini, A.; Cinellu, M. A.; Inorg. Chem. 2018, 57, 14852.

92. Casini, A.; Kelter, G.; Gabbiani, C.; Cinellu, M. A.; Minghetti, G.; Fregona, D.; Fiebig, H. H.; Messori, L.; J. Biol. Inorg. Chem. 2009, 14, 1139.

93. Gabbiani, C.; Casini, A.; Kelter, G.; Cocco, F.; Cinellu, M. A.; Fiebig, H. H.; Messori, L.; Metallomics 2011, 3, 1318.

94. Casini, A.; Cinellu, M. A.; Minghetti, G.; Gabbiani, C.; Coronnello, M.; Mini, E.; Messori, L.; J. Med. Chem. 2006, 49, 5524.

95. Shaik, N.; Martínez, A.; Augustin, I.; Giovinazzo, H.; Varela-Ramírez, A.; Sanaú, M.; Aguilera, R. J.; Contel, M.; Inorg. Chem. 2009, 48, 1577.

96. Vela, L.; Contel, M.; Palomera, L.; Azaceta, G.; Marzo, I.; J. Inorg. Biochem. 2011, 105, 1306.

97. Zhang, J. J.; Sun, R. W. Y.; Che, C. M.; Chem. Commun. 2012, 48, 3388.

98. Messori, L.; Abbate, F.; Marcon, G.; Orioli, P.; Fontani, M.; Mini, E.; Mazzei, T.; Carotti, S.; O'Connell, T.; Zanello, P.; J. Med. Chem. 2000, $43,3541$.

99. Martins, A. P.; Ciancetta, A.; de Almeida, A.; Marrone, A.; Re, N.; Soveral, G.; Casini, A.; ChemMedChem 2013, 8, 1086.

100. Kusayama, M.; Wada, K.; Nagata, M.; Ishimoto, S.; Takahashi, H.; Yoneda, M.; Nakajima, A.; Okura, M.; Kogo, M.; Kamisaki, Y.; Cancer Sci. 2011, 102, 1128.

101. De Almeida, A.; Mósca, A. F.; Wragg, D.; Wenzel, M.; Kavanagh, P.; Barone, G.; Leoni, S.; Soveral, G.; Casini, A.; Chem. Commun. 2017, 53,3830 . 
102. Wenzel, M. N.; Mósca, A. F.; Graziani, V.; Aikman, B.; Thomas, S. R.; De Almeida, A.; Platts, J. A.; Re, N.; Coletti, C.; Marrone, A.; Soveral, G.; Casini, A.; Inorg. Chem. 2019, 58, 2140.

103. Radisavljević, S.; Bratsos, I.; Scheurer, A.; Korzekwa, J.; Masnikosa, R.; Tot, A.; Gligorijević, N.; Radulović, S.; Rilak Simović, A.; Dalton Trans. 2018, 47, 13696.

104. Lum, C. T.; Wong, A. S. T.; Lin, M. C.; Che, C. M.; Sun, R. W. Y.; Chem. Commun. 2013, 49, 4364.

105. Lum, C. T.; Wai-Yin Sun, R.; Zou, T.; Che, C. M.; Chem. Sci. 2014, 5, 1579.

106. Chow, K. H. M.; Sun, R. W. Y.; Lam, J. B. B.; Li, C. K. L.; Xu, A.; Ma, D. L.; Abagyan, R.; Wang, Y.; Che, C. M.; Cancer Res. 2010, 70, 329.
107. Akerman, K. J.; Fagenson, A. M.; Cyril, V.; Taylor, M.; Muller, M. T.; Akerman, M. P.; Munro, O. Q.; J. Am. Chem. Soc. 2014, 136, 5670.

108. Sun, R. W. Y.; Lok, C. N.; Fong, T. T. H.; Li, C. K. L.; Yang, Z. F.; Siu, A. F. M.; Che, C. M.; Chem. Sci. 2013, 4, 1979.

109. Bertrand, B.; Fernandez-Cestau, J.; Angulo, J.; Cominetti, M. M. D.; Waller, Z. A. E.; Searcey, M.; O’Connell, M. A.; Bochmann, M.; Inorg. Chem. 2017, 56, 5728.

110. Haque, R. A.; Ghdhayeb, M. Z.; Budagumpi, S.; Khadeer Ahamed, M. B.; Abdul Majid, A. M. S.; RSC Adv. 2016, 6, 60407. 